\title{
Review
}

\section{Anion Receptor Chemistry}

\author{
Philip A. Gale, ${ }^{1, \star}$ Ethan N.W. Howe, ${ }^{1}$ and Xin Wu${ }^{1}$
}

This review covers advances in anion complexation in 2013, 2014, and 2015. The review focuses on the applications of anion receptor chemistry, including sensing, self-assembly, extraction, transport, catalysis, and fundamental advances in the area.

\section{INTRODUCTION}

As the field of anion coordination chemistry continues to develop, we are seeing a shift away from systems that function only under laboratory conditions (e.g., hydrogen-bond-based anion receptors that function only in organic solvents) to new anion receptors that employ a variety of interactions to function under realworld conditions. In this review, we cover recent advances in the design of anion receptors and the increase in the proportion of systems involving non-classical non-covalent interactions, together with the latest developments in anion sensing and separation, as well as new self-assembling systems involving anions in 2013, 2014, and 2015. We also highlight advances in catalysis and anion-transport processes. These advances highlight the interdisciplinary nature of this area of supramolecular chemistry with advances at the borders of materials science and biology. ${ }^{1}$

\section{FUNDAMENTAL ANION-BINDING STUDIES}

\section{Classical Hydrogen-Bond-Based Anion Receptors}

There is still much to learn about the behavior of receptors that use hydrogen-bond donors to interact with anions. In this section, we refer to anion receptors that use $\mathrm{NH}$ and $\mathrm{OH}$ groups as their main hydrogen-bond donors as classic hydrogen-bondbased receptors. In the last 3 years, new anion-binding motifs and scaffolds have continued to be developed. Arylboronic acids are well known for their ability to form covalent adducts with basic anions such as hydroxide and fluoride to the Lewis acidic boron center. Martínez-Aguirre and Yatsimirsky ${ }^{2}$ demonstrated that, in addition to Lewis-acid-type covalent binding, arylboronic acids can also interact with anions via hydrogen bonding with the $\mathrm{B}(\mathrm{OH})_{2}$ hydroxyl groups (Figure 1). In DMSO, the formation of tetrahedral covalent adducts was found to dominate over hydrogen-bonding adducts for fluoride and dihydrogenphosphate; however, less basic anions, including chloride, bromide, hydrogensulfate, and acetate, only formed hydrogen-bonding adducts with arylboronic acids, as revealed by ${ }^{1} \mathrm{H}$ and ${ }^{11} \mathrm{~B}$ nuclear magnetic resonance (NMR) binding studies in DMSO- $d_{6}$ and $\mathrm{CD}_{3} \mathrm{CN}$. Compared with commonly used hydrogen-bond-based anion receptors such as phenylureas and isophthalamides, the phenylboronic acids showed a less pronounced decrease in anion-binding affinity on going from chloroform to the highly competitive solvent DMSO. Surprisingly, the affinity for chloride and acetate in DMSO- $d_{6}$ was found to be higher than that of simple phenylureas and isophthalamides. By adding a nitro substituent, the authors achieved an anion-induced UV-visible (UV-Vis) spectroscopic response. Thus, this work illustrated the overlooked potential of phenylboronic acids as non-covalent anion receptors for possible sensing applications.
The Bigger picture

Anion receptor chemistry concerns the design of molecules that recognize, respond to, or sense species that carry a negative charge. This area of supramolecular chemistry has a number of applications, including in organocatalysis (where metalfree molecules can catalyze reactions via hydrogen-bonding interactions), in separating mixtures of anions in industrial or radioactive waste, and in producing anion sensors that can be used under real-world conditions to sense trace quantities of anions such as fluoride. Anion receptor chemistry may also be useful in the future treatment of diseases, such as cystic fibrosis, caused by problems with chloride transport through faulty ion channels in epithelial cell membranes. One proposed approach to tackling this is "channel replacement therapy," wherein small molecules facilitate the transport of chloride; significant effort is currently being devoted in this area. 


\section{Covalent binding}

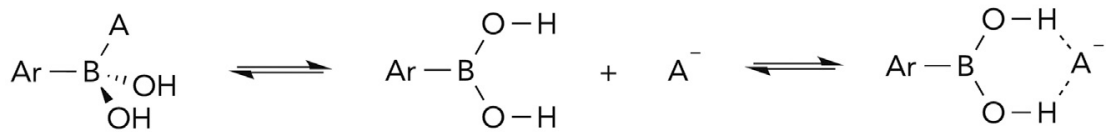

$$
\begin{aligned}
& \mathrm{A}^{-}=\mathrm{F}^{-}, \mathrm{H}_{2} \mathrm{PO}_{4}^{-} \quad \mathrm{A}^{-}=\mathrm{AcO}^{-}, \mathrm{Cl}^{-}, \mathrm{Br}^{-}, \mathrm{HSO}_{4}^{-}
\end{aligned}
$$

Figure 1. Two Possible Anion-Binding Modes of Arylboronic Acids

Shokri et al. ${ }^{3}$ examined the acidity, chloride binding, and catalytic properties of three polyols 1-3 (Figure 2). These compounds stabilize their deprotonated forms by intramolecular hydrogen bonds (Figure 2) and contain $\mathrm{CF}_{3}$ groups, leading to strong Brønsted acids. Negative-ion photoelectron spectroscopic measurements revealed that deprotonated anions in the gas phase of 1 and 2 were much more stable than those of 1,3-propanediol and 1,2-ethanediol. In solutions, 1-3 were found to be rather acidic in DMSO $\left(\mathrm{p} K_{\mathrm{a}}=16.0,4.8\right.$, and 7.1 for 1,2 , and 3 , respectively) and water ( $p K_{a}=5.6$ and 7.1 for 2 and 3 , respectively). Notably, despite separation of the $\mathrm{CF}_{3}$ groups by three carbons in 3, 3 was more acidic than 1,1,1,3,3,3-hexafluoro-2propanol by $2.2 \mathrm{p} K_{\mathrm{a}}$ units in water. This demonstrated that the inductive effect can be transmitted via intramolecular hydrogen bonds even in an aqueous environment. Remarkably, 1 and 2 showed the highest chloride affinity in $\mathrm{CD}_{3} \mathrm{CN}(3,300$ for 1 and 6,700 for $2 \mathrm{M}^{-1}$ ) among reported aliphatic alcohols. Compounds $1-3$ were found to act as hydrogen bond and Brønsted acid catalysts in a Friedel-Crafts reaction and a styrene oxide aminolysis reaction, respectively.

Elmes et al. ${ }^{4}$ reported anion binding and spectroscopic sensing properties of squaramide-based anion receptors 4-6 (Figure 3), which showed the highly unusual behavior of deprotonation by the relatively weakly basic anion chloride in DMSO.<smiles>OC(CC(O)C(F)(F)F)C(F)(F)F</smiles>

1<smiles>FC(F)(F)C1CC(C(F)(F)F)[OH+]O1</smiles>

Deprotonated form of $\mathbf{1}$<smiles>CC1OC(C(F)(F)F)CC(C(F)(F)F)O1</smiles>

1. $\mathrm{Cl}^{-}$complex

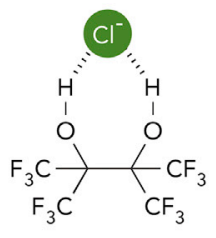

2. $\mathrm{Cl}^{-}$complex

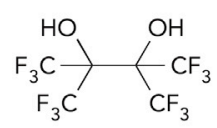

2

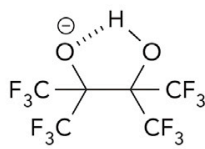

Deprotonated form of 2

\section{.}


<smiles>O=c1c(NCBr)c(NCc2c3ccccc3cc3ccccc23)c1=O</smiles><smiles>FC(F)(F)c1cc(I)cc(C(F)(F)F)c1</smiles>

4

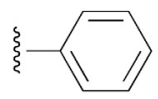

8
7

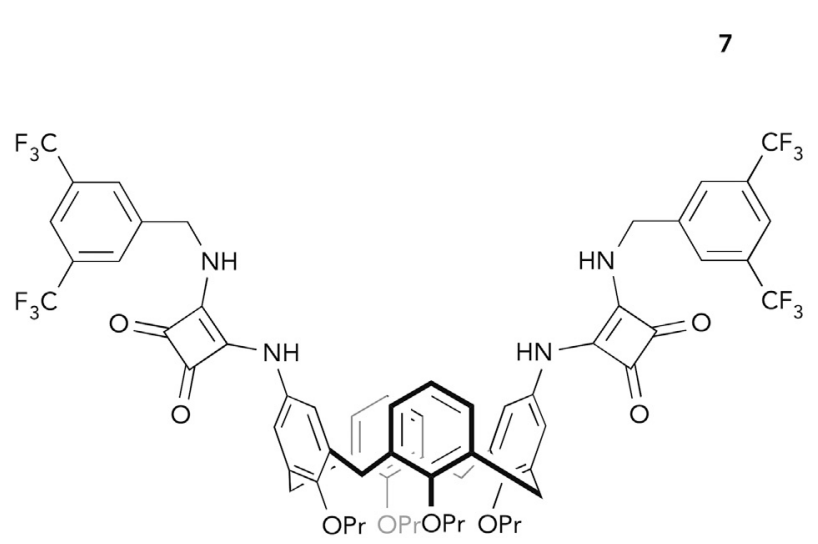

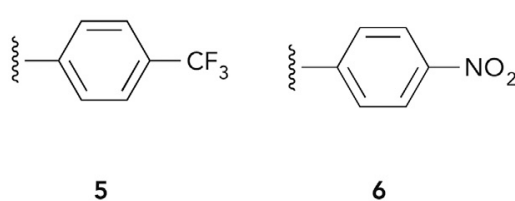

6

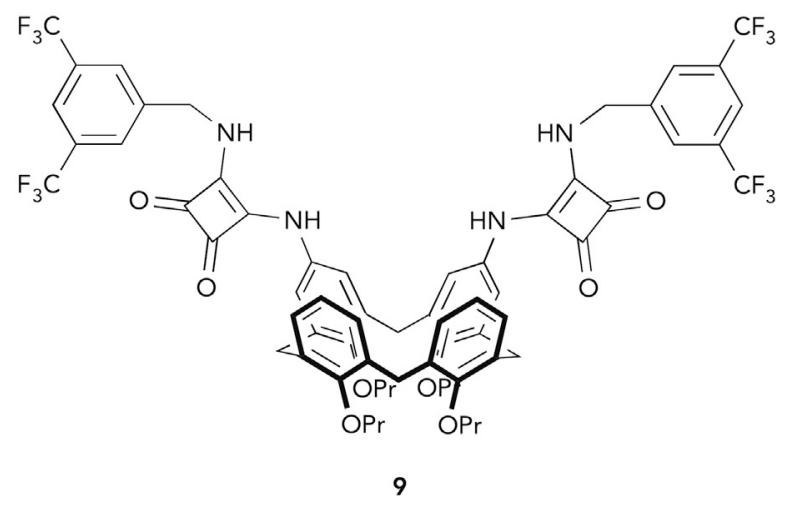

Figure 3. Structures of Squaramide-Based Receptors 4-9

Titration of 4-6 with chloride led to dramatic changes in the color of the solution and quenching of the excimer emission at $530 \mathrm{~nm}$. On the basis of the disappearance of the $\mathrm{NH}{ }^{1} \mathrm{H}-\mathrm{NMR}$ resonances and color changes induced by high concentrations of chloride, the authors proposed that 4-6 could be deprotonated by chloride at high concentrations, whereas hydrogen bonding to chloride occurred at low chloride concentrations. Deprotonation was not observed with less basic anions (bromide, iodide, and nitrate) or with the less acidic squaramide 7 in the presence of chloride.

Calix[4]arene is an ideal scaffold for constructing multivalent anion receptors for high-affinity anion binding and sensing. ${ }^{5}$ Gaeta et al. ${ }^{6}$ developed two anion receptors, 8 and 9 (Figure 3), in which two squaramide moieties were attached to the upper rim of the calix[4]arene scaffold. Interestingly, spherical anions including chloride and bromide were found to induce dimerization of both 8 and 9, forming 2:1 calixarene-anion complexes as demonstrated by Job plots and electrospray ionization mass spectrometry (ESI-MS) data. Binding and dimerization with trigonal-planar anions, including benzoate and nitrate, however, was only observed for the proximal isomer 9, which was ascribed to an intramolecular hydrogen bond in 9 that favors binding with trigonal-planar anions via one squaramide moiety.

Pinter et al. ${ }^{7}$ reported anion-binding studies of a new class of anion receptors, 10-12, that are based on the tetrazole-pyrrole-amide framework (Figure 4). These compounds show a much stronger affinity for chloride (with binding constants in the order of $10^{5} \mathrm{M}^{-1}$ in $\mathrm{CD}_{3} \mathrm{CN}$ ) than bis-amidopyrroles do. Surprisingly, ester 10 binds $\mathrm{Cl}^{-}$with an affinity similar to that of amides 11 and 12 . Given 


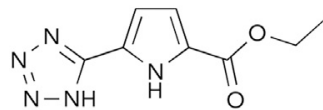

10

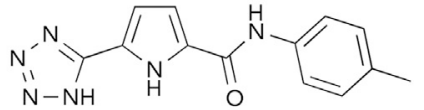

11

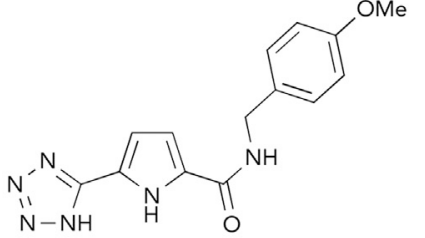

12

Figure 4. Structures of Receptors 10-12

the small chloride-induced shift of amide $\mathrm{NH}$ resonance of these compounds, the authors concluded that the amide groups in 11 and 12 do not donate strong hydrogen bonds to chloride. Instead, like the role of the ester group in 10, the amide groups in 11 and 12 influenced anion binding by inductive effects, causing increased acidity of the central pyrrole NH. The work demonstrated that incorporating tetrazole motifs can aid in the design of high-affinity anion receptors.

The [n]polynorbornane framework has been used to preorganize anion-binding motifs to develop high-affinity anion receptors. Long and Pfeffer $^{8}$ investigated the influence of the [n]polynorbornane framework size on anion binding (using NMR) in a series of bis-thiourea-functionalized receptors, 13-18 (Figure 5). Job plot analysis revealed that all receptors formed 1:1 complexes with pyrophosphate, pimelate, and terephthalate in DMSO- $d_{6}$, presumably with the anion bound cooperatively between the two thiourea moieties at the two-armed end. Surprisingly, whereas the larger receptors 16 and 17 bound acetate similarly in a 1:1 cooperative manner (with binding constants $10^{2.6}$ for 16 and $10^{2.7}$ for 17), compound 14 accommodated up to two acetate anions with $K_{1}\left(10^{3.9}\right)>K_{2}\left(10^{2.1}\right)$. The authors proposed that

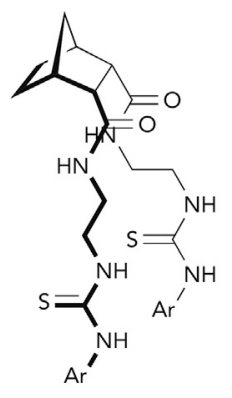

13

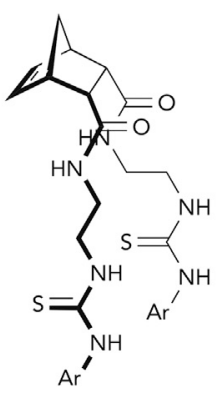

14

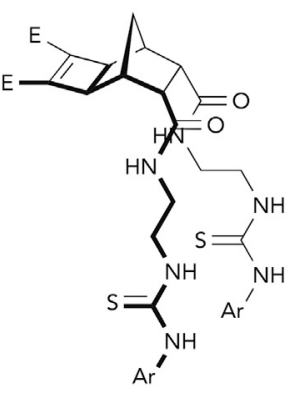

15

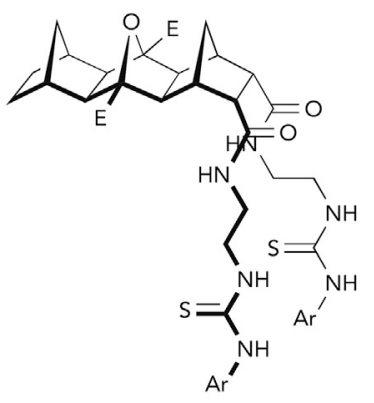

16

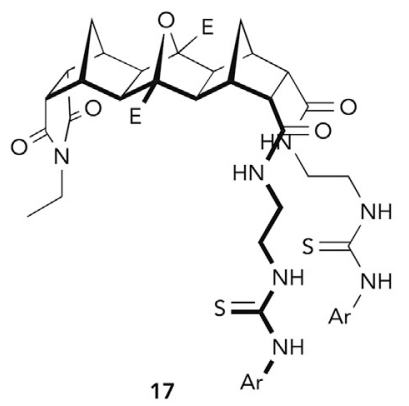

17

Figure 5. Structures of Receptors 13-20

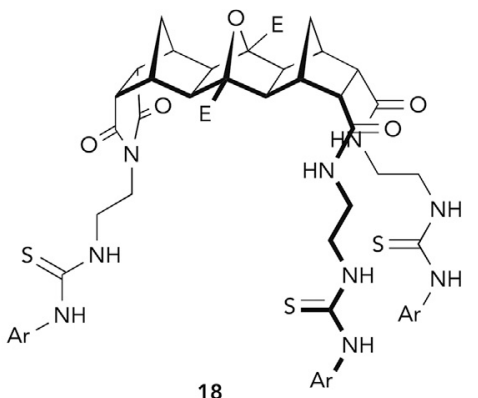

18

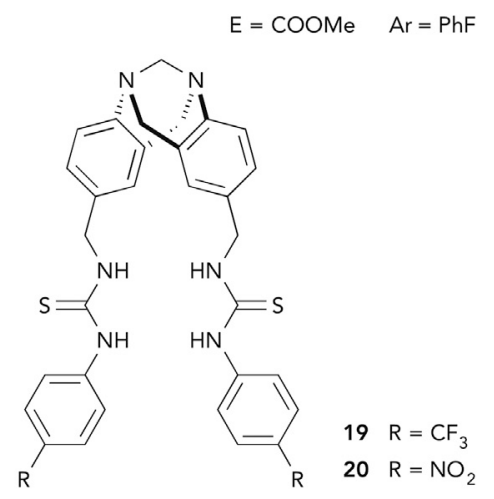


<smiles>CCNC(=O)c1cccc(C(=O)NCC)n1</smiles>

21<smiles></smiles>

24<smiles>CCNC(=O)NCC</smiles>

22

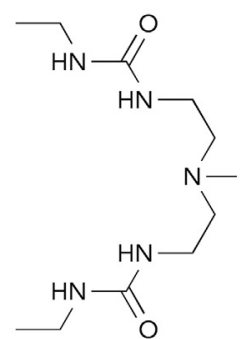

25

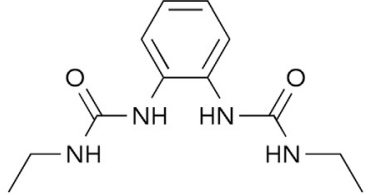

23

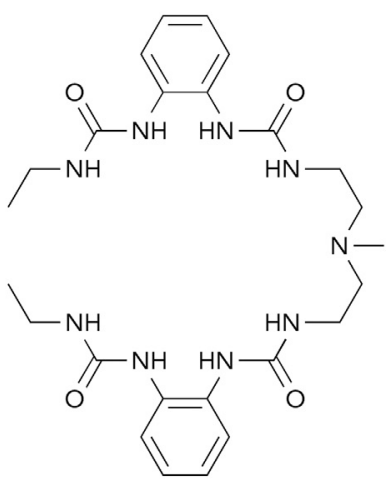

26

Figure 6. Structures of Acyclic Receptors 21-26

solvation effects or stabilization of the acetate $\mathrm{CH}_{3}$ group by the larger hydrophobic framework could be the cause of the different acetate binding behaviors. The framework size, however, had no influence on the dihydrogenphosphate binding stoichiometry. Tris-thiourea 18 bound a single $\mathrm{H}_{2} \mathrm{PO}_{4}{ }^{-}$, whereas the stoichiometry was 1:2 (receptor: $\mathrm{H}_{2} \mathrm{PO}_{4}{ }^{-}$) for 13-17.

Tröger's base is a rigid scaffold that contains two aryl rings almost perpendicular to each other. Boyle et al. ${ }^{9}$ used this scaffold to preorganize two thiourea groups for the binding and sensing of anions. Receptors 19 and 20 (Figure 5) were found to form 1:1 and 1:2 (receptor:anion) hydrogen-bond complexes with dihydrogenphosphate and acetate in DMSO, and interestingly neither of them bound sulfate. Notably, dihydrogenphosphate and acetate binding resulted in dramatic changes in the UV-Vis absorption spectra of 20 but only small changes in that of 19 , allowing compound 20 to function as a colorimetric sensor for these anions. For both receptors, titration with $\mathrm{F}^{-}$led to the initial formation of hydrogen-bond complexes, followed by deprotonation at higher $\mathrm{F}^{-}$concentrations.

In a very elegant study, Jia et al. ${ }^{10}$ reported a detailed analysis of chelation effects on sulfate binding by six amide- or urea-based receptors, 21-26 (Figure 6). Job plot experiments indicated that all of the compounds formed 1:1 complexes with sulfate. The sulfate affinity in DMSO- $d_{6}$ containing $0.5 \%-50 \% \mathrm{H}_{2} \mathrm{O}$ was found to be in the order $21<22<23<24<25<26$, which corresponds to increasing numbers of hydrogen-bond donors in the receptors, highlighting chelation-enhanced binding. The strong binders $24-26$ could bind sulfate in a highly competitive medium of DMSO- $d_{6} / 25 \% \mathrm{H}_{2} \mathrm{O}$, and binding constants were determined to be $68 \mathrm{M}^{-1}$ (24), $294 \mathrm{M}^{-1}(25)$, and $7,025 \mathrm{M}^{-1}(26)$.

Selectivity for sulfate over phosphate is an important attribute of bacterial sulfate binding proteins and facilitates selective transmembrane transport of sulfate ions. 

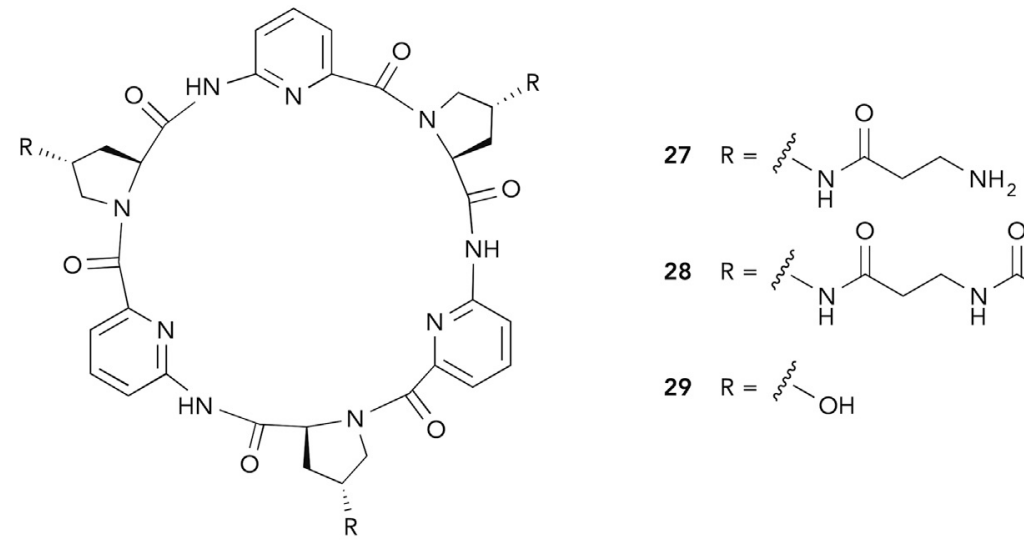<smiles>[R]C=CNC(=O)CCNC(=O)OCc1ccccc1</smiles>

$29 \mathrm{R}=$ s $^{\mathrm{s}} \mathrm{OH}$

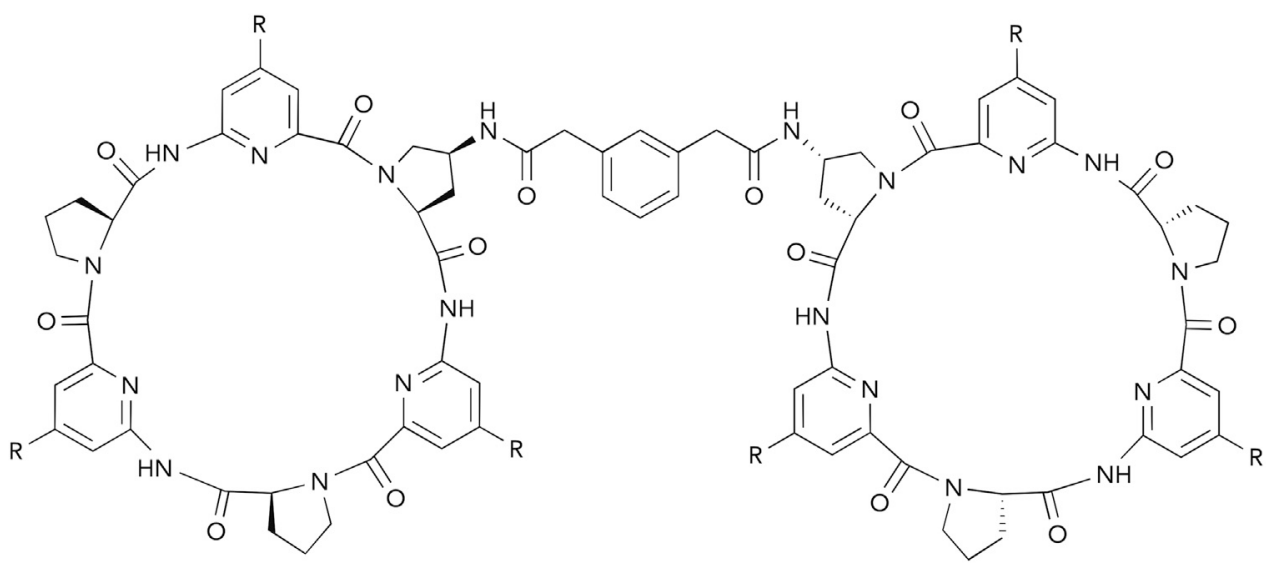

Figure 7. Structures of Cyclic Peptides 27-31

Schaly et al. ${ }^{11}$ developed a cyclopeptide 27 (Figure 7) that binds sulfate selectively even in aqueous phosphate buffer. Compound 27 is based on the cyclic hexapeptide scaffold with amide NH hydrogen-bond donors. The three pendent ammonium-containing side chains serve as additional anion-binding sites via Coulombic attractions and hydrogen bonds. The structure of a $1: 1 \mathrm{SO}_{4}{ }^{2-} \cdot 27 \cdot 3 \mathrm{H}^{+}$complex was optimized, which showed that sulfate was bound by $27 \cdot 3 \mathrm{H}^{+}$by nine hydrogen bonds. The formation of the $1: 1 \mathrm{SO}_{4}{ }^{2-} \cdot 27 \cdot 3 \mathrm{H}^{+}$complex was demonstrated by ESI-MS measurements. Potentiometric titrations revealed the strong sulfate affinity of 27, and $\mathrm{SO}_{4}{ }^{2-}$ binding constants were determined to be $10^{4.04}, 10^{3.44}$, and $10^{3.08}$ for the tri-, di-, and mono-protonated 27, respectively. Control compounds 28 and 29 (Figure 7) were also investigated and showed decreased sulfate affinity in the order $27>28>29$. Importantly, isothermal titration calorimetry (ITC) studies in water revealed that replacing the acetate buffering agent (40 mM, pH 4.8) with phosphate $(40 \mathrm{mM}, \mathrm{pH} 4.6)$ only slightly decreased the sulfate binding constant of 27 from $10^{4.20}$ to $10^{3.62}$, demonstrating the high sulfate selectivity of 27.

In a separate study, Sommer and Kubik ${ }^{12}$ studied solvent-dependent binding of sulfate and iodide by a neutral bis(cyclopeptide) 31 (Figure 7). Compared with the previously reported compound 30, the attachment of triethylene glycol chains allowed solubility of 31 in $95 \%$ water-methanol without compromising its anionbinding affinity. Using $\mathrm{Nal}$ and $\mathrm{Na}_{2} \mathrm{SO}_{4}$, ITC anion-binding studies of compound 31 were carried out in water-methanol mixtures with the water content ranging 


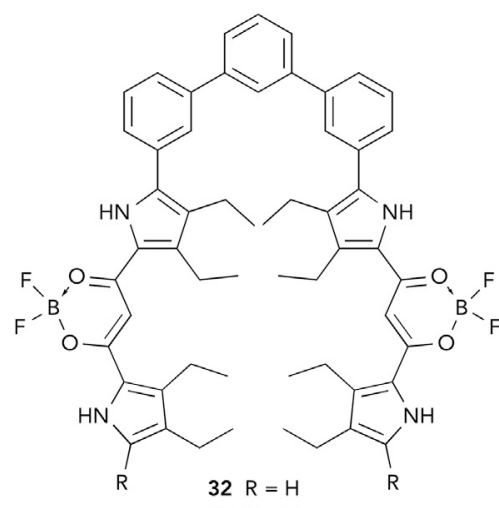

$33 \mathrm{R}=\mathrm{Ph}$

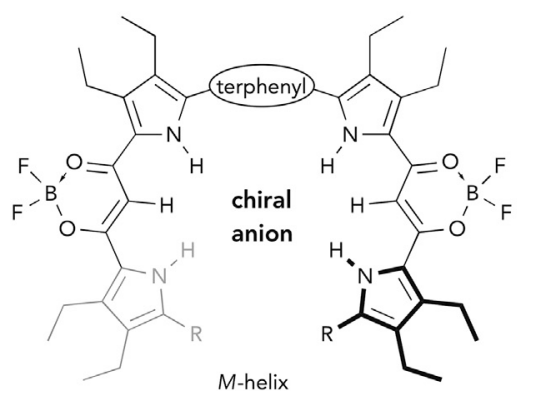

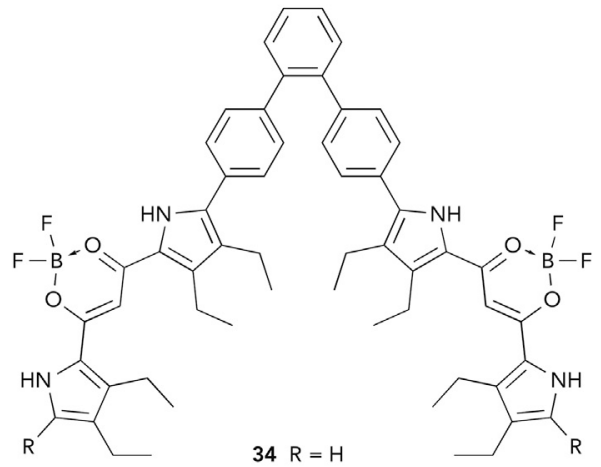

$35 \mathrm{R}=\mathrm{Ph}$

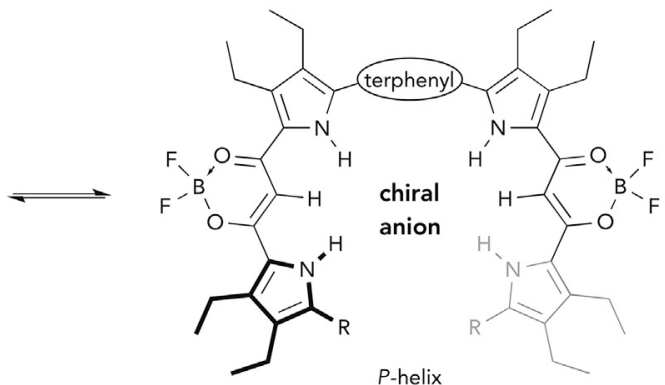

Figure 8. Helical Chirality of Receptors 32-35 Induced by Binding of Chiral Anions

from $20 \%$ to $95 \%$. Compound 31 was found to bind sulfate and iodide with binding constants in the order of $10^{4} \mathrm{M}^{-1}$ in $95 \%$ water-methanol; it showed a slight preference for iodide over sulfate in $95 \%$ water-methanol but a strong selectivity for sulfate in 30\% water-methanol. Interestingly, although the Gibbs free energy for the formation of both sulfate and iodide complexes decreased with increasing water content, the complexation enthalpy and entropy for both anions showed U-shaped curves with minima at $50 \%$ water-methanol. Although the increasingly unfavorable binding enthalpy and favorable entropy with high water content can be explained by anion desolvation, the same trend observed with high methanol content was unexpected. The authors ruled out potential ion pairing to be responsible on the basis of no counterion dependence. Instead, the authors proposed that free 31 remained preferentially solvated by water molecules even under solvent conditions with high methanol content and that the release of solvated water molecules from 31 upon anion binding is enthalpically more penalizing but entropically more favorable with high methanol content.

Receptors that show chiroptical properties induced by chiral substrate binding are potentially useful in sensing and developing electronic and optical materials. Maeda et al. ${ }^{13}$ developed $\pi$-conjugated anion receptors $32-35$ and studied their interactions with chiral anions (Figure 8). Binding of an L-phenylalanine anion (L-Phe) to 33-35 in $\mathrm{CH}_{2} \mathrm{Cl}_{2}$ led to the induction of circular dichroism (CD) signals from the $\pi$-conjugated chromophore. The signs of the $C D$ signals indicate that L-Phe dictated the predominant formation of the M-helix configuration in the case of 33 and the P-type helix in the cases of 34 and 35 . Furthermore, these helical complexes emitted circularly polarized luminescence $(\mathrm{CPL})$ at $-50^{\circ} \mathrm{C}$, representing the first examples of chiral anion-induced CPL from $\pi$-conjugated molecules. 
$\mathbf{A}$

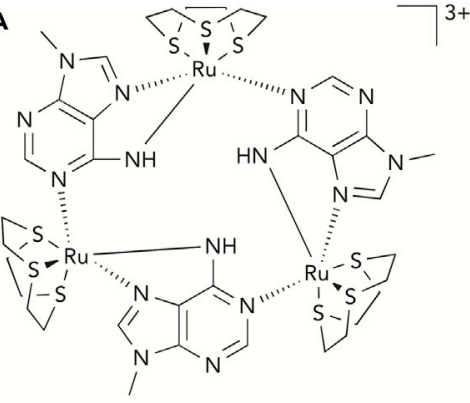

$36^{3+}$

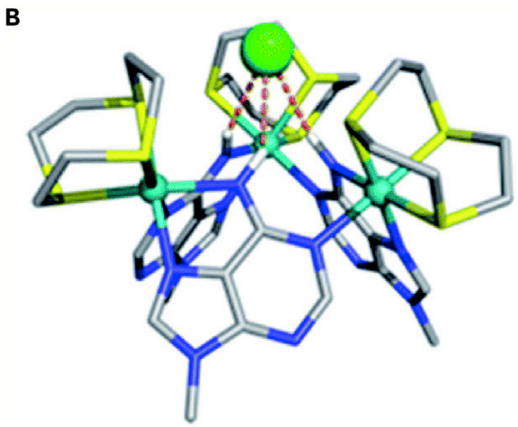

Figure 9. Redox-Active Anion Receptor 36 (A) Structure of $36^{3+}$.

(B) Optimized structure of the $36^{3+} \cdot \mathrm{Cl}^{-}$complex. Most hydrogen atoms have been omitted for clarity. The red dashed lines represent hydrogen bonds.

Reproduced with permission from Zubi et al. ${ }^{14}$ Published by the Royal Society of Chemistry.

Mixed-valence metal complexes that display reversible redox activities are attractive candidates for developing molecular-scale electronic devices. Zubi et al. ${ }^{14}$ demonstrated that the redox properties of a mixed-valence complex can be modulated by anion binding. The receptor under study was a kinetically locked trinuclear $\mathrm{Ru}(\mathrm{II})$ metallamacrocycle $36^{3+}$ (Figure 9A), which could be oxidized to mixedvalence states. Cationic $36^{3+}$ was found to bind halide ions with affinities in the sequence $\mathrm{Cl}^{-}>\mathrm{Br}^{-}>\mathrm{I}^{-}>\mathrm{F}^{-}$(using tetrabutylammonium [TBA ${ }^{+}$] salts) in $\mathrm{CD}_{3} \mathrm{CN}$. Theoretical studies showed that the cavity size matched chloride better than other halides, allowing chloride binding by three $\mathrm{NH}$ hydrogen bonds (Figure 9B). Cationic $36^{3+}$ has three redox potentials, corresponding to oxidations to the $36^{4+}\left(\mathrm{Ru}_{2}{ }_{2} \mathrm{Ru} \mathrm{I}^{\mathrm{III}}\right), 36^{5+}\left(\mathrm{Ru}^{\prime \prime} \mathrm{Ru}^{\mathrm{III}}{ }_{2}\right)$, and $36^{6+}\left(\mathrm{Ru}^{\prime \prime \prime}{ }_{3}\right)$ states. Square-wave voltammograms showed that fluoride and chloride induced anodic shifts of all three oxidation potentials, whereas bromide shifted the first two oxidation potentials anodically but the third potential cathodically. lodide led to small perturbations of the potentials. The magnitude of the shifts revealed that the most charge-dense anion fluoride stabilized the highest oxidation state $36^{6+}$ more than other halides, whereas chloride and bromide selected for the intermediate $36^{5+}$ state. Finally, the authors demonstrated that, without a change in applied potential, the addition of fluoride could switch the receptor from the $36^{4+}$ state to the $36^{5+}$ state, leading to a large change in the intervalence charge-transfer absorption band as a result of increased electronic delocalization in the $36^{5+}$ state.

Chang et al. ${ }^{15}$ have reported hexapyrrolic calix[4]pyrrole isomers 37 and 38 (Figure 10), which interact with anions via different types of interactions, leading to different anion-binding affinities. Compounds 37 (trans-isomer) and 38 (cis-isomer) differ in the orientation of two pyrrole side arms with respect to the calixpyrrole macrocycle. On the basis of ${ }^{1} \mathrm{H}-\mathrm{NMR}, 2 \mathrm{D} N M R$, and density functional theory (DFT) calculation studies, the authors deduced that 38 binds $\mathrm{F}^{-}$via four pyrrolic hydrogen bonds from the bottom calix[4]pyrrole macrocycle and, surprisingly, additional anion- $\pi$ interactions with $\mathrm{F}^{-}$sandwiched between the electron-deficient side-arm pyrrole rings. Fluoride binding by 37 , by contrast, involves binding of only one of the side-arm pyrroles via a hydrogen bond, in addition to the four hydrogen bonds provided by the calix[4]pyrrole macrocycle. Interestingly, UV-Vis binding studies in acetonitrile showed cross-reactivity of 38 toward different anions, whereas 37 was more selective toward $\mathrm{F}^{-}$over other anions such as $\mathrm{Cl}^{-}, \mathrm{AcO}^{-}, \mathrm{BzO}^{-}$, and $\mathrm{H}_{2} \mathrm{PO}_{4}^{-}$. 


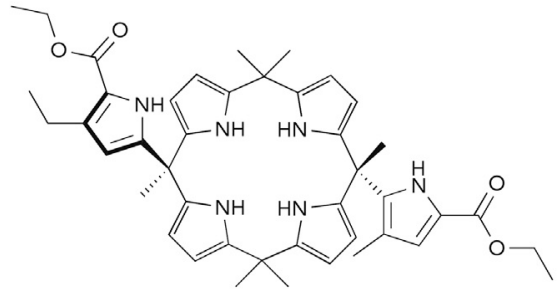

37

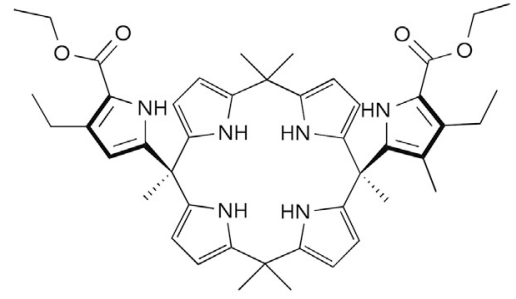

38

Figure 10. Structures of Hexapyrrolic Calix[4]pyrrole Isomers 37 and 38

Although 37 and 38 are not interconvertible, it would be of interest to develop anion receptors that can switch between isomers that differ in anion-binding affinity. Such systems would be reminiscent of biological membrane transporters that change their substrate affinity by switching between different conformations, triggered by ligand binding or dissociation, or a change in $\mathrm{pH}$ or voltage. Wezenberg et al. ${ }^{16}$ reported a bis-urea receptor, 39, that upon irradiation or heating, isomerizes reversibly between three states with different $\mathrm{H}_{2} \mathrm{PO}_{4}{ }^{-}$affinities, namely a stable trans-isomer, a stable cis-isomer, and an unstable cis-isomer (Figure 11). Both cis-isomers show a much higher affinity for $\mathrm{H}_{2} \mathrm{PO}_{4}{ }^{-}$than the trans-isomer as a result of cooperative binding with four hydrogen bonds. In addition, the $\mathrm{H}_{2} \mathrm{PO}_{4}{ }^{-}$affinity differs significantly for the stable and unstable cis-isomers because of different torsion angles (Figure 11).

${ }^{31} \mathrm{P}-\mathrm{NMR}$ spectra demonstrated the ability of this system to reversibly control the fraction of bound phosphate in a 1:1 receptor-phosphate mixture by switching between the three photostationary states.<smiles>Cc1cc(N2C[C@@H]3C=C[C@@H](c4ccccc4)N3C(=O)N2c2ccccc2)c2c(c1C)/C(=C1\c3c(C)c(NC(=O)Nc4ccccc4)cc(C)c3CC1C)C(C)C2</smiles>
stable trans-39, $\mathrm{K}_{\mathrm{a}}\left(\mathrm{H}_{2} \mathrm{PO}_{4}{ }^{-}\right)=1.3 \times 10^{2} \mathrm{M}^{-1}$

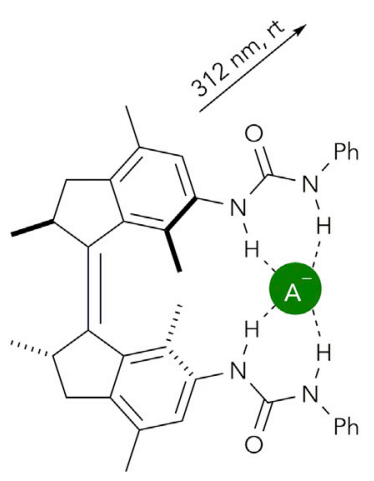

stable cis-39, $\mathrm{K}_{\mathrm{a}}\left(\mathrm{H}_{2} \mathrm{PO}_{4}{ }^{-}\right)=7.5 \times 10^{3} \mathrm{M}^{-1}$
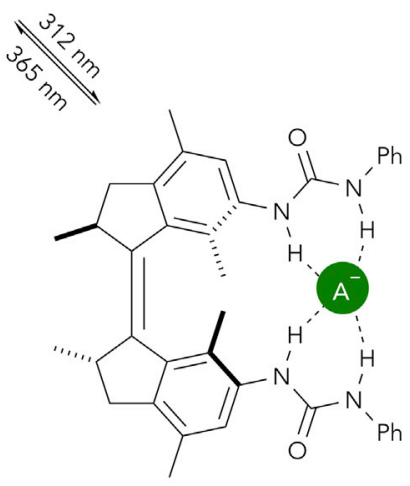

unstable cis-39, $\mathrm{K}_{\mathrm{a}}\left(\mathrm{H}_{2} \mathrm{PO}_{4}{ }^{\mathrm{T}}\right)=2.3 \times 10^{3} \mathrm{M}^{-1}$

Figure 11. Isomerization of 39 between Three States with Different $\mathrm{H}_{2} \mathrm{PO}_{4}{ }^{-}$Binding Affinities, $K_{a}$, in DMSO- $d_{6} / 0.5 \% \mathrm{H}_{2} \mathrm{O}$ 


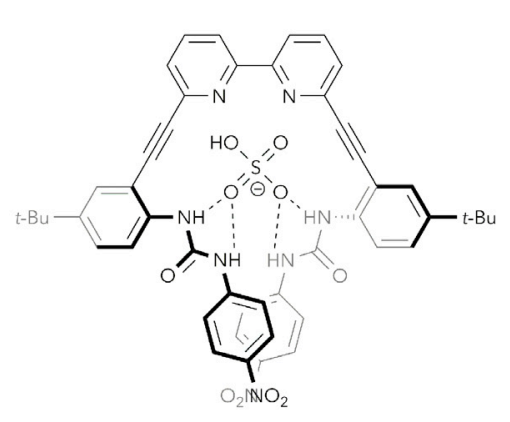

$40 \cdot \mathrm{HSO}_{4}{ }^{-}$complex (U-conformation)

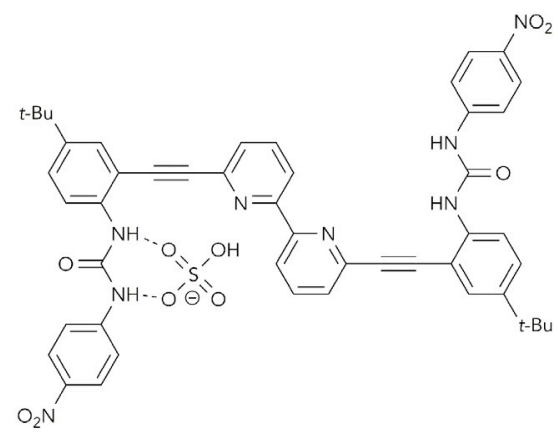

$40 \cdot \mathrm{HSO}_{4}{ }^{-}$complex (S-conformation)<smiles>CC(C)(C)c1ccc(NC(=O)Nc2ccc([N+](=O)[O-])cc2)c(C#Cc2cccc(-c3ccc4c(n3)[C@H]3C[C@H]4N(C(=O)Nc4ccc([N+](=O)[O-])cc4)C(=O)N3c3ccc(C(C)(C)C)cc3C#Cc3ccccc3)n2)c1</smiles>

$40 \cdot \mathrm{Cl}^{-}$complex (Z-conformation)

Figure 12. Three Anion-Binding Conformations of Receptor 40

Stereodynamic anion receptors that change conformations upon anion binding have attracted significant interest because they mimic the induced-fit binding model of naturally occurring enzymes. Gavette et al. ${ }^{17}$ reported an example of an anion-modulated molecular switch that adopted three distinct conformations depending on the anionic guest species. Molecular rotor 40 (Figure 12) featured two urea anion-binding moieties connected via a flexible rotor that consisted of two arylacetylene units and a bipyridine unit. Interestingly, halide ions $\mathrm{Cl}^{-}$, $\mathrm{Br}^{-}$, and $\left.\mathrm{I}^{-}\right)$and oxoanions $\left(\mathrm{H}_{2} \mathrm{PO}_{4}{ }^{-}, \mathrm{HSO}_{4}{ }^{-}, \mathrm{OAc}^{-}\right.$, and $\left.\mathrm{NO}_{3}{ }^{-}\right)$led to different binding conformations. It was concluded from ${ }^{1} \mathrm{H}-\mathrm{NMR}$ (in $10 \% \mathrm{DMSO}-\mathrm{d}_{6} / \mathrm{CDCl}_{3}$ ) and DFT studies that compound 40 binds halides via a $Z$ conformation that involves both urea $\mathrm{NH}$ hydrogen bonds and an aryl $\mathrm{CH}$ hydrogen bond, whereas protic oxoanions do not form aryl $\mathrm{CH}$ hydrogen bonds and prefer $\mathrm{U}$ or $\mathrm{S}$ (at high anion concentrations) conformations presumably as a result of hydrogenbond donation to the pyridine nitrogen lone pair. A follow-up study involving other model compounds provided more evidence for $U$ conformation preference in the case of $1: 140 \cdot \mathrm{HSO}_{4}{ }^{-}$binding, but it also raised uncertainty for the originally assigned binding conformation of $40 \cdot \mathrm{Cl}^{-} .{ }^{18}$ Proton NMR studies demonstrated the reversibility of the conformational switch modulated by changing the anionic guest from $\mathrm{Cl}^{-}$to $\mathrm{HSO}_{4}{ }^{-}$. Another interesting aspect of the chemistry of 40 is selective binding of $\mathrm{H}_{2} \mathrm{PO}_{4}{ }^{-}$, which probably results from hydrogen bonding or even proton transfer between the $\mathrm{H}_{2} \mathrm{PO}_{4}{ }^{-}$proton and the pyridine nitrogen.

\section{CH Hydrogen-Bond-Based Receptors}

Anion binding utilizing aromatic or aliphatic $\mathrm{CH}$ - anion hydrogen bonds has gained increasing popularity in recent years. $\mathrm{CH}$ groups are generally less acidic than 


$41 \mathrm{R}=\mathrm{H}$
$42 \mathrm{R}=\mathrm{CH}_{3}$
$43 \mathrm{R}=\mathrm{CH}_{2} \mathrm{Cl}$
$44 \mathrm{R}=\mathrm{CHCl}_{2}$
$45 \mathrm{R}=\mathrm{CCl}_{3}$

Figure 13. Anion Binding by Receptors 41-45 Based on the 6-Crown-3 Scaffold

$\mathrm{NH}$ and $\mathrm{OH}$ groups, leading to weak binding energy with anions for an individual $\mathrm{CH}$ donor. Nevertheless, moderate-to-strong anion binding can be achieved by preorganization of a multivalent receptor. The weak acidity and relative hydrophobicity of $\mathrm{CH}$ groups have sometimes proved crucial to aqueous anion binding and preference for more hydrophobic (chaotropic) anions, as will be demonstrated in some of the following examples.

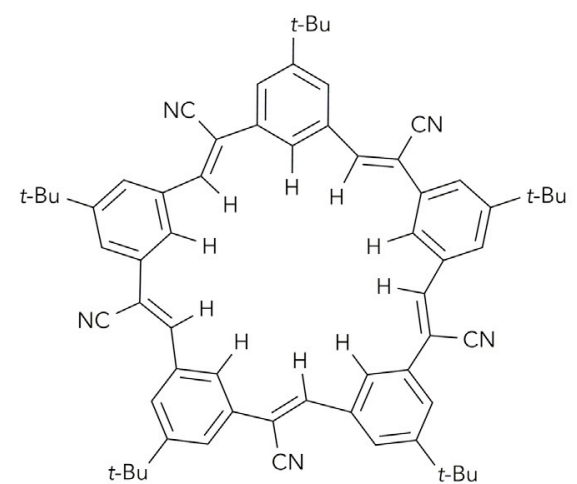

46

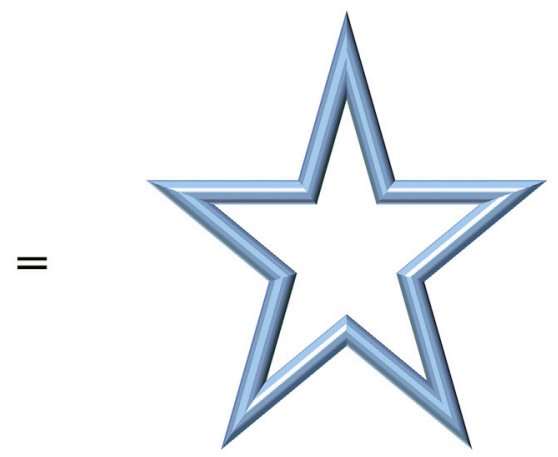<smiles>COC(=O)c1cc([NH3+])cc(C(=O)OC)c1</smiles><smiles>C#CCOP(=O)([O-])OCC#C</smiles><smiles>COC(=O)c1cc(N)cc(C(=O)OC)c1</smiles>

$$
\begin{aligned}
& \mathrm{CuBr} / \mathrm{TBTA} \\
& \mathrm{Et}_{3} \mathrm{~N} / \mathrm{CH}_{2} \mathrm{Cl}_{2}
\end{aligned}
$$

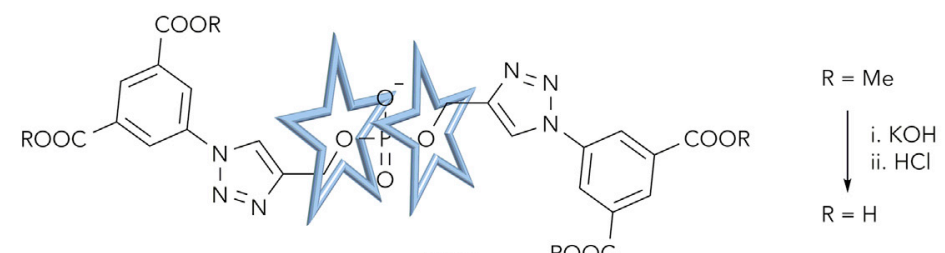

$\mathrm{TBA}^{+}$

Figure 14. Formation of a Rotaxane between 46 and a Diakylphosphate Ligand

$\mathrm{TBA}^{+}$, tetrabutylammonium ion; TBTA, tris((1-benzyl-1H-1,2,3-triazol-4-yl)methyl)amine. 

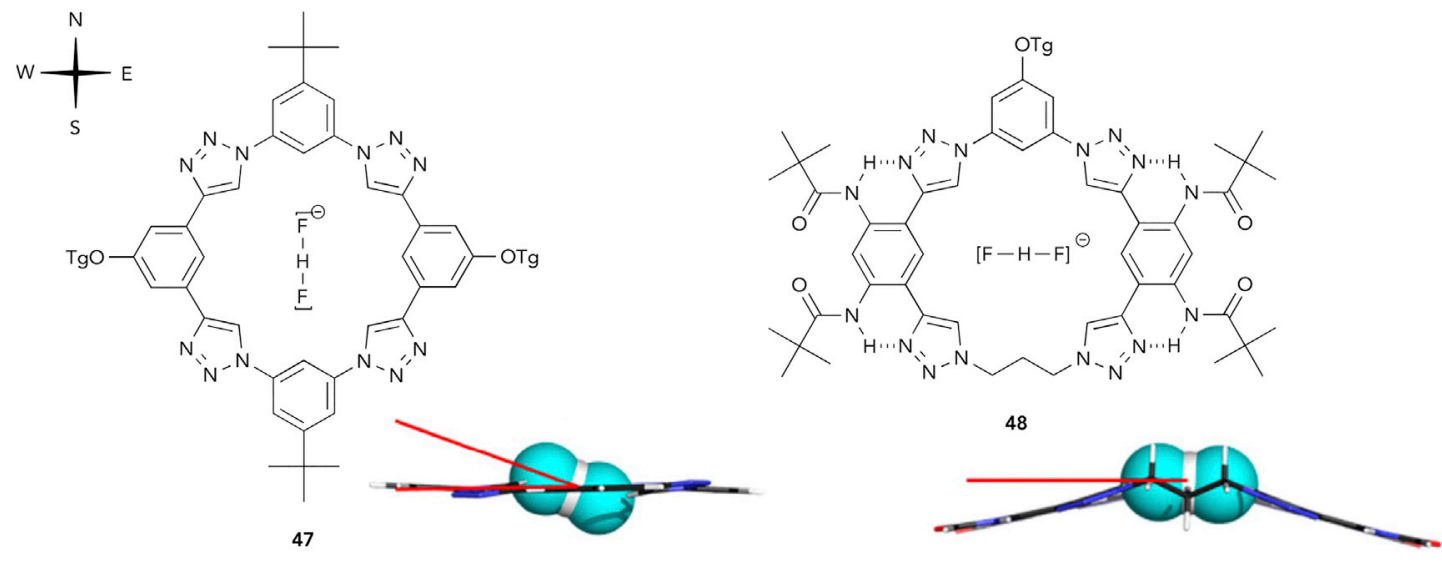

$\mathrm{OTg}=\mathrm{s}_{\mathrm{s}}^{\mathrm{O}} \sim \mathrm{NOW}_{\mathrm{O}} \sim \mathrm{O}_{\mathrm{O}}$

Figure 15. Schematic Representation Showing Tilting of $\mathrm{HF}_{2}{ }^{-}$within the Cavity of 47 and Elimination of Tilting in the Case of $\mathrm{HF}_{2}{ }^{-}$Binding to 48

The designation of cardinal directions of the receptors is shown in the top left corner. Reprinted with permission from Ramabhadran et al. ${ }^{22}$ (c)2014 American Chemical Society.

Shi et al. ${ }^{19}$ reported a new class of $\mathrm{CH}$ anion receptors, 41-45, based on the 6-crown-3 scaffold (Figure 13). The three axially positioned $\mathrm{CH}$ bonds, polarized by adjacent oxygen atoms, served as the anion-binding motif. Although the $\mathrm{CH}$ bond polarization in 41 and 42 was not sufficient for anion binding and $\mathbf{4 5}$ gradually decomposed in solutions, 43 and 44 showed observable interactions with anions, including $\mathrm{NO}_{2}{ }^{-}, \mathrm{AcO}^{-}$, and halides, with binding constants ranging from $2 \mathrm{M}^{-1}$ to $15 \mathrm{M}^{-1}$ in $\mathrm{C}_{6} \mathrm{D}_{6}$ or $\mathrm{CD}_{3} \mathrm{CN}$.

Lee et al. $^{20}$ have continued their efforts to create new anion receptors based on $\mathrm{CH}$ hydrogen bonds. In addition to the well-known 1,2,3-triazole motif, they incorporated a new $\mathrm{CH}$ hydrogen-bond motif, cyanostilbene, into a macrocyclic receptor cyanostar, 46, that contains ten $\mathrm{CH}$ hydrogen-bond donors in its central cavity (Figure 14). Compound 46 was easily obtained via a Knoevenagel selfcondensation reaction in high yield. In $40 \%$ methanol/ $\mathrm{CH}_{2} \mathrm{Cl}_{2}, 46$ formed 2:1 (46:anion) sandwich complexes with large weakly coordinating anions, including $\mathrm{PF}_{6}{ }^{-}, \mathrm{ClO}_{4}{ }^{-}$, and $\mathrm{BF}_{4}{ }^{-}$, with unprecedented high affinity $\left(\beta_{2}\right.$ in the order of $10^{11}$ $\left.10^{12} \mathrm{M}^{-2}\right)$ and positive cooperativity $\left(K_{12} / K_{11}>8\right)$. Compound 46 showed selectivity based on the size of anions; too large (e.g., $\mathrm{PtCl}_{6}^{-}$) or too small $\left(\mathrm{Cl}^{-}\right)$anions showed weakened affinity and cooperativity. Another interesting property of 46 is its ability to form a [3]rotaxane with a dialkylphosphate ligand.

The bifluoride ion $\left(\mathrm{HF}_{2}{ }^{-}\right)$has largely been overlooked in the area of anion receptor chemistry. ${ }^{21}$ Ramabhadran et al. ${ }^{22}$ investigated bifluoride $\left(\mathrm{HF}_{2}{ }^{-}\right)$binding to a previously reported triazoloplane macrocycle, 47, and subsequently optimized the receptor structure by using computer-aided design to develop triazoloplane 48 (Figure 15), which showed enhanced affinity for $\mathrm{HF}_{2}^{-}$(in relation to $\mathrm{Cl}^{-}$affinity). A combination of computational and experimental NMR binding studies indicated that, in the case of the $47 \cdot \mathrm{HF}_{2}{ }^{-}$complex, the bound $\mathrm{HF}_{2}{ }^{-}$preferentially oriented along the north-south direction, with a tilting angle of $20^{\circ}$ out of the macrocyclic plane. Although the calculated gas-phase binding energies for 47 with $\mathrm{Cl}^{-}$and $\mathrm{HF}_{2}{ }^{-}$were almost the same, experimental results showed that $\mathrm{HF}_{2}{ }^{-}$bound with an affinity 25 times weaker than that of $\mathrm{Cl}^{-}$, which was attributed to solvation 
of tilted $\mathrm{HF}_{2}{ }^{-}$in the complex that attenuated its hydrogen bonding with 47. The structure of $\mathbf{4 7}$ was then modified by extension of the cavity size and increase of $\mathrm{CH}$ bond polarization by adding electron-withdrawing groups or forming intramolecular hydrogen bonds. The new receptor 48 accommodated an untilted $\mathrm{HF}_{2}{ }^{-}$along its east-west axis. The elimination of tilting resulted in a bifluoride affinity of $48\left(6.2 \times 10^{5} \mathrm{M}^{-1}\right)$ now of the same magnitude as its chloride affinity in $\mathrm{CH}_{2} \mathrm{Cl}_{2}$.

Although examples of binding apolar guests in water on the basis of hydrophobic interactions are well known, Hua et al. ${ }^{23}$ demonstrated in a seminal report that hydrophobic interactions can be exploited to drive the binding of hydrophilic anions in aqueous solutions. The two aryl-triazole foldamers 49 and 50 (Figure 16) were studied, in which the main chain could associate intramolecularly or intermolecularly via $\pi$-stacking, and the azobenzene unit further shielded the anion-binding site from solvents. Compounds 49 and 50 could bind chloride via the formation of single-helix 1:1 complexes or double-helix 2:1 complexes. Formation of single-helix $1: 1 \mathrm{Cl}^{-}$ complexes of 49 and 50 were found to dominate in pure acetonitrile, with a negative cooperativity for forming the duplex. Remarkably in $50 \% \mathrm{CH}_{3} \mathrm{CN} / \mathrm{H}_{2} \mathrm{O}$, chloride binding induced the formation of the double helix of 50 , which has $\sim 80 \%$ of its $\pi$-surfaces buried. This led to a solvent-excluding microenvironment favorable for $\mathrm{Cl}^{-}$ binding via $\mathrm{CH}$ hydrogen bonds. The effect of hydrophobic collapse was manifested in the surprisingly high chloride affinity ( $\left.\log \beta_{2}=13.0\right)$ and high cooperativity $\left(K_{2} / K_{1}=165\right)$ in $50 \% \mathrm{CH}_{3} \mathrm{CN} / \mathrm{H}_{2} \mathrm{O}$, which compensated for the dehydration energetic cost of chloride.

High-affinity anion binding by neutral, non-covalent receptors in pure water still represents a formidable challenge for supramolecular chemists. A promising solution is to use macrocycles with a hydrophobic cavity. The success of this approach was highlighted in the bambusuril macrocycle receptor 51 (Figure 17) reported by Yawer et al. ${ }^{24}$ Compound 51 contains twelve $\mathrm{CH}$ hydrogen-bond donors $\left(\mathrm{H}_{\mathrm{a}}\right)$ and negatively charged carboxylate groups ensuring its solubility in pure water. Compound 51 showed exceptionally strong affinity for weakly hydrated anions, including $\mathrm{ClO}_{4}{ }^{-}, \mathrm{I}^{-}, \mathrm{BF}_{4}{ }^{-}$, and $\mathrm{PF}_{6}{ }^{-}$, with binding constants above $10^{6} \mathrm{M}^{-1}$ in $\mathrm{D}_{2} \mathrm{O}$. In contrast, strongly hydrated anions, such as $\mathrm{F}^{-}$and $\mathrm{Cl}^{-}$, which typically showed strong binding in organic solvents, bound relatively weakly to 51 in $\mathrm{D}_{2} \mathrm{O}\left(\mathrm{K}_{1} 1,000 \mathrm{M}^{-1}\right)$. Interestingly, complexes with strongly bound anions (e.g., $\mathrm{ClO}_{4}^{-}, \mathrm{I}^{-}, \mathrm{BF}_{4}^{-}$, and $\mathrm{PF}_{6}^{-}$) showed slow exchange with the free receptor on the NMR timescale, whereas those formed with weakly bound anions (e.g., $\mathrm{F}^{-}$and $\mathrm{Cl}^{-}$) showed fast exchange. The

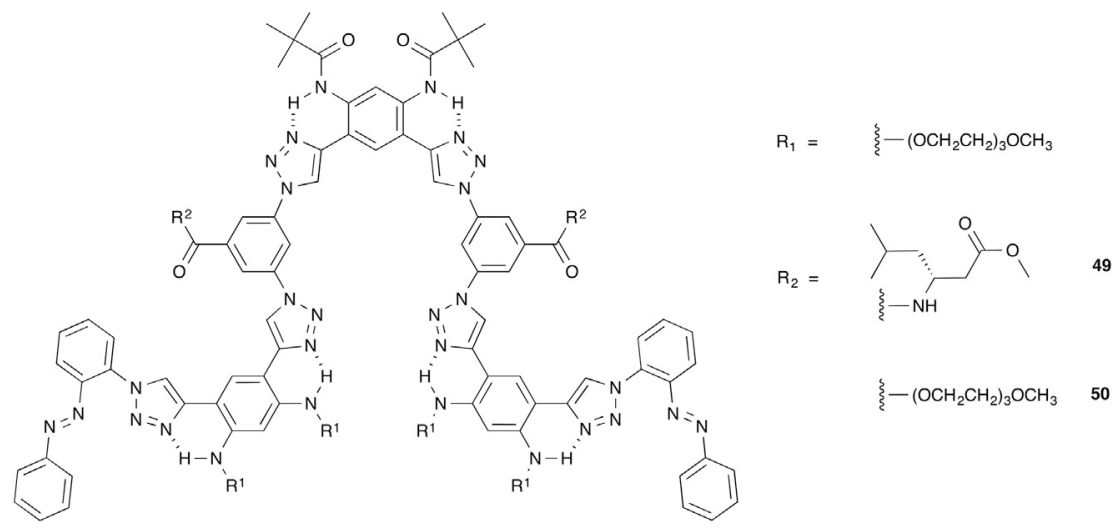

Figure 16. Structures of Aryl-triazole Foldamers 49 and 50 

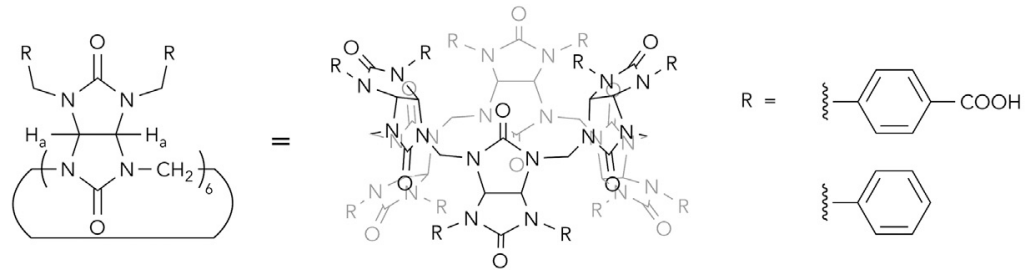

51

52

Figure 17. Structures of Bambusurils 51 and 52

anion binding was found to be enthalpically driven and entropically unfavorable. Bambusurils 51 and 52 (Figure 17) were later used for sensing of multiple anion mixtures by NMR in aqueous solutions. ${ }^{25}$ This was made possible because of the slow exchange on the NMR timescale of all examined anion complexes of 51 in $5 \% \mathrm{D}_{2} \mathrm{O} / \mathrm{DMSO}-d_{6}$ and complexes of 52 with some strongly bound anions in $\mathrm{D}_{2} \mathrm{O}$. Different anions gave unique ${ }^{1} \mathrm{H}-\mathrm{NMR}$ fingerprints from their complexes, which were insensitive to their concentration and presence of other anions. This method could identify up to nine anions simultaneously or quantify up to five coexisting anions.

The biotin[6]urils are another class of macrocyclic $\mathrm{CH}$ hydrogen-bond anion receptors capable of binding anions in pure water, and they have found applications as transmembrane $\mathrm{Cl}^{-}$transporters. ${ }^{26,27}$ In the initial report, compound 53 (Figure 18A) was synthesized by condensation of a carboxylate-containing biotin with formaldehyde in the presence of semi-concentrated $\mathrm{HCl}$, in which the $\mathrm{Cl}^{-}$ion served as the template for the selective formation of the $6+6$ macrocyclic adduct. ${ }^{26}$ The crystal structure of the 53. Nal complex (Figure 18B) showed favorable encapsulation of $\mathrm{I}^{-}$within the cavity of the macrocycle. Compound 53 showed a sub-millimolar affinity for $\mathrm{I}^{-}$and a selectivity of $\mathrm{I}^{-}>\mathrm{Br}^{-}>\mathrm{Cl}^{-}$in water. Later lipophilic derivatives of 53, including 54 and 55 (Figure 18A), were exploited for membrane-transport applications. ${ }^{27}$ Proton NMR binding studies showed that 54 has a $\sim 100$-fold $\mathrm{Cl}^{-} / \mathrm{HCO}_{3}{ }^{-}$ binding selectivity in $\mathrm{CD}_{3} \mathrm{CN}$. Importantly, the $\mathrm{Cl}^{-} / \mathrm{HCO}_{3}{ }^{-}$selectivity was also
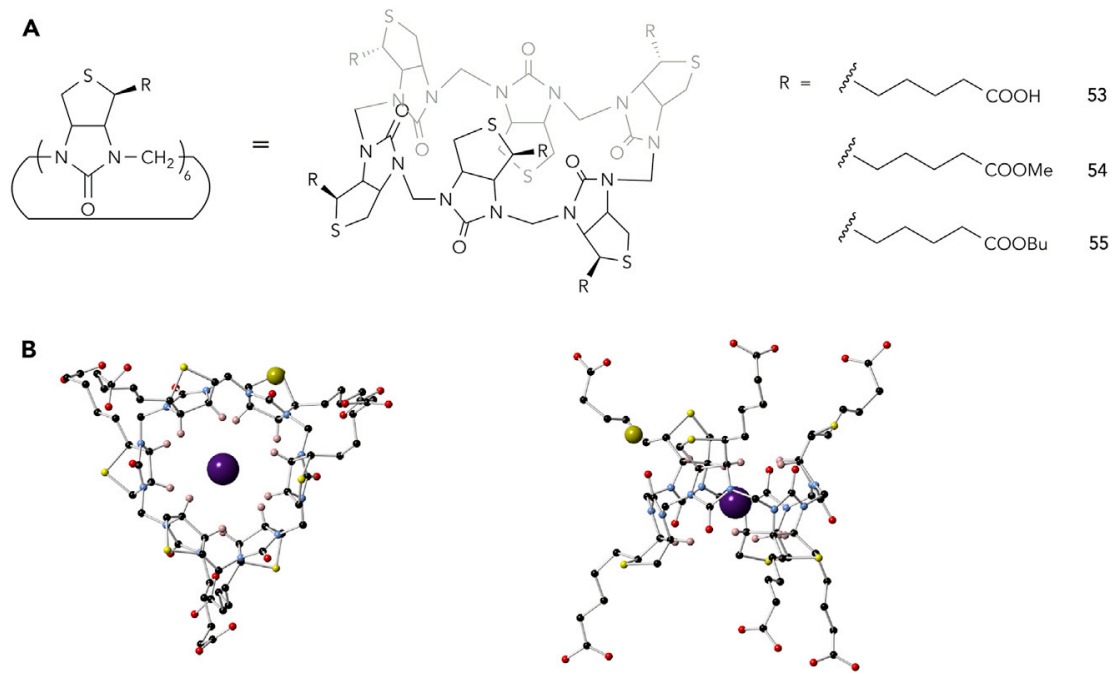

Figure 18. Anion Binding by Biotin[6]urils

(A) Structures of biotin[6]urils 53-55.

(B) Top and side views of the single-crystal structure of the $53 \cdot \mathrm{Nal}$ complex. Most hydrogen atoms have been omitted for clarity. 
observed in membrane transport. In liposome models, 55 was able to facilitate $\mathrm{Cl}^{-} / \mathrm{NO}_{3}{ }^{-}$exchange without $\mathrm{Cl}^{-} / \mathrm{HCO}_{3}{ }^{-}$exchange, whereas a previously reported bis-urea transporter facilitated both processes. The $\mathrm{Cl}^{-} / \mathrm{HCO}_{3}{ }^{-}$selectivity is potentially useful for certain biological applications because $\mathrm{Cl}^{-}$and $\mathrm{HCO}_{3}{ }^{-}$are two of the most prevalent anions in living organisms.

\section{Hydrophobic Binding}

Recently, examples of anion binding that do not involve strong covalent, ionic, or ion-dipole interactions but instead rely on hydrophobic interactions have been reported. As an enquiry into the Hofmeister effect, which was historically interpreted as making or breaking water structure, Carnegie et al. ${ }^{28}$ examined the effect of coexisting salts on binding of $\mathrm{ClO}_{4}^{-}$to an octa-anionic cavitand, 56 (Figure 19), in $\mathrm{H}_{2} \mathrm{O}$ and demonstrated the importance of direct ion-solute interactions. Several $\mathrm{Na}^{+}$salts of different anions, ranging from the strongly hydrated (kosmotropic) anion $\mathrm{F}^{-}$to the weakly hydrated (chaotropic) $\mathrm{SCN}^{-}$, were used to adjust the ionic strength of the solutions, in which binding constants between 56 and $\mathrm{ClO}_{4}{ }^{-}$were measured by ${ }^{1} \mathrm{H}-\mathrm{NMR}$ titrations. Similarly to the known ability of kosmotropes and chaotropes to increase and decrease hydrophobic interactions, respectively, it was found that kosmotropic salts (e.g., NaF) enhanced $\mathrm{ClO}_{4}{ }^{-}$binding, and chaotropic salts (e.g., $\mathrm{NaSCN}$ ) weakened $\mathrm{ClO}_{4}^{-}$binding. Salts between the two extremes (e.g., $\mathrm{NaClO}_{3}$ ) showed more complex behavior of slightly enhancing $\mathrm{ClO}_{4}{ }^{-}$binding at low concentrations but decreasing $\mathrm{ClO}_{4}{ }^{-}$binding at high concentrations. The data were fit to a model that took into account the competitive binding of the examined co-anion to the cavity of 56 and enhanced anion binding by $\mathrm{Na}^{+}$ complexation to the carboxylate groups of 56 . The authors concluded that (1) kosmotropes led to "salting-in" binding enhancement, mainly because cation binding to the anionic host reduced its net charge, and (2) chaotropes induced "saltingout" binding attenuation as a result of competitive binding of the hydrophobic anion to the hydrophobic cavity. The complex behavior of "intermediate" salts was explained as domination of cation-induced binding enhancement (1) at low salt concentrations and domination of competitive anion binding (2) at high salt concentrations.

Subsequently, Sokkalingam et al. ${ }^{29}$ carried out experimental binding studies and calculations (quantum mechanics and molecular dynamics [MD]) on binding of 56 to several anions. Compound 56 was found to bind weakly hydrated anions in $\mathrm{H}_{2} \mathrm{O}$; among the tested anions, $\mathrm{Cl}_{3} \mathrm{CCO}_{2}{ }^{-}$showed the highest affinity $\left(6,337 \mathrm{M}^{-1}\right.$

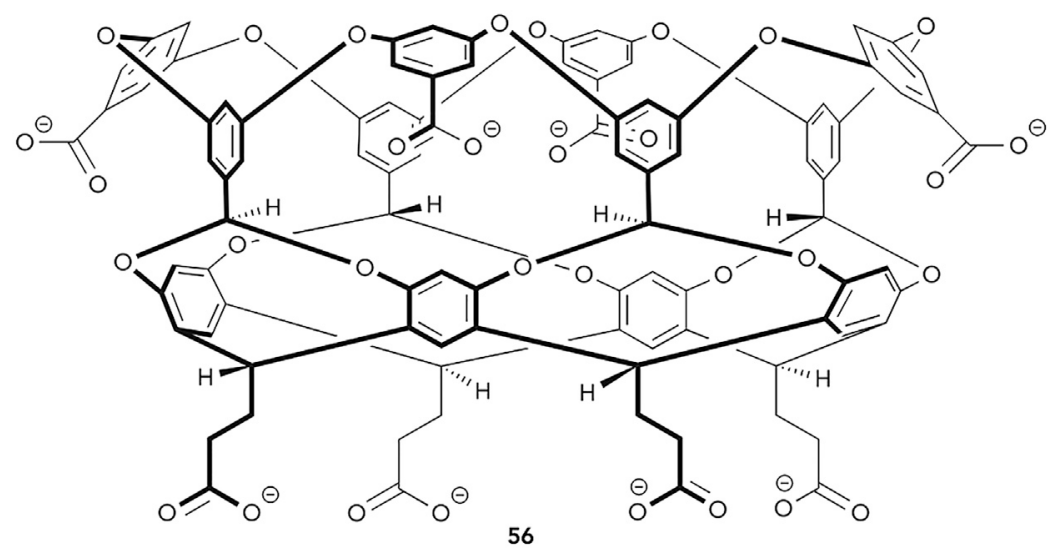

Figure 19. Structure of the Cavitand $\mathbf{5 6}$ 
determined by ITC), $\mathrm{ClO}_{4}^{-}$showed an intermediate affinity $\left(160 \mathrm{M}^{-1}\right.$ by ITC), $\mathrm{I}^{-}$showed a weak affinity (17 $\mathrm{M}^{-1}$ by ITC), and $\mathrm{Cl}^{-}$showed no measureable bonding. As determined with ITC, the anion binding was enthalpically driven and entropically penalized. The authors demonstrated in $\mathrm{MD}$ simulations that $\mathrm{ClO}_{4}{ }^{-}$and $\mathrm{I}^{-}$retained about half of their solvation shell water molecules when bound in the cavity compared with in the bulk, whereas $\mathrm{Cl}^{-}$kept most of its solvation shell when bound. On the basis of these results, it was proposed that the high entropic cost caused by the organized solvated waters in the cavity accounted for the low or no affinity of smaller and "harder" ions and the low or no solvation of large ions inside the cavity.

Assaf et al. ${ }^{30}$ reported the surprisingly high-affinity binding of doubly negatively charged dodecaborate clusters to the $\gamma$-cyclodextrin ( $\gamma$-CyD) cavity. The dodecaborate anions $\left(\mathrm{B}_{12} \mathrm{X}_{12}{ }^{2-}\right.$ and $\mathrm{B}_{12} \mathrm{X}_{11} \mathrm{Y}^{2-}: \mathrm{X}=\mathrm{H}, \mathrm{Cl}$, or $\mathrm{Br}, \mathrm{l} ; \mathrm{Y}=\mathrm{OH}, \mathrm{SH}, \mathrm{NH}_{3}{ }^{+}$, or $\left.\mathrm{NR}_{3}{ }^{+}\right)$ feature highly delocalized negative charges and are therefore not ideal guests for implementing interactions typically used in anion receptor chemistry. However, they bound to $\gamma$-CyD with high affinities up to micromolar levels, which did not show a dramatic size-dependent variation (binding constants within two orders of magnitude among the dodecaborate anions tested). The $\gamma$-CyD-dodecaborate interactions were characterized by high negative enthalpies along with high entropic costs. The authors proposed that despite the importance of dispersion interactions between dodecaborates and $\gamma-C y D$, the dominant driving force was a "chaotropic effect" that was based on recovery of the water hydrogen-bonding network upon release of water molecules that weakly solvated chaotropic anions, leading to enthalpic gain but loss of entropy.

Halogen and Chalcogen Bonding

Halogen bonding, ${ }^{31}$ the attractive interaction between the electropositive region ( $\sigma$-hole) of a polarized halogen atom and a Lewis base, has received increasing attention in the area of anion receptor chemistry. Langton et al. ${ }^{32}$ demonstrated the utility of halogen bonding and its potential superiority to hydrogen bonding in achieving anion binding in water in a series of cyclodextrin-functionalized acyclic (57-59) and rotaxane (60-62) hosts (Figure 20). Rotaxane 60, which bound anions via a combination of halogen bonding and hydrogen bonding, displayed a remarkably high affinity of $2,200 \mathrm{M}^{-1}$ for $\mathrm{I}^{-}$and a selectivity of $\mathrm{I}^{-}>\mathrm{Br}^{-}>\mathrm{Cl}^{-}>$ $\mathrm{SO}_{4}{ }^{2-}$ in $\mathrm{D}_{2} \mathrm{O}$. In comparison, purely hydrogen-bond receptors, rotaxanes 61 and 62 showed weak halide affinities $\leq 50 \mathrm{M}^{-1}$. It is noticeable that even the acyclic halogen-bond receptor 57 showed measurable halide binding (e.g., $50 \mathrm{M}^{-1}$ with $\mathrm{I}^{-}$), much stronger than the acyclic hydrogen-bond receptors 58 and 59 . Interestingly, I $^{-}$binding to halogen-bond-based 60 and to hydrogen-bond-based 61 and 62 showed opposite signs of enthalpy and entropy changes. $1^{-}$binding to 60 was enthalpically driven and entropically disfavored, which the authors interpreted as an indication of strong halogen-bond interactions. In contrast, the weaker binding of $\mathrm{I}^{-}$to 61 and 62 showed favorable entropy and unfavorable enthalpy, in which cases the entropic gain caused by desolvation of $\mathrm{I}^{-}$and the receptors was likely the driving force.

Robinson et al. ${ }^{33}$ later reported anion-binding properties of acyclic pyridiniumbistriazole receptors 63-66 and a [2]catenane receptor 68 (Figure 21A) and provided experimental evidence of halogen-bond covalency. The crystal structure of the $64 \cdot \mathrm{Cl}^{-}$complex (Figure 21B) showed $\mathrm{I} \cdot \mathrm{Cl}^{-}$distances ranging from 3.121 to $3.195 \AA$, which correspond to $84 \%-86 \%$ of the sum of their van der Waals radii, indicating strong halogen bonding. Whereas 63 displayed selectivity following anion 

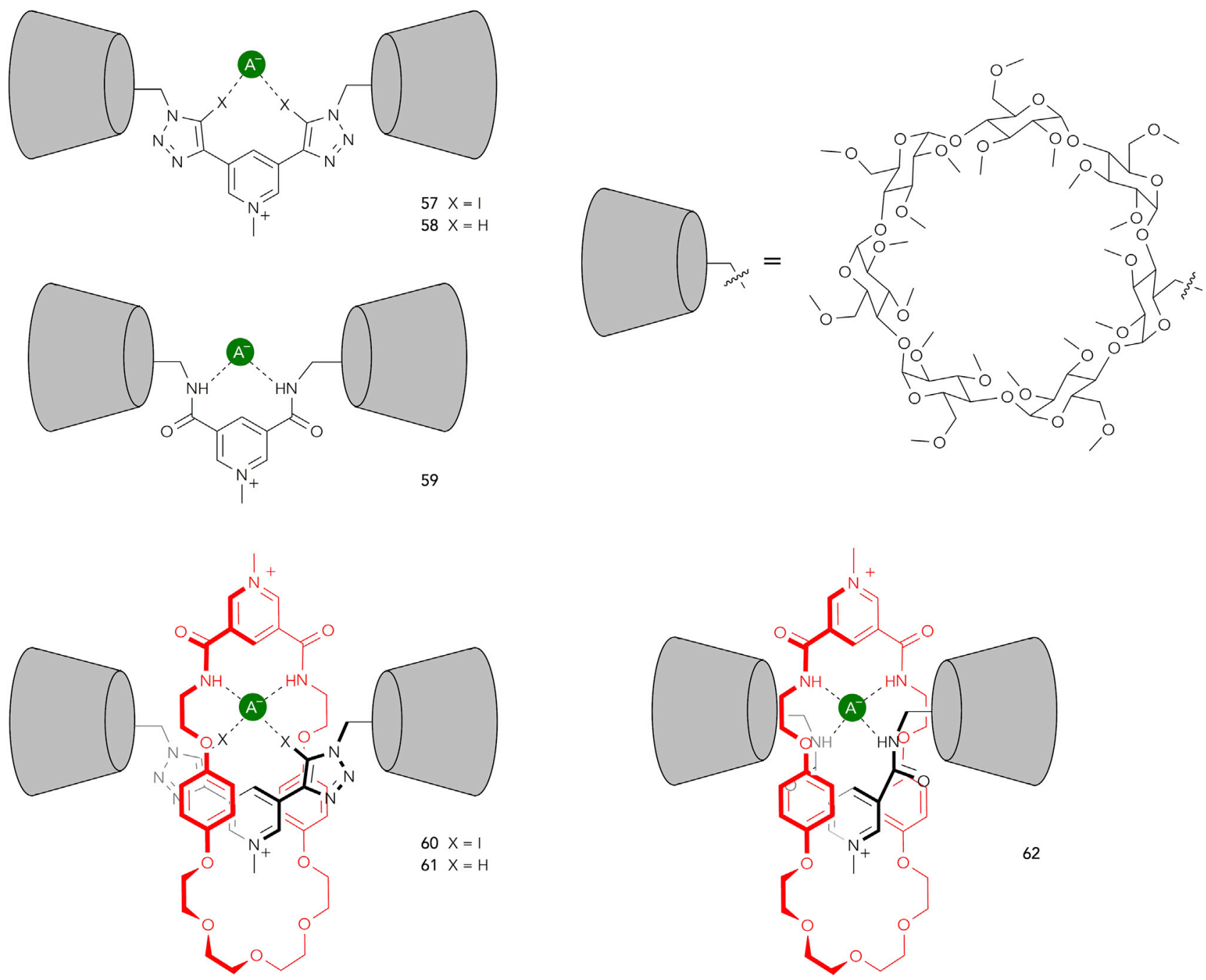

Figure 20. Anion Complexes of Acyclic Receptors 57-59 and Rotaxanes 60-62

basicity trends $\left(\mathrm{AcO}^{-}>\mathrm{Cl}^{-}>\mathrm{Br}^{-}>\mathrm{I}^{-}\right)$in DMSO, catenane 68 preferentially bound large halides $\left(K_{\mathrm{a}}>10^{4}\right.$ for $\mathrm{Br}^{-}$and $\mathrm{I}^{-}$in 10:45:45 $\left.\mathrm{D}_{2} \mathrm{O} / \mathrm{CDCl}_{3} / \mathrm{CD}_{3} \mathrm{CN}\right)$ over $\mathrm{Cl}^{-}$and showed no observable binding for $\mathrm{AcO}^{-}$and $\mathrm{H}_{2} \mathrm{PO}_{4}{ }^{-}$. This was attributed to exclusion of large oxoanions from the catenane cavity as a result of mismatch of size and geometry. The anion affinities of both 66 and 68 were higher than their corresponding $\mathrm{CH}$ hydrogen-bond analogs. Finally, using $\mathrm{Cl} \mathrm{K}$-edge X-ray absorption spectroscopy (XAS), the authors observed intense pre-edge features in chloride complexes of 63,67 , and 68 , which were assigned to charge transfer between the halogen-bond acceptor and the donor. Based on calculations of the XAS data, the authors found a $\sim 6 \%$ charge transfer in the $67 \cdot \mathrm{Cl}^{-}$complex. This is comparable with the degree of charge transfer in transition-metal coordination complexes, which have high covalency. In contrast, the $66 \cdot \mathrm{Cl}^{-}$complex displayed no observable $\mathrm{Cl}$ $\mathrm{K}$-edge XAS pre-edge feature, indicating minimal covalency in this $\mathrm{CH}$ hydrogenbond system.

The chalcogen bond is a non-covalent interaction analogous to the halogen bond, in which electron-deficient chalcogen atoms serve as Lewis acidic components. Their 
A<smiles>[X]c1c(-c2cc(-c3nnn([R])c3[X])c[n+](C)c2)nnn1[R]</smiles>

$63 \mathrm{R}=\mathrm{t}-\mathrm{BuBn}, \mathrm{X}=1$ $64 \mathrm{R}=$ octyl, $X=1$ $65 \mathrm{R}=$ hexyl, $\mathrm{X}=\mathrm{H}$ $66 \mathrm{R}=$ octyl, $\mathrm{X}=\mathrm{H}$

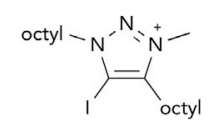

67
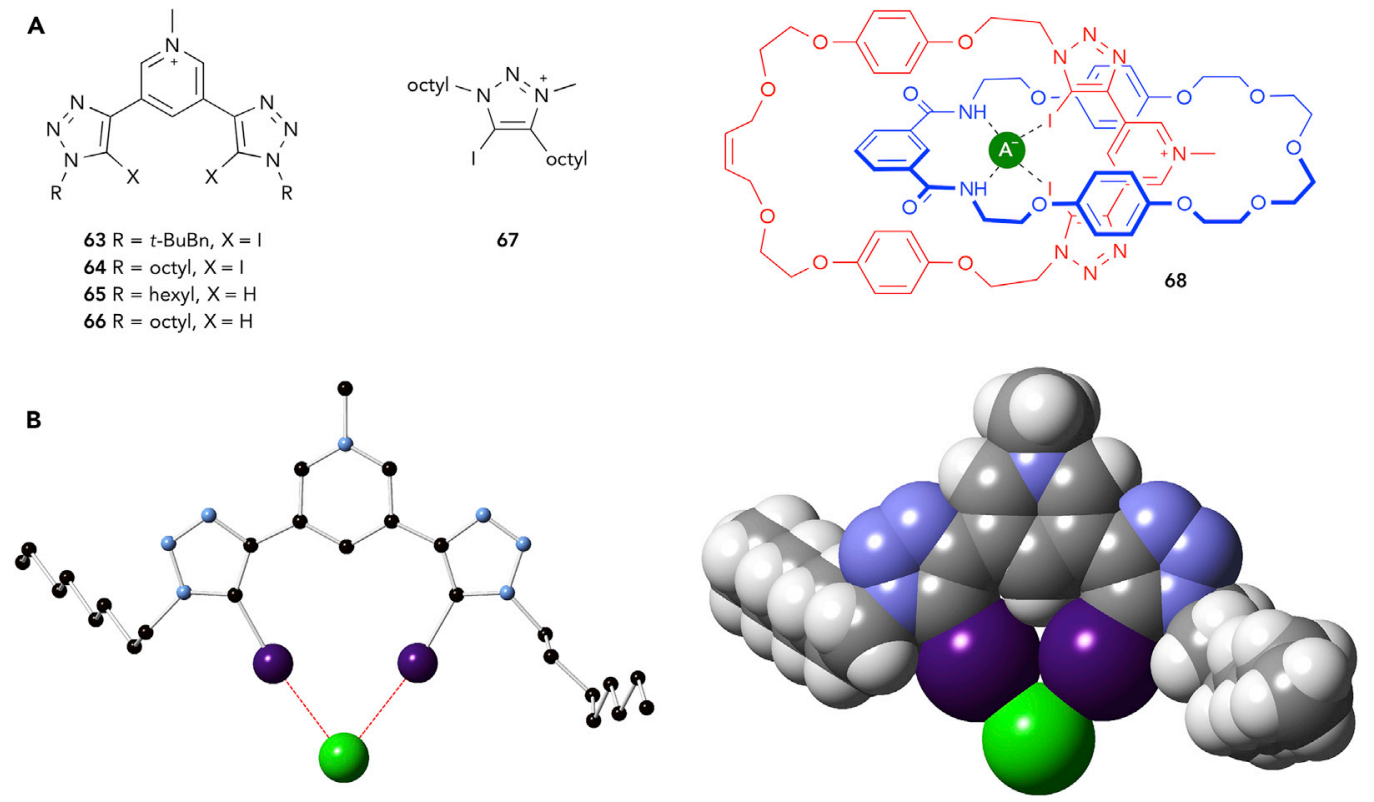

Figure 21. Anion Binding by Halogen Bonds

(A) Structures of receptors 63-67 and anion binding by catenane 68 .

(B) The crystal structure of the $64 \cdot \mathrm{Cl}^{-}$complex is shown in a ball-and-stick model (left) and a space-filling model (right).

potential utility in solution-phase anion receptor chemistry was recently brought into the spotlight by Semenov et al. ${ }^{34}$ and Garrett et al. ${ }^{35}$ Semenov et al. ${ }^{34}$ reported solidstate structures, solution-phase binding, and theoretical studies of anion complexes of 4,5-dicyano-1,2,5-chalcogendiazoles (69-71; Figure 22A). The crystal structure of $\left[\mathrm{K}(18 \text {-crown-6) }]^{+}[69 \cdot 1]^{-}\right.$showed alternating bridging of Te and I atoms to form infinite chains, whereas no bridging occurred in $\left[\left(\mathrm{Me}_{2} \mathrm{~N}\right)_{3} \mathrm{~S}\right]^{+}[69 \cdot \mathrm{F}]^{-}$and $[\mathrm{K}(18-$ crown-6) $]^{+}[69 \cdot \mathrm{SPh}]^{-}$crystals. The authors concluded, on the basis of quantum calculations, that charge transfer from anions to the receptor was the main cause for the chalcogen-bonding interactions. The calculated gas-phase bonding energies showed stronger interactions with heavier chalogens $(69>70>71)$ and with charge-dense anions $\left(\mathrm{F}^{-}>\mathrm{Cl}^{-}>\mathrm{Br}^{-}>\mathrm{I}^{-}\right)$. The most strongly interacting pair, $69 \cdot \mathrm{F}^{-}$, had a bonding energy of $\sim 86 \mathrm{kcal} \mathrm{mol}^{-1}$, comparable with that of a $\mathrm{C}-\mathrm{C}$ covalent bond. UV-Vis titrations yielded $69 \cdot \mathrm{I}^{-}$binding constants of $6.8 \times 10^{5} \mathrm{M}^{-1}$ in tetrahydrofuran (THF) and $1.5 \times 10^{3} \mathrm{M}^{-1}$ in acetonitrile. In an independent paper, Garrett et al. ${ }^{35}$ reported a series of chalcogen-bond donors 72-77 (Figure 22A) based on benzochalcogenadiazoles and examined their interactions with anionic and uncharged Lewis bases. These receptors bound anions and the neutral Lewis base quinuclidine with a selectivity for more charge-dense anions $\left(\mathrm{Cl}^{-}>\mathrm{Br}^{-}>\mathrm{I}^{-}\right)$in THF. The anion-binding abilities revealed by electrostatic potential calculations and experimental binding studies show good agreement, i.e., $69>77>76>73>$ $72>74>75$. The strength of the chalcogen bond association could reach micromolar affinity (for the $77 \cdot \mathrm{Cl}^{-}$complex) in $\mathrm{THF}$, comparable with $\mathrm{Cl}^{-}$binding by electrondeficient $\mathrm{N}, \mathrm{N}$-diarylureas. The major drawback of existing chalcogen-bond donors is their limited stability in the presence of moisture and basic anions such as $\mathrm{F}^{-}$and $\mathrm{AcO}^{-}$, especially for the strong binders, telluradiazoles. Future efforts to improve their stability are required before these systems can find real-world application, but these initial studies provide an important new interaction in the anion-binding toolbox. 
A<smiles></smiles>

$E=T e \quad 69$

$E=\operatorname{Se} 70$

$E=S \quad 71$

B

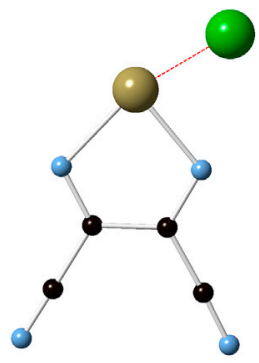

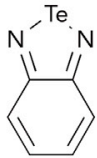

72

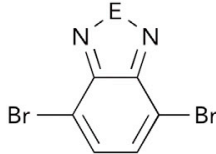

$E=T e \quad 73$

$E=S e 74$

$E=S \quad 75$

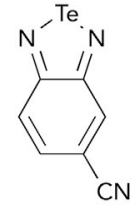

76

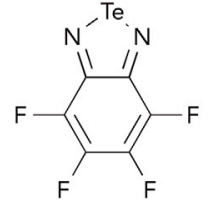

77
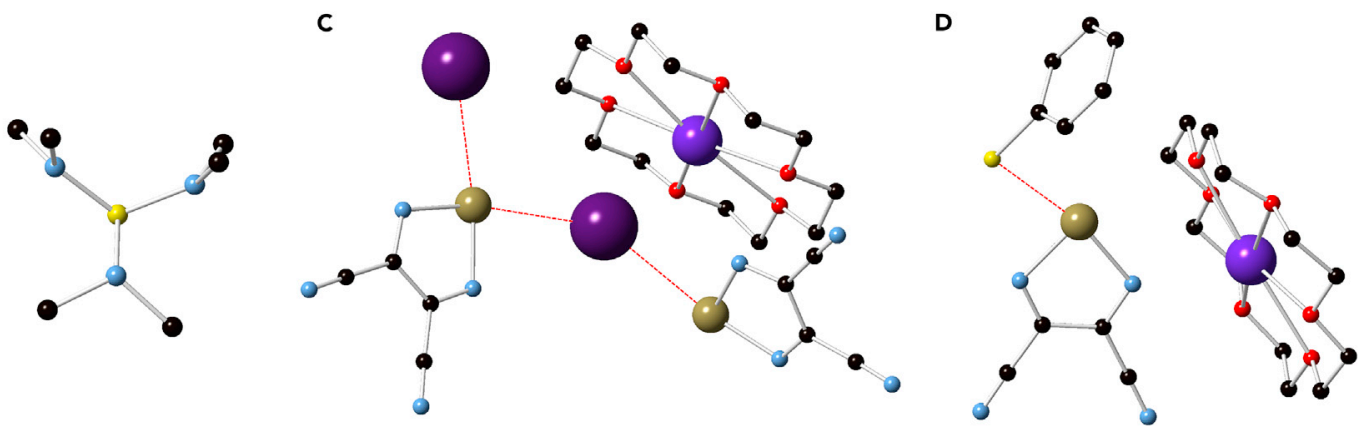

Figure 22. Anion Binding by Chalcogen Bonds

(A) Structures of chalcogen-bond donors.

(B-D) The single-crystal structures of $(\mathrm{B})\left[\left(\mathrm{Me}_{2} \mathrm{~N}\right)_{3} \mathrm{~S}\right]^{+}[69 \cdot \mathrm{F}]^{-},(\mathrm{C})[\mathrm{K}(18-\mathrm{crown}-6)]^{+}[69 \cdot 1]^{-}$, and (D)

$\left[\mathrm{K}(18-\text { crown-6) }]^{+}[69 \cdot \mathrm{SPh}]^{-}\right.$.

\section{Metal-Coordination-Based Receptors}

Binding of aqueous fluoride, which is strongly hydrated, has been a considerable challenge, especially for neutral anion receptors. Hirai and Gabbai ${ }^{36}$ reported a neutral bidentate antimony $(\mathrm{V})$-based receptor 78, which was the first example of a neutral main group Lewis acid capable of binding fluoride in water (Figure 23). Compared with that of the monodentate control compound 79, the high Lewis acidity of bidentate 78 was revealed by the stronger $\mathrm{OH}^{-}$affinity of $78\left(\mathrm{p} K_{\mathrm{a}}=5.77 \pm\right.$ $0.08)$ than that of $79\left(\mathrm{pK}_{\mathrm{a}}=7.40 \pm 0.08\right)$ in $\mathrm{H}_{2} \mathrm{O} / \mathrm{THF}(9.5 / 0.5, \mathrm{v} / \mathrm{v})$ in the presence of Triton X-100 (0.045) to solubilize the receptors. Indeed, in the same medium, 78 bound fluoride with a stability constant of $700 \pm 30 \mathrm{M}^{-1}$, whereas 79 displayed no interaction with fluoride at low concentrations. The X-ray single-crystal structure of the $78 \cdot \mathrm{F}$ complex confirmed the chelation of fluoride between two

A<smiles>CC1(C)c2cccc([Sb](=O)(O)(c3ccccc3)c3ccccc3)c2Oc2c1cccc2[Sb-]1(c2ccccc2)(c2ccccc2)OCCO1</smiles>

78<smiles>Clc1c(Cl)c(Cl)c2c(c1Cl)O[Sb]O2</smiles>

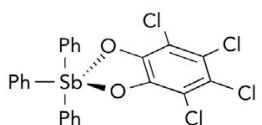

79

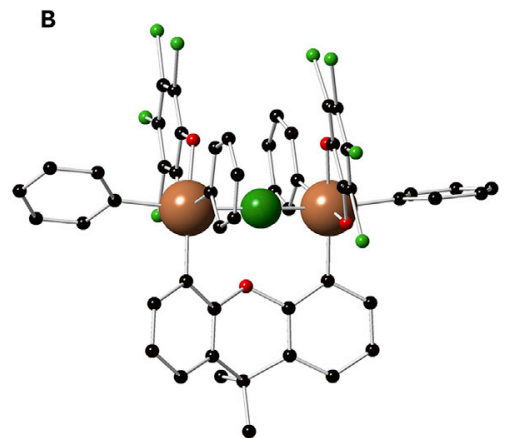

Figure 23. $\mathrm{F}^{-}$Binding by $\mathrm{Sb}(\mathrm{V})$-Based Receptors

(A) Structures of $\mathrm{Sb}(\mathrm{V})$-based receptors 78 and 79

(B) The $\mathrm{X}$-ray single-crystal structure of the $78 \cdot \mathrm{F}^{-}$complex. 

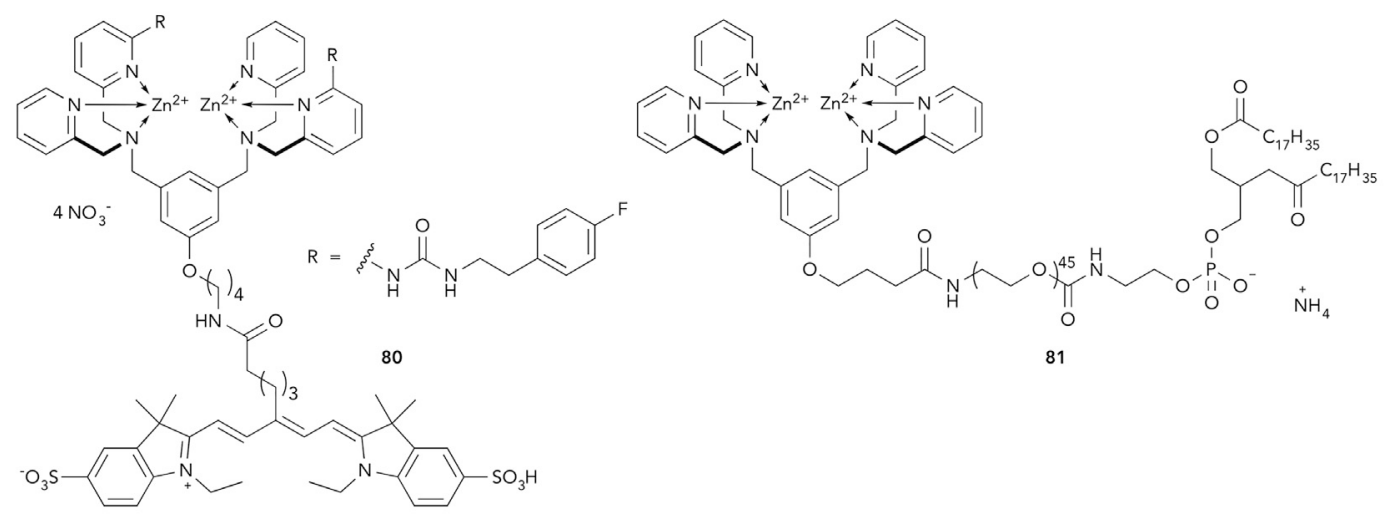

81

Figure 24. Structures of Fluorophore Conjugated $Z n_{2} B D P A 80$ and $Z n_{2}$ BDPA-PEG-Lipid

Conjugate 81

hexacoordinate $\mathrm{Sb}(\mathrm{V})$ centers (Figure 23B), which was proposed to be key to its higher fluoride affinity than that of 79.

The zinc(II)-bis(dipicolylamine) ( $Z \mathrm{n}_{2}$ BDPA) moiety was used by Plaunt et al. ${ }^{37}$ and Turkyilmaz et al. ${ }^{38}$ to target anionic lipids, which are biomarkers of dead and dying cells, via binding the phosphate head group. Through library screening, they identified a modified $Z \mathrm{n}_{2}$ BDPA scaffold with high affinity for phosphatidylserine (PS) and conjugated the scaffold to a deep-red fluorophore to obtain probe 80 (Figure 24). ${ }^{37}$ Compound 80 selectively bound to anionic 1-palmitoyl-2-oleoyl-sn-glycero-3-phosphoserine:1-palmitoyl-2-oleoyl-sn-glycero-3-phosphocholine (POPC) (1:1) vesicles $\left(K_{d}=39 \pm 6 \mathrm{nM}\right)$ over neutral POPC vesicles $\left(K_{d}=190 \pm 31 \mathrm{nM}\right)$. Fluorescence microscopy studies on both cell cultures treated with 80 demonstrated the selective staining of 80 to dead and dying cells over healthy cells, and permeation of 80 into the cytosol. In addition, the authors showed distribution of $80 \mathrm{in}$ dead and dying cells in tumor tissues in an animal model. Later, the authors developed liposomes containing $Z \mathrm{n}_{2}$ BDPA head groups by incorporating an amphiphilic $\mathrm{Zn}_{2}$ BDPA-PEGlipid conjugate 81 into POPC liposomes. ${ }^{38}$ The resultant liposomes were found to selectively recognize anionic lipid bilayers and cell membranes, leading to agglutination of anionic liposomes and bacterial cells. Furthermore, the $\mathrm{Zn}_{2}$ BDPA-coated liposomes doped with a fluorescence dye selectively stained dead and dying human cancer cells without staining healthy cells. Potential diagnostic and therapeutic applications of $\mathrm{Zn}_{2}$ BDPA-functionalized fluorescence probes and liposomes were proposed.

Molecular receptors that mimic the allosteric regulation of substrate binding in biological proteins are of interest. Mendez-Arroyo et al. ${ }^{39}$ demonstrated an elegantly designed system in which anion binding to a metal center in a calix[4]arene-based receptor could control guest binding to the cavity of the receptor. A hemilabile $\mathrm{Pt}$ (II) complex was placed above the cavitand and served as the regulatory site by dictating the charge and conformation of the receptor. Depending on binding of chloride or cyanide to the $\mathrm{Pt}(\mathrm{II})$ center, the receptor could adapt three different states (Figure 25): (1) a closed, doubly cationic form, 82; (2) a semi-open, monocationic form, 83; (3) and an open, neutral form, 84. A neutral guest, pyridine N-oxide, and a cationic guest, methylpyridinium, were studied as the guests to form inclusion complexes with the receptor. It was found that 82 failed to bind either guest, 83 bound only pyridine $\mathrm{N}$-oxide, and 84 bound only methylpyridinium. The different binding behaviors of the three states were attributed to different cavity sizes and 


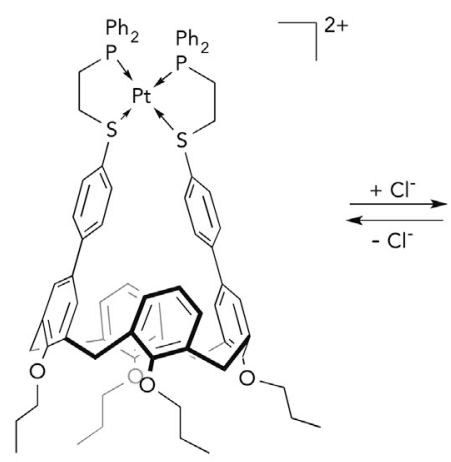

82

Closed (Inactive)

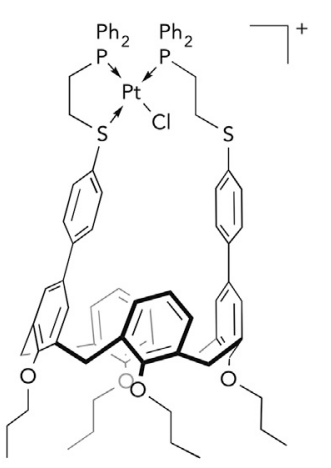

83

Semiopen
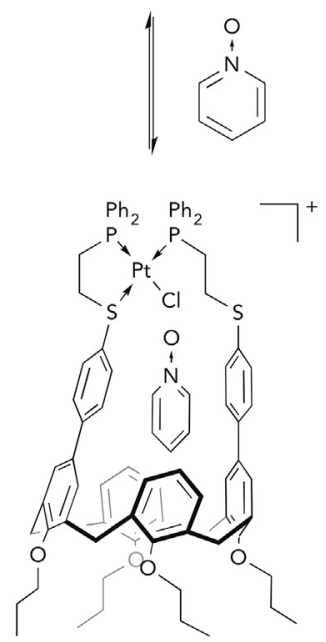
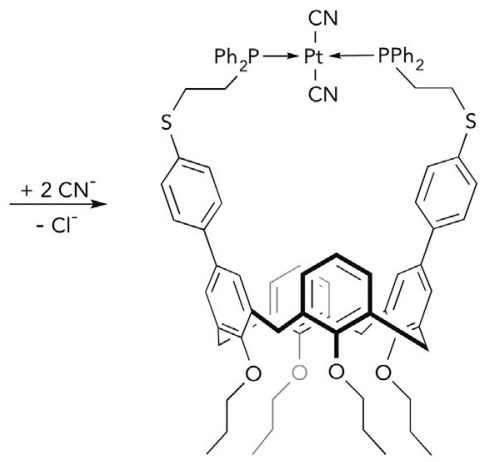

84

Open

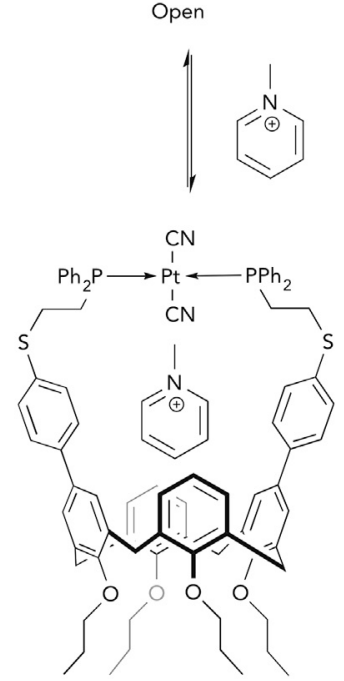

Figure 25. Anion-Regulated Guest Binding to the Cavities of 82-84

electrostatic or dipolar interactions. The reversible switching between the pyridine $\mathrm{N}$-oxide-excluded 82 and occupied 83 was demonstrated in an ${ }^{1} \mathrm{H}-\mathrm{NMR}$ study in which $\mathrm{Cl}^{-}$was abstracted from 83 with sodium tetrakis[3,5-bis(trifluoromethyl) phenyl]borate.

\section{Ion-Pair Binding}

Qiao et al. ${ }^{40}$ have developed aryl-triazole-ether macrocycles $85-87$ as heteroditopic receptors designed for contact ion-pair binding. Compound 85 was shown to have significant positive cooperative ion-pair binding from ${ }^{1} \mathrm{H}-\mathrm{NMR}$ titration studies in $\mathrm{CD}_{2} \mathrm{Cl}_{2} / \mathrm{CD}_{3} \mathrm{CN}\left(4: 1, \mathrm{v} / \mathrm{v}\right.$ ) with $\mathrm{NaClO}_{4}$ and $\mathrm{Nal}$ but weak binding with $\mathrm{Na}^{+}$(added as the tetraphenylborate salt) and $\mathrm{ClO}_{4}{ }^{-}$or $\mathrm{I}^{-}$(as the tetrabutylammonium salt) alone. The single-crystal structures of the $86 \cdot \mathrm{NaClO}_{4}$ and $86 \cdot \mathrm{Nal}$ complexes revealed the contact ion-pair binding mode within the macrocycle (Figure 26), illustrating the ion-pairing cooperativity from electrostatic attraction. A new approach was implemented to quantify the binding cooperativity $\left(\alpha=\beta_{\text {overall }} /\left(K_{\text {cation }} \times K_{\text {anion }}\right)\right.$, in which $\beta_{\text {overall, }} K_{\text {cation, }}$ and $K_{\text {anion }}$ are the binding constants of the receptors for the ion pair, the cation component, and the anion component, respectively). The results showed the remarkable positive cooperativity in the binding to both $\mathrm{NaClO}_{4}(\alpha=$ 400 ) and $\mathrm{Nal}(\alpha=1300)$ determined from ${ }^{1} \mathrm{H}-\mathrm{NMR}$ titration studies in $\mathrm{CD}_{2} \mathrm{Cl}_{2} /$ $\mathrm{CD}_{3} \mathrm{CN}(4: 1, v / v)$. This result indicates that the cooperativity is governed by the electrostatic attraction and the resulting ion-pair distance; this effect can be further 
A

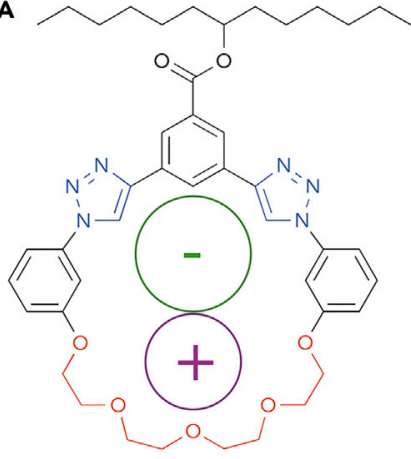

85

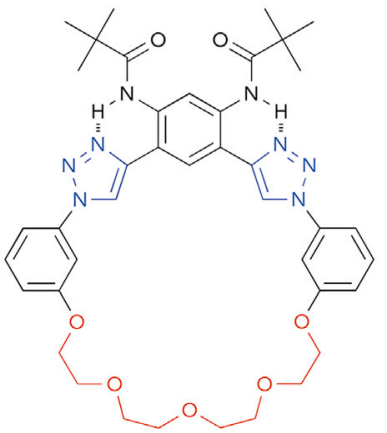

86

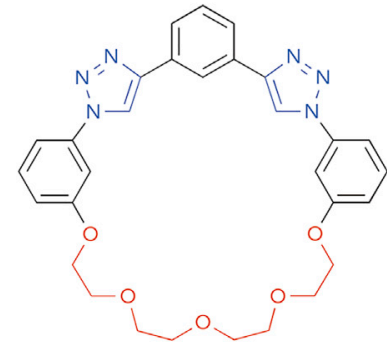

87
B

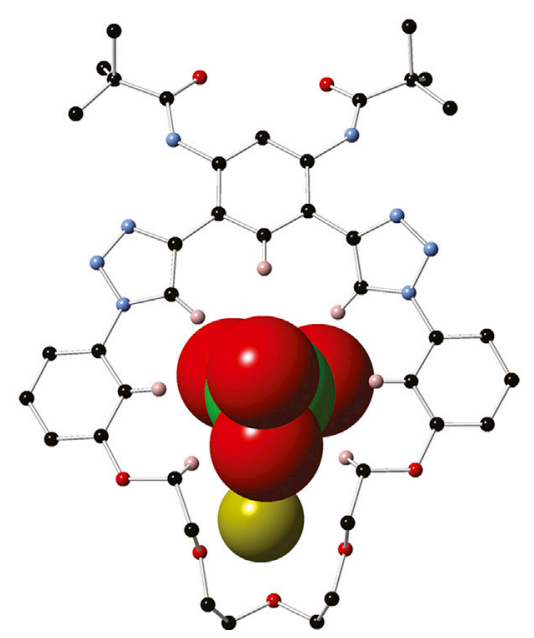

C

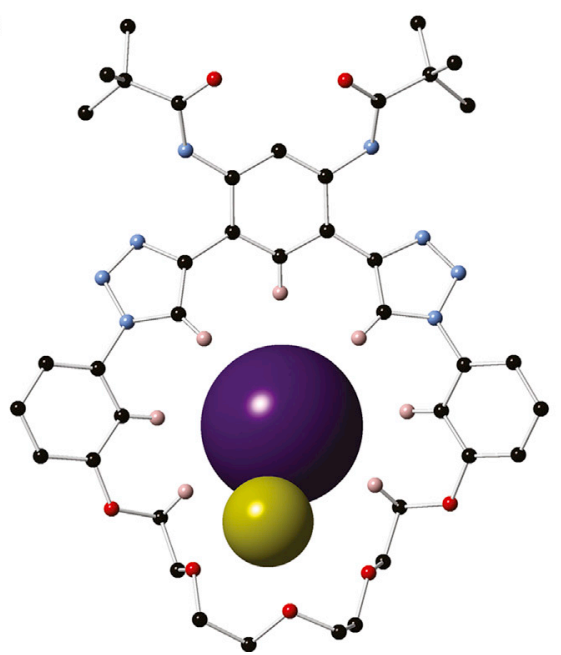

Figure 26. Ion-Pair Binding by Aryl-Triazole-Ether Macrocycles (A) Structures of aryl-triazole-ether macrocycles 85-87.

( $B$ and $C$ ) The single-crystal structures of the (B) $86 \cdot \mathrm{NaClO}_{4}$ and (C) $86 \cdot \mathrm{Nal}$ complexes. Solvent molecules are omitted for clarity.

proven by the good correlation of ion-pair distance to the observed cooperativity: $d_{\mathrm{NaClO} 4} / d_{\mathrm{Nal}} \approx \Delta G_{\alpha, \mathrm{Nal}} / \Delta G_{\alpha, \mathrm{NaClO} 4}$. The simplified structure of 87 was used for computational analysis using DFT methods to deconvolute the cooperativity contribution from electrostatic (70\%) and allosteric effects (30\%) for ion-pair binding to $\mathrm{NaCl}, \mathrm{NaBr}$, and $\mathrm{Nal}$ in $\mathrm{CH}_{2} \mathrm{Cl}_{2}$.

Moerkerke et al. ${ }^{41}$ described the use of calix[6]arene-based ditopic and tritopic ion-pairing receptors for the binding toward the zwitterionic 1,2-dioleoyl-sn-glycero-3-phosphocholine (DOPC). Notably, bis-calix[6]arene tris(thio)urea heterotritopic receptors 88 and 89 showed strong binding affinity toward DOPC in $\mathrm{CDCl}_{3}$ with $K_{\mathrm{a}}>10^{5} \mathrm{M}^{-1}$, and in a $\mathrm{CDCl}_{3} / \mathrm{CD}_{3} \mathrm{OD}(50: 1, \mathrm{v} / \mathrm{v})$ mixture with $K_{\mathrm{a}}$ of $3.7 \times 10^{5} \mathrm{M}^{-1}$ and $584 \mathrm{M}^{-1}$ for compounds 88 and 89 , respectively. The combination of ${ }^{1} \mathrm{H}-\mathrm{NMR}$ and $2 \mathrm{D}$ rotating frame Overhauser effect spectroscopy NMR studies of compound 89 in the presence of DOPC in $\mathrm{CDCl}_{3}$ revealed the inclusion of the cationic choline motif within the calix[6]arene cone and the binding of the anionic phosphate group via hydrogen-bond interactions from the (thio)urea groups (Figure 27). Furthermore, compound 89 was shown to bind DOPC more strongly than dodecylphosphocholine (DPC). Energy-minimized structures of 89つDOPC and 


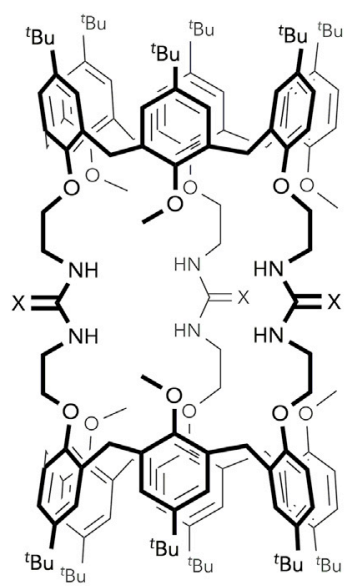

$88 \mathrm{X}=\mathrm{O}$ $89 \mathrm{X}=\mathrm{S}$

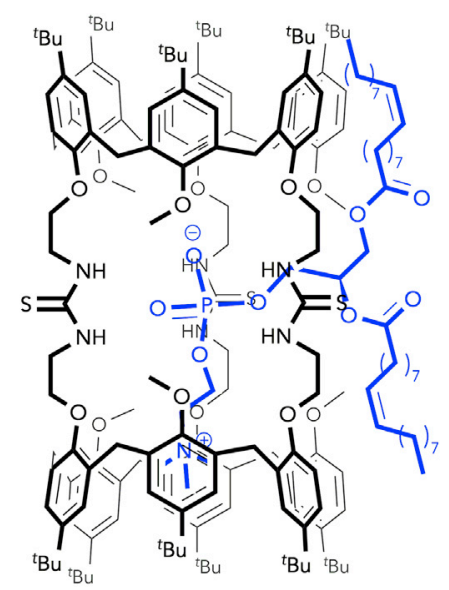

$89 \supset D O P C$

Figure 27. General Structure of Bis-calix[6]arene Tris(thio)urea Hetero-tritopic Receptors 88 and 89 and the NMR-Elucidated Structure of the $89 \supset$ DOPC Complex

89 DPC revealed the complementarity of the bent conformation of DOPC to the curvature of the binding tunnel of 89 .

Calix[4]pyrroles have previously been shown to function as heteroditopic ion-pair receptors. In recent work by Valderrey et al., ${ }^{42}$ a bis(calix[4]pyrrole) receptor 90 (Figure 28) was shown to form an unprecedented five-component complex by the combination of cascade contact ion-pair binding modes. The addition of 2 equiv of tetrabutylammonium cyanate $\left(\mathrm{TBA}^{+} \mathrm{NCO}^{-}\right)$resulted in the formation of a cascade complex with two $\mathrm{NCO}^{-}$anions bound to the calix[4] pyrrole anion-binding sites and one $\mathrm{TBA}^{+}$cation sandwiched between forming contact ion-pair interactions. An
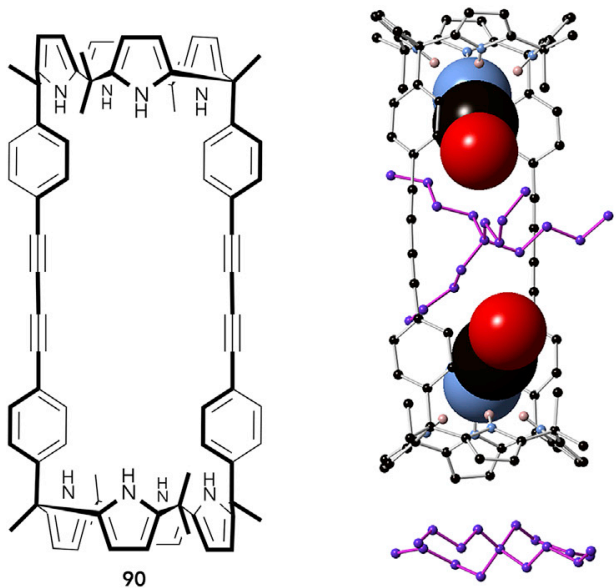

$90 \supset\left(\mathrm{TBA}^{+} \mathrm{NCO}^{-}\right)_{2}$

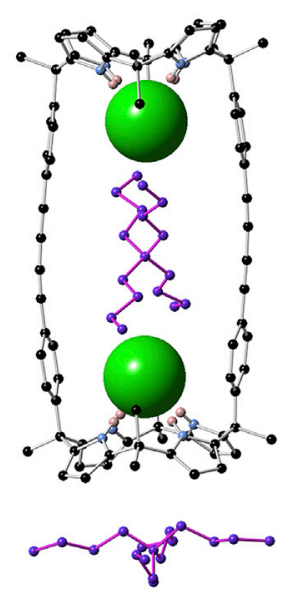

$90 \supset\left(\mathrm{TBA}^{+} \mathrm{Cl}^{-}\right)_{2}$

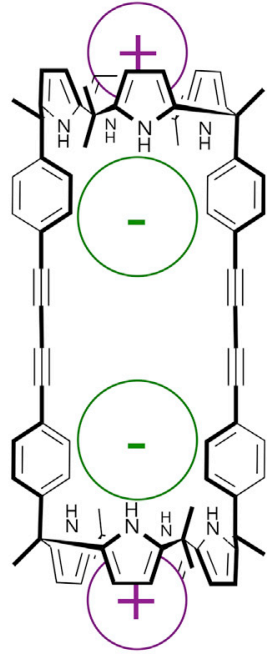

$90 \supset\left(\mathrm{MTOA}^{+} \mathrm{Cl}^{-}\right)_{2}$

Figure 28. Ion-Pair Binding by Bis(calix[4]pyrrole) Receptor 90 The structure of bis(calix[4]pyrrole) receptor 90 and single-crystal structures of the $\left(\mathrm{TBA}^{+} \mathrm{NCO}^{-}\right)_{2} \supset 90$ and $\left(\mathrm{TBA}^{+} \mathrm{Cl}^{-}\right)_{2} \supset 90$ complexes show the different binding modes of the $\left(\mathrm{TBA}^{+} \mathrm{NCO}^{-}\right)_{2} \supset 90,\left(\mathrm{TBA}^{+} \mathrm{Cl}^{-}\right)_{2} \supset 90$, and $\left(\mathrm{MTOA}^{+} \mathrm{Cl}^{-}\right)_{2} \supset 90$ complexes. 

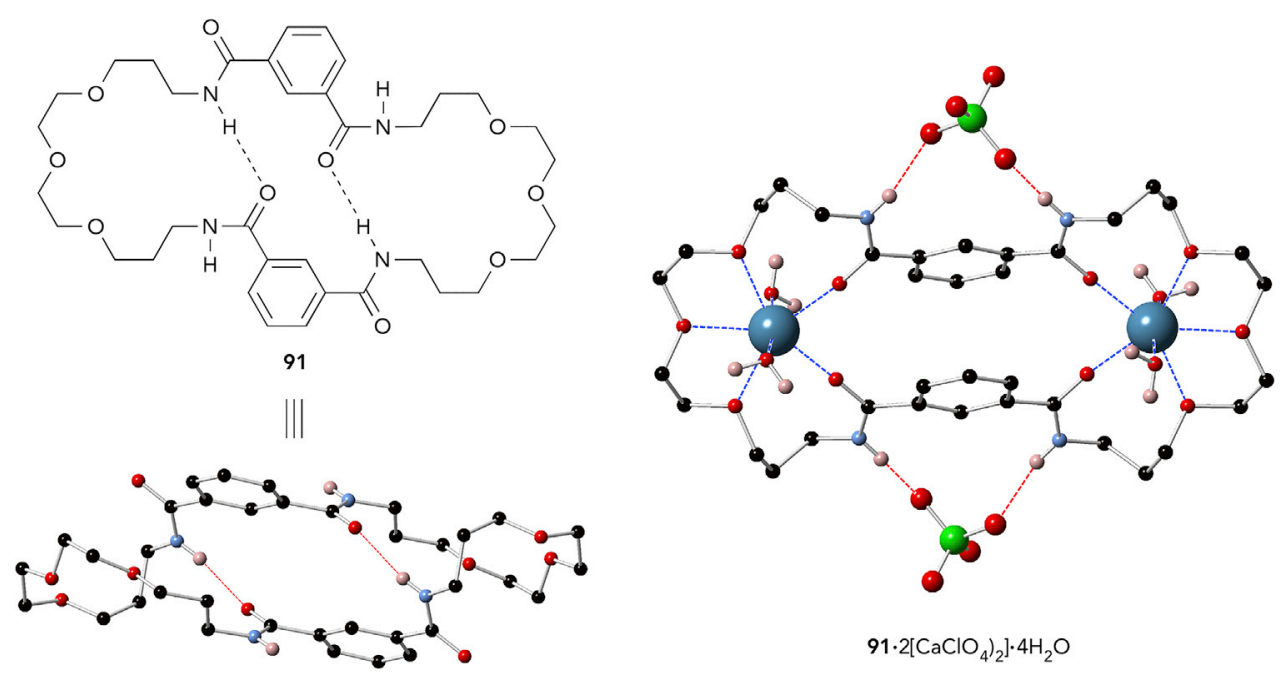

$\left.91 \cdot 2[\mathrm{CaClO})_{2}\right)_{2} \cdot 4 \mathrm{H}_{2} \mathrm{O}$

Figure 29. Structure of Tetratopic lon-Pairing Host 91 and the Single-Crystal Structures of the Free Host and $91 \cdot 2\left[\mathrm{Ca}\left(\mathrm{ClO}_{4}\right)_{2}\right] \cdot 4 \mathrm{H}_{2} \mathrm{O}$ Complex

Most hydrogen atoms and two unbound perchlorate anions are omitted for clarity.

additional $\mathrm{TBA}^{+}$cation was bound in the cone of a calix[4]pyrrole, as demonstrated by $\mathrm{NMR}$ studies in $\mathrm{CDCl}_{3}$ and single-crystal structure elucidation (Figure 28). Likewise, 2 equiv of tetrabutylammonium chloride $\left(\mathrm{TBA}^{+} \mathrm{Cl}^{-}\right)$resulted in a similar binding mode. The overall binding constants for the 2:1 (anion:receptor) complexes were obtained from ITC experiments in $\mathrm{CHCl}_{3}$, with $K_{2: 1}$ of $1.5 \times 10^{11} \mathrm{M}^{-2}$ and $1.9 \times$ $10^{9} \mathrm{M}^{-2}$ for $\left(\mathrm{TBA}^{+} \mathrm{NCO}^{-}\right)_{2} \supset 90$ and $\left(\mathrm{TBA}^{+} \mathrm{Cl}^{-}\right)_{2} \supset 90$, respectively, and accompanied by strong cooperativity of $10^{8}$ for both tetrabutylammonium salts. The methyl trioctylammonium cation was a better fit to the calix[4]pyrrole cone, and this resulted in a different binding mode of $\left(\mathrm{MTOA}^{+} \mathrm{Cl}^{-}\right)_{2} \supset 90$ (Figure 28), with a much reduced cooperativity of 35 .

Howe et al. ${ }^{43}$ reported the first example of a tetratopic ion-pairing host 91 to systematically study the cooperativity in homotropic binding of two cations or two anions, as well as heterotropic cooperativity between ions of opposite charges. The singlecrystal structure of the free host (Figure 29) revealed intramolecular hydrogen-bond interactions between the carboxyamides of the two isophthalamide anion-binding sites, resulting in a folded-closed conformation of the macrocyclic host. The solidstate structure of the $91 \cdot 2\left[\mathrm{Ca}\left(\mathrm{ClO}_{4}\right)_{2}\right] \cdot 4 \mathrm{H}_{2} \mathrm{O}$ complex (Figure 29) showed a hostseparated binding mode with the inclusion of two calcium cations by two unusual half-crown-two carbonyl cation-binding sites and induced significant structural reorganization of the macrocyclic host to facilitate the binding of two perchlorate anions. Proton NMR titration studies were conducted with various ions in four different solvent environments, and binding data were analyzed by several plausible binding models. The macrocyclic host exhibited strong negative cooperativity $(\alpha=0.007-$ $0.55)$ in the binding of two anions and was more selective toward chloride and acetate anions, whereas negative, neutral, and mild positive cooperativity ( $\alpha=0.01-6.3$ ) was observed for the complexation of two cations with strong selectivity toward calcium cation. In $\mathrm{CD}_{3} \mathrm{OD} / \mathrm{CDCl}_{3}(1: 9, \mathrm{v} / \mathrm{v})$, no $\mathrm{Cl}^{-}$binding was observed as a result of a strong competing solvent effect, but the presence of $\mathrm{Ca}^{2+}$ switched on the binding of chloride, and this positive heterotropic cooperativity phenomenon was induced by a pronounced allosteric effect on the host from the binding with $\mathrm{Ca}^{2+}$. Furthermore, the 1:2 binding of $\mathrm{Cl}^{-}$in the presence of $\mathrm{Ca}^{2+}$ (added as $\mathrm{CaCl}_{2}$ or $\mathrm{Ca}\left(\mathrm{ClO}_{4}\right)_{2}$ ) 


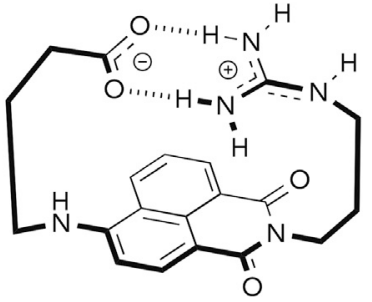

92

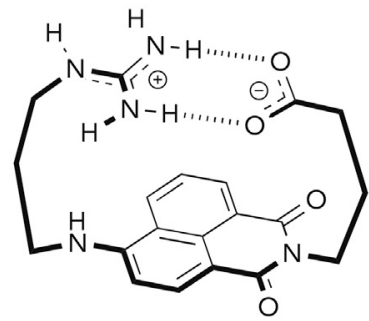

93

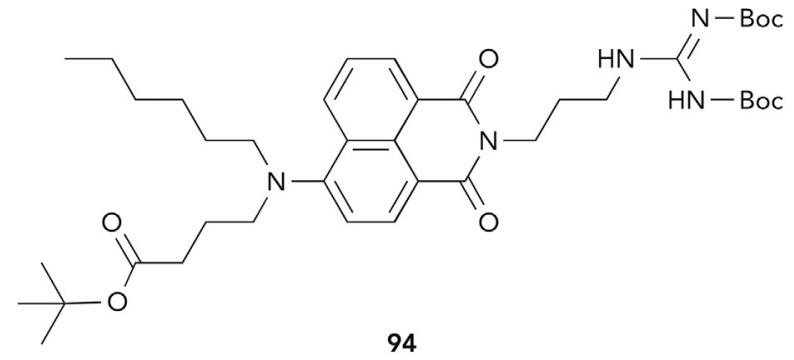

Figure 30. Structures of Naphthalimide-Based Ion-Pair- $\pi$ Aromatic Compounds 92-94

demonstrated positive cooperativity $(\alpha=3.4-23)$ with overall binding constants $\left(\beta_{12}\right)$ of $1.0-5.0 \times 10^{4} \mathrm{M}^{-2}$.

Fujisawa et al. ${ }^{44}$ have demonstrated a new concept of ion-pair binding, i.e., binding of an ion pair to the same aromatic surface via simultaneous anion- $\pi$ and cation- $\pi$ interactions, which were termed "ion-pair- $\pi$ interactions." The authors designed and synthesized two model compounds, 92 and 93, containing an intramolecular guanidinium-carboxylate ion pair conjugated to a naphthalimide group (Figure 30). They were designated as "antiparallel" (92) or "parallel" (93) on the basis of the orientation of the ion pair with respect to the push-pull naphthalimide dipole. The authors confirmed the existence of ion-pair- $\pi$ interactions in both antiparallel and parallel arrangements by ${ }^{1} \mathrm{H}-\mathrm{NMR}$ shifts of 92 and 93 , whereas control 94 was ionpair free. The authors reported stronger ion-pair- $\pi$ interactions in the excited state of 92 than in the ground state, which led to red-shifted (compared with 93 and 94), solvent-polarity-insensitive absorption and emission maxima of 92. The different photophysical behavior of parallel 93 was attributed to an excited state proton transfer between the guanidinium and the carboxylate groups to prevent their repulsion with the more polarized naphthalimide dipole in the excited state. Semi-covalent systems were then investigated, in which the carboxylate-free or the guanidiniumfree analogs of 92 and 93 were found to bind their ion-pair partners in THF, with the parallel arrangement showing higher association affinity. The authors also demonstrated functional relevance of ion pair- $\pi$ interactions in membrane transport.

\section{SENSING}

Although anion sensing is a relatively mature area of research, only a small proportion of the anion sensors reported to date are practically useful because many of them cannot function in an aqueous environment. Recent efforts have been made to improve the sensitivity, selectivity, and most importantly, the aqueous compatibility of anion sensors that function by non-covalent interactions. Such improvements could be achieved via designing new binding motifs, incorporating anion receptors into new functional materials, or exploiting supramolecular polymerization, as demonstrated in some of the following examples.

Amendola et al. ${ }^{45}$ studied the anion-binding and fluorometric responses of ureas 95 and 96 to different anions in $\mathrm{CH}_{3} \mathrm{CN}$ and DMSO. Weakly basic anions including $\mathrm{Cl}^{-}$ and $\mathrm{Br}^{-}$led to bathochromic shifts of the emission bands of both receptors. Carboxylate binding induced fluorescence quenching and, in some cases, development of a new weakly emissive band at a longer wavelength, which were attributed to an electron-transfer and an intra-complex proton-transfer process (from the urea moiety to the carboxylate anion) in the excited states of the complexes, respectively. 
<smiles>O=C(Nc1ccccc1)Nc1ccc2cc3ccccc3cc2c1</smiles>

95<smiles>O=C(Nc1ccccc1)Nc1ccc2ccc3cccc4ccc1c2c34</smiles>

96

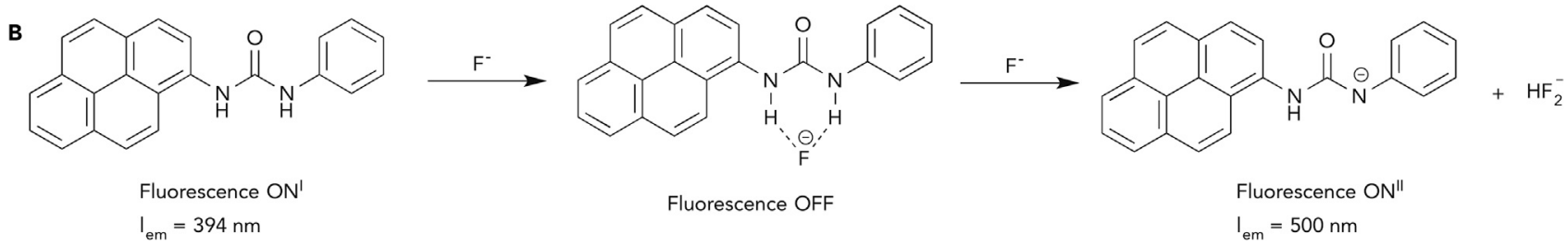

Figure 31. $\mathrm{F}^{-}$Sensing by Fluorescent Ureas

(A) Structures of receptors 95 and 96 .

(B) Schematic illustration of hydrogen-bonding and proton-transfer interactions between 96 and $\mathrm{F}^{-}$.

Interestingly, 96 exhibited a three-mode $\mathrm{ON}^{1}-\mathrm{OFF}-\mathrm{ON}^{2}$ response to $\mathrm{F}^{-}$in $\mathrm{CH}_{3} \mathrm{CN}$, corresponding to fluorescence quenching when 96 formed a hydrogen-bond complex with $\mathrm{F}^{-}$and emission of yellow fluorescence when 96 was deprotonated by excess of $\mathrm{F}^{-}$(Figure 31B).

Given the high hydration energy of $\mathrm{F}^{-}$in water, most neutral hydrogen-bond receptors fail to bind $\mathrm{F}^{-}$in aqueous solutions. It has been demonstrated, however, that highly electron-deficient neutral hydrogen-bond donors could bind strongly hydrophilic monovalent anions such as $\mathrm{H}_{2} \mathrm{PO}_{4}{ }^{-}, \mathrm{F}^{-}$, and $\mathrm{AcO}^{-}$in aqueous organic media. ${ }^{46}$ Ashokkumar et al. ${ }^{47}$ recently reported a structurally simple hydrogenbond receptor, 97, (Figure 32) that allowed selective binding and optical sensing of fluoride in an organic aqueous media with 50\% water content. Compound 97 contains an amidothiourea anion-binding motif attached to BODIPY dye as a spectroscopic reporter. In 1:1 DMSO/ $\mathrm{H}_{2} \mathrm{O}, 97$ displayed a selective fluorescence quenching response to fluoride with a surprisingly high binding constant of $5.35 \times 10^{4} \mathrm{M}^{-1}$ and was selective over $\mathrm{AcO}^{-}\left(8.31 \times 10^{3} \mathrm{M}^{-1}\right)$ and $\mathrm{H}_{2} \mathrm{PO}_{4}{ }^{-}$ $\left(2.88 \times 10^{3} \mathrm{M}^{-1}\right)$. The authors used computational analysis to demonstrate the extreme electron deficiency of the thiourea moiety of 97 in comparison with other structurally related examples in the literature. Detection of fluoride in $100 \%$ water can be achieved by a test-strip assay, with sensitivity down to $0.2 \mathrm{ppm}$.<smiles>CC1=CC(C)=[N+]2C1=C(c1ccc(C(=O)NNC(=S)Nc3ccc([N+](=O)[O-])cc3)cc1)c1c(C)cc(C)n1[B-]2(F)F</smiles>

97

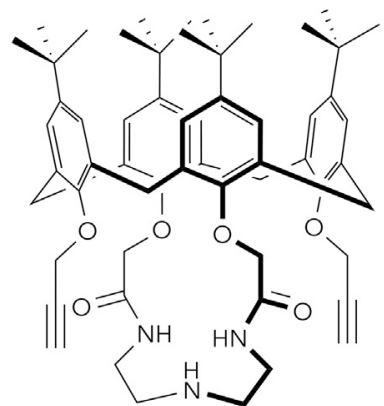

98

Figure 32. Structures of Anion Receptors 97 and 98 

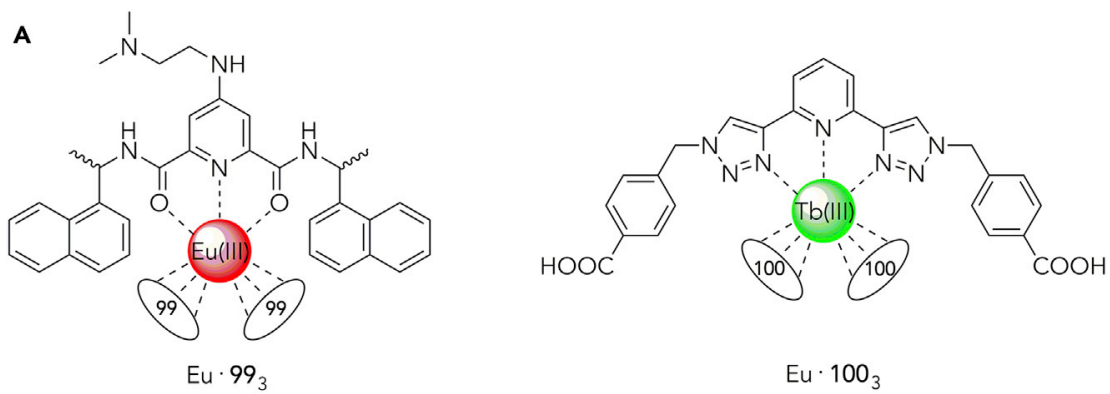

\begin{tabular}{cc|ccc} 
B & Input 1 \\
{$\left[\mathrm{H}^{+}\right]$} & $\begin{array}{c}\text { Input 2 } \\
{\left[\mathrm{F}^{-}\right]}\end{array}$ & $\begin{array}{c}\text { Output 1 } \\
615 \mathrm{~nm}\end{array}$ & $\begin{array}{c}\text { Output 2 } \\
490 \mathrm{~nm}\end{array}$ & $\begin{array}{c}\text { Output 3 } \\
338 \mathrm{~nm}\end{array}$ \\
\hline 0 & 0 & 1 & 1 & 0 \\
1 & 0 & 1 & 0 & 0 \\
0 & 1 & 0 & 0 & 1 \\
1 & 1 & 1 & 0 & 1 \\
\hline & & Reverse & NOR & TRANSFER [F]
\end{tabular}

Figure 33. Lanthanide-Based Molecular Logic Gate System Developed by Bradberry et al.

(A) Structures of lanthanide complexes Eu. $99_{3}$ and $\mathrm{Tb} \cdot 100_{3}$.

(B) Truth table of the logic functions.

By immobilizing a calix[4]arene-based anion receptor 98 (Figure 32) onto the surface of a nanochannel in a polyimide membrane, Nie et al. ${ }^{48}$ developed a highly selective $\mathrm{F}^{-}$-sensing nanodevice functioning in aqueous solutions. Upon binding of $\mathrm{F}^{-}$to 98 via three NH hydrogen bonds, the ionic conductance through the 98-modified nanochannel at negative voltage increased. An apparent $\mathrm{F}^{-}$binding constant of $1.17 \times$ $10^{6} \mathrm{M}^{-1}$ was determined, which is quite remarkable because most hydrogen-bond receptors for $\mathrm{F}^{-}$cannot function in water. It is possible that the membrane surface created a water-excluding microenvironment favorable for $\mathrm{F}^{-}$binding. The recyclability of the sensor and feasibility of sensing $\mathrm{F}^{-}$in the presence of interfering ions and in serum samples have been demonstrated.

Because of their Lewis acidity and potentially rich spectroscopic features, lanthanide complexes have also been shown to be good candidates for binding and sensing of $\mathrm{F}^{-49}$ or carboxylates ${ }^{50}$ in aqueous solutions, in which anion binding can lead to changes in luminescence, ${ }^{49,50} \mathrm{NMR}^{51}$ or electron paramagnetic resonance $(E P R)^{51}$ spectra. Recently, Bradberry et al. ${ }^{52}$ used two lanthanide complexes, Eu.993 and $\mathrm{Tb} \cdot 100_{3}$, to construct a two-input, four-output molecular logic system (Figure 33). Both complexes showed luminescence responses to $\mathrm{H}^{+}$and $\mathrm{F}^{-}$, allowing these species to be used as inputs for the logic gate. A mixture of the two complexes was encapsulated non-covalently into a polymer gel matrix and exposed to these inputs $(\mathrm{HCl}$ and TBAF) in methanol. The luminescence intensities at $615 \mathrm{~nm}$ (from $\mathrm{Eu}(\mathrm{III})$ centered phosphorescence), $490 \mathrm{~nm}$ (from Tb(III)-centered phosphorescence), and $338 \mathrm{~nm}$ (from fluorescence of ligand 100) were chosen as output signals. The Eu(III) emission at $615 \mathrm{~nm}$ (output 1) could only be quenched by $\mathrm{F}^{-}$in the absence of the $\mathrm{H}^{+}$ $(0,1)$ state because of deprotonation of $\mathrm{Eu} \cdot 99_{3}$, leading to a more efficient photoinduced electron transfer. This gave a Reverse-IMPLICATION $\left(\left[\mathrm{H}^{+}\right]\right)$operation. The $\mathrm{Tb}(\mathrm{III})$ emission at $490 \mathrm{~nm}$ (output 2) functioned as an NOR $\left(\left[\mathrm{H}^{+}\right] /\left[\mathrm{F}^{-}\right]\right)$operation because dissociation of $\mathrm{Tb} \cdot 100_{3}$ by either $\mathrm{H}^{+}$or $\mathrm{F}^{-}$suppressed the ligand-sensitized $\mathrm{Tb}$ (III) emission. Only the presence of $\mathrm{F}^{-}$led to substantial enhancement of the ligand fluorescence at $338 \mathrm{~nm}$, which therefore functioned as a TRANSFER ([F- $]$ ) 
A

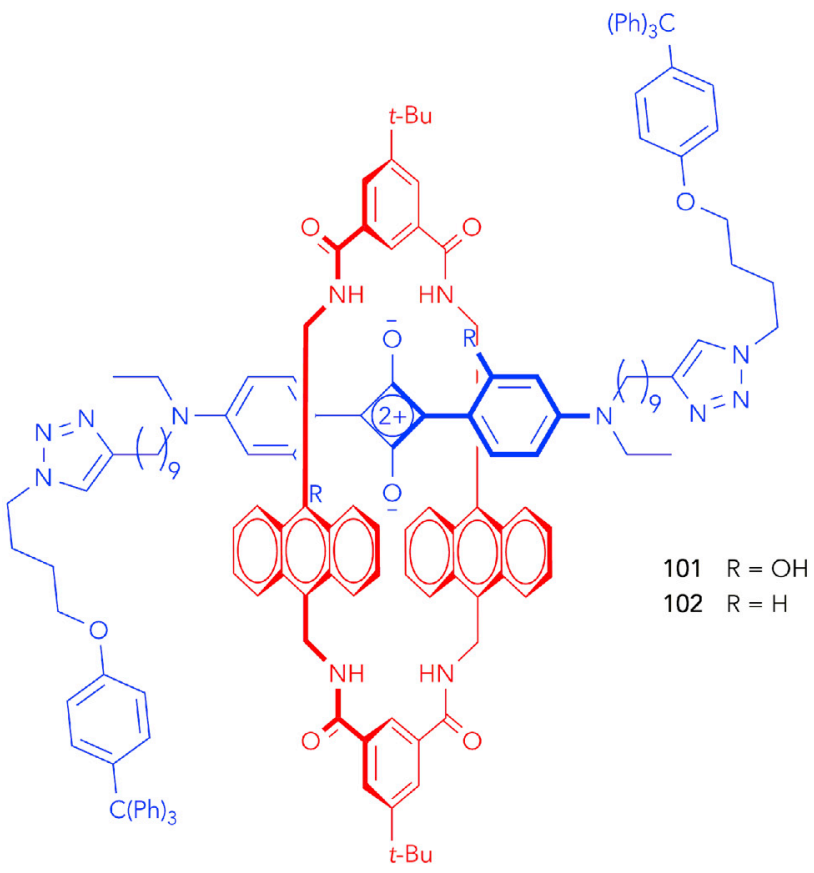

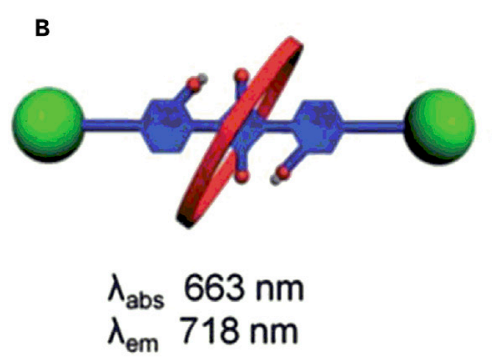

101

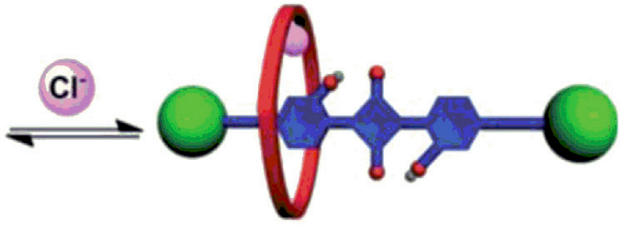

$\lambda_{\text {abs }} 647 \mathrm{~nm}$

$\lambda_{\text {em }} 693 \mathrm{~nm}$

$101 \cdot \mathrm{Cl}^{-}$complex

Figure 34. $\mathrm{Cl}^{-}$Sensing by a Squaraine Rotaxane

(A) Structure of 101 and 102.

(B) $\mathrm{Cl}^{-}$-sensing mechanism of 101 .

Reproduced from Collins et al. ${ }^{53}$ with permission from The Royal Society of Chemistry.

output. The responses were not reversible because of dissociation of $\mathrm{Tb} \cdot 100_{3}$ and subsequent leeching of ligand 100 from the gel matrix.

A ratiometric $\mathrm{Cl}^{-}$sensor, 101 (Figure 34A), was recently developed by Collins et al. ${ }^{53}$ on the basis of a squaraine rotaxane scaffold. In 101, the tetralactam macrocycle binds to the center of the squaraine anion via four amide $\mathrm{NH}$ hydrogen-bond donors, causing a red-shift of squaraine fluorescence that was attributed to squaraine rigidification as a result of encapsulation. $\mathrm{Cl}^{-}$binding to the tetralactam macrocycle in 101 in acetone led to loss of the rotaxane fluorescence band at $718 \mathrm{~nm}$ and the development of a new band at $693 \mathrm{~nm}$, which was attributed to displacement of the macrocycle away from the central squaraine anion (Figure 34B), suppressing the above-mentioned red-shift effect. Control rotaxane 102 showed no spectral responses to $\mathrm{Cl}^{-}$, indicating that $\mathrm{Cl}^{-}$was unable to change the conformation of 102 possibly as a result of too strong binding of the squaraine anion to the macrocycle. Compound 101 showed a modest selectivity for $\mathrm{Cl}^{-}$(binding constant $=$ $[1.9 \pm 0.2] \times 10^{3} \mathrm{M}^{-1}$ in acetone) over $\mathrm{Br}^{-}$(binding constant $=[2.8 \pm 1.1] \times 10^{2} \mathrm{M}^{-1}$ 


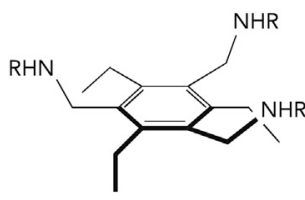

$\mathrm{R}=$<smiles>CCC(=O)c1ccc[nH]1</smiles>

103<smiles>CCC(=S)Nc1ccc(C)cc1</smiles>

104

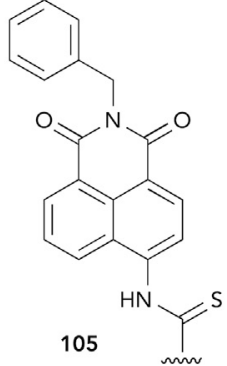<smiles>CCNC(=S)Nc1ccc(N(C)C)c2ccccc12</smiles>

106<smiles>CCC(=S)Nc1ccc(-c2c3ccc(=O)cc-3oc3cc(O)ccc23)cc1</smiles>

107<smiles>[R]NC1CC2C3CN(C)CC(C3CNC(=O)c3ccc[nH]3)C1C2CC</smiles>

$\mathrm{R}^{\prime}=$<smiles>CCCCCCCCNC(=S)Nc1ccc(N(C)C)c2ccccc12</smiles>

108<smiles>CC(=S)Nc1ccc2c3c(cccc13)C(=O)N(Cc1ccccc1)C2=O</smiles>

$R^{\prime \prime}=$

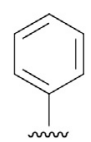

110

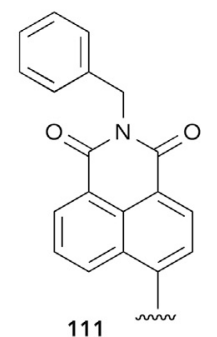

Figure 35. Structures of Receptors 103-111

in acetone) and no observable response to ${ }^{-}$. Sensing of aqueous tetrabutylammonium chloride was achieved by a dipstick method.

The Anzenbacher group has continued to develop anion receptors and sensors based on the triethylbenzene scaffold (Figure 35). ${ }^{54,55}$ These receptors possess a cup-like binding cavity and in most cases form 1:1 complexes with guest anions in solution. In a study focused on sensing hydrolysis products of nerve gas sarin (isopro-

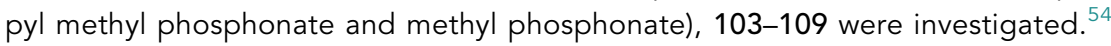
Among them, fluorescent receptors 105-109 displayed "turn-on" fluorescence responses to basic anions, including fluoride, phosphates, and phosphonates in DMSO. Because these sensors generate different extents of fluorescence "turnon" responses to different anions, a cross-reactivity microarray analysis using two sensors was conducted, which showed satisfactory differentiation between six anions and the blank control in water-containing DMSO. More recently, Minami et al. ${ }^{55}$ implemented an "intramolecular indicator displacement assay" concept to develop 110 and 111 as sensors for glyphosate ion. Sensors 110 and 111 contain an arm ("intramolecular indicator") that includes a fluorophore and a carboxylate group that loosely associate with the other two arms via hydrogen bonding in the 


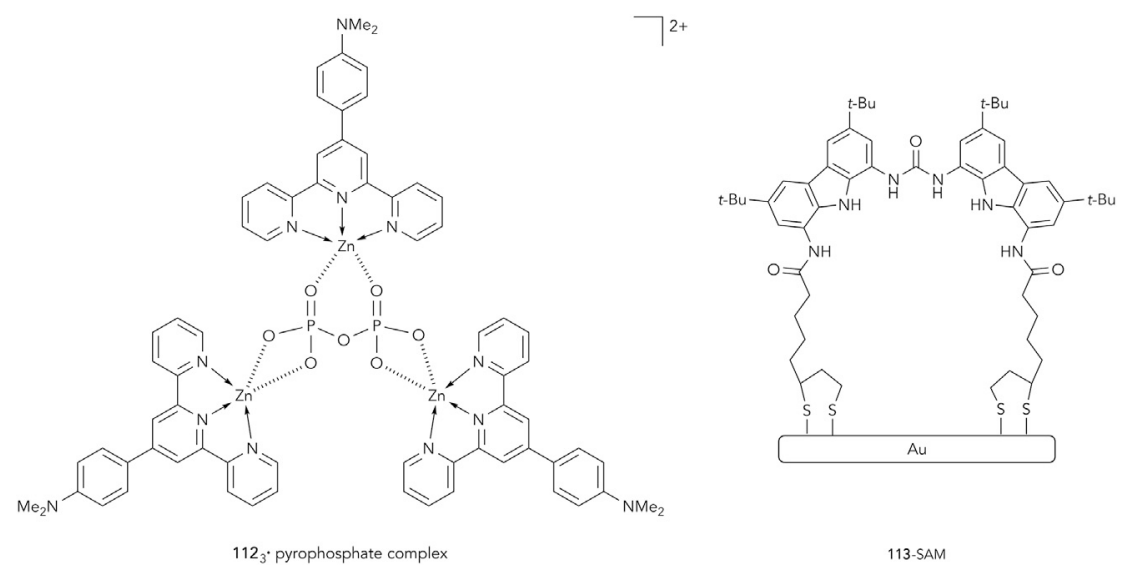

Figure 36. Structure of the 3:1 112-Pyrophosphate Complex and Pyrophosphate Receptor 113 Immobilized on a Self-Assembled Monolayer

absence of anionic guests. Competitive binding of an anionic guest replaces the carboxylate group from the anion-binding cavity, leading to dramatic changes in fluorescence from the intramolecular indicator. Sensors 110 and 111 were found to show large fluorescence quenching (110) and enhancement (111) responses to basic anions in DMSO containing 5\% water. Sensors 110 and 111 were embedded into polyurethane matrices, which enabled differentiation between 11 anions as well as sensitive sensing of glyphosate in pure water.

Bhowmik et al. ${ }^{56}$ reported a highly sensitive and selective pyrophosphate sensor based on a simple terpyridine- $\mathrm{Zn}^{2+}$ complex 112 (Figure 36), which displayed nanomolar sensitivity to pyrophosphate (PPi). Complex 112 showed a $~ 500$-fold fluorescence enhancement response to pyrophosphate in water via formation of a $112_{3}$. pyrophosphate 3:1 complex. Interestingly, other tested anions, including $\mathrm{HPO}_{4}{ }^{2-}, \mathrm{PO}_{4}{ }^{3-}, \mathrm{ADP}$, and ATP, did not change the fluorescence intensity of 112 . Complex 112 was applied to fluorescence imaging of PPi in HeLa cells and showed a high sensitivity and the ability to map the entire cell. In addition, 112 could form a hydrogel, which was used by the authors to coat disposable paper strips for pyrophosphate detection.

Apart from using Lewis acid metal complexes, Sanchez et al. ${ }^{57}$ have demonstrated an alternative approach to sensing pyrophosphate in water. A bis(carbazolyl)urea receptor 113 was immobilized onto a gold surface to produce self-assembled monolayers of 113 (113-SAM; Figure 36), which functioned as an extremely sensitive sensor for $\mathrm{HP}_{2} \mathrm{O}_{7}{ }^{3-}$ (HPPi) in water. Binding of $\mathrm{HPPi}$ to 113 on the gold surface produced an increase in the surface plasmon resonance (SPR) signals from the gold surface caused by a change in the reflective index. An HPPi binding constant of $4.39 \times 10^{5} \mathrm{M}^{-1}$ and a detection limit of $17 \mathrm{ppt}$ were estimated based on the SPR responses. The sensor showed a high selectivity for $\mathrm{HPPi}$ over $\mathrm{H}_{2} \mathrm{PO}_{4}{ }^{-}$and a moderate selectivity over ATP and ADP.

Brunetti et al. ${ }^{58}$ developed calix[6]arene-based fluorescent receptors 114 and 115 (Figure 37) for binding and sensing of $\mathrm{SO}_{4}{ }^{2-}$ and contact ion pairs. In DMSO, 114 showed strong binding (1:1 stoichiometry) and a selective fluorescence quenching response to $\mathrm{SO}_{4}{ }^{2-}$. In $\mathrm{CDCl}_{3}$, both receptors displayed cooperative binding of $\mathrm{SO}_{4}{ }^{2-}$ anion with several alkylammonium cations, with the alkyl chain of the alkylammonium cations included in the calixarene cavity. This led to a decrease in the pyrene 


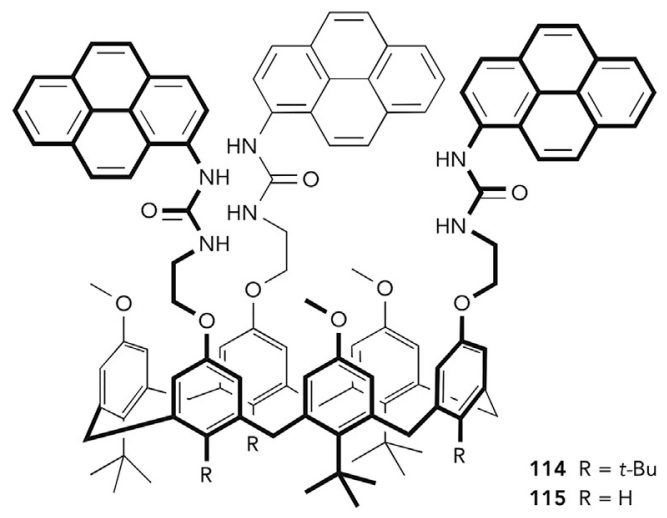

Figure 37. Structures of Receptors 114 and 115

excimer emission and an increase in the pyrene monomer fluorescence band. Although both receptors can bind ammonium salts with small or linear alkyl groups, binding of the large 3,4-O-dimethyldopammonium ion was only observed for the less bulky 115. This demonstrates the potential of using such scaffolds to develop selective sensors for biologically important ammonium salts.

Recently, the use of supramolecular assemblies instead of small-molecule probes has become an increasingly popular approach to creating highly responsive sensory materials. Zhang et al. ${ }^{59}$ discovered that expanded porphyrins 116 and 117 (Figure 38) formed supramolecular polymers with several diacids (including 4,4'-biphenyldisulfonic acid and oxalic acid) in $\mathrm{CH}_{2} \mathrm{Cl}_{2}$, which could be utilized for sensing organic solvents and anions. The polymerization resulted from association between protonated receptors and the anions of the diacids, leading to either 1:1 diprotonated porphyrin-dianion polymer or 1:2 diprotonated porphyrin-monoanion polymers, the latter of which was stabilized by hydrogen bonding between the remaining protonated carboxylic acid groups. The solubility, color, and fluorescence of the assemblies changed dramatically when they were treated with polar solvents or Lewis basic anions, presumably as a result of a decrease in the extent of aggregation. The authors demonstrated the ability to differentiate complex solvent mixtures by using cross-reactivity discriminant analysis on the basis of the fluorescence response from several assemblies.

Chang et al. ${ }^{60}$ reported an interesting example of anion-induced self-assembly utilized for anion sensing. The sensors 118 and 119 (Figure 39) existed as monomers in 1:1 $\mathrm{H}_{2} \mathrm{O}$-EtOH but formed face-to-face stacked $\mathrm{H}$-type aggregates induced by

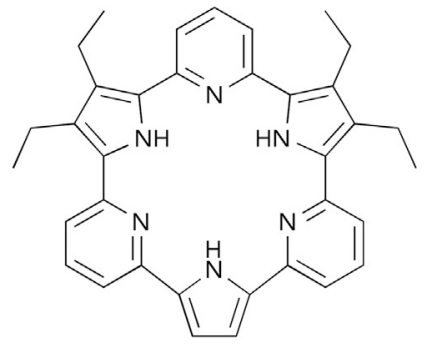

116

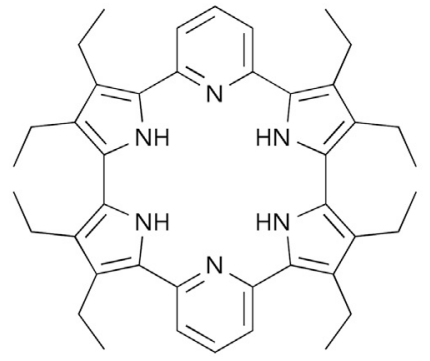

117

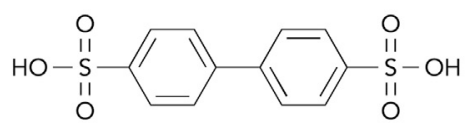

4,4'-biphenyldisulfonic acid

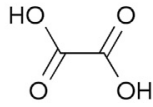

oxalic acid

Figure 38. Structures of Expanded Porphyrins 116 and 117 and 4,4'-Biphenyldisulfonic Acid and Oxalic Acid 
<smiles>C[N+]1=C(/C=C/c2ccc(O)cc2)C(C)(C)c2ccccc21</smiles>

118

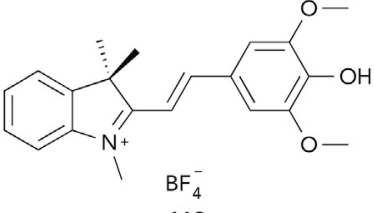

119

Figure 39. Structures of Receptors 118 and 119

$\mathrm{HSO}_{4}{ }^{-}$binding. The apparent $\mathrm{HSO}_{4}{ }^{-}$affinities of both receptors were surprisingly high (in the range of $10^{4} \mathrm{M}^{-1}$ ) in the highly competitive medium of 1:1 $\mathrm{H}_{2} \mathrm{O}$-EtOH. Other anions tested did not induce aggregation. The formation of $\mathrm{H}$ aggregates led to the development of hypsochromically shifted bands in the visible absorption and fluorescence spectra of 118 and 119 , rendering 118 and 119 as ratiometric $\mathrm{HSO}_{4}{ }^{-}$sensors.

\section{EXTRACTION AND SELECTIVE CRYSTALLIZATION}

The separation of sulfate from aqueous mixtures of anions continues to present a significant challenge with direct industrial relevance. Custelcean et al. ${ }^{61}$ have recently presented a new approach to the isolation of this strongly hydrated anion (the free energy of hydration of sulfate is $-1,080 \mathrm{~kJ} \mathrm{~mol}^{-1}$ ). A bis-guanidinium cation glyoxal bis(amidiniumhydrazone) (GBAH) was prepared by condensation of different aminoguanidinium salts with glyoxal in water as shown in Scheme 1.

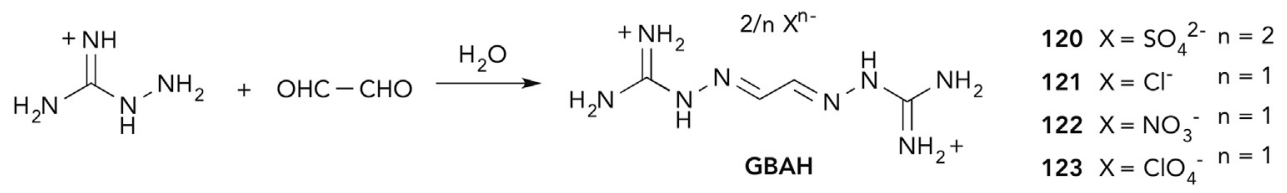

Scheme 1. Preparation of the GBAH Salts of 120-123 by Hydrazine Condensation in Water

Mixing aminoguanidinium sulfate and glyoxal in water led to the crystallization of the sulfate salt shown in Figure 40. In this salt, the sulfate crystallizes as a cluster with five water molecules, which in turn accepts eight hydrogen bonds from adjacent water molecules in the crystal. The clusters run along the crystallographic $b$ axis in the crystal (Figure 40). Each sulfate anion in the crystal accepts eight hydrogen bonds from bound water molecules so retaining two-thirds of its hydration sphere (sulfate accepts 12 hydrogen bonds from its first coordination sphere in aqueous solution). From the series of salts studied, the sulfate salt had the lowest solubility (Table 1) even though this anion had the highest hydration energy. This was presumably caused by stacking of the GBAH cations in this structure and the partial hydration of the anion in the solid state. The authors foresee that this approach could be used to rationally design future sulfate-extraction systems on the basis of the molecular recognition of sulfate-water clusters.

Table 1. Solubilities of 120 to 123 in Water at $25^{\circ} \mathrm{C}$

\begin{tabular}{|l|l|}
\hline Compound (Anion) & Solubility (M) \\
\hline $120\left(\mathrm{SO}_{4}{ }^{2-}\right)^{\mathrm{a}}$ & $7.2(6) \times 10^{-4}$ \\
\hline $121\left(\mathrm{Cl}^{-}\right)^{\mathrm{b}}$ & $0.88(8)$ \\
\hline $122\left(\mathrm{NO}_{3}^{-}\right)^{\mathrm{a}}$ & $1.2(2) \times 10^{-3}$ \\
\hline $123\left(\mathrm{ClO}_{4}^{-}\right)^{\mathrm{a}}$ & $1.36(1) \times 10^{-2}$ \\
\hline
\end{tabular}

${ }^{a}$ Measured by UV spectroscopy.

${ }^{b}$ Determined gravimetrically. 


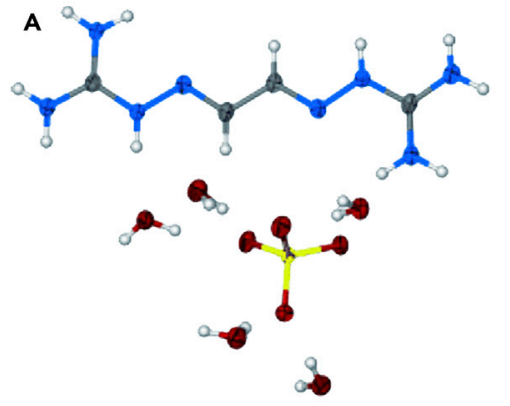

c
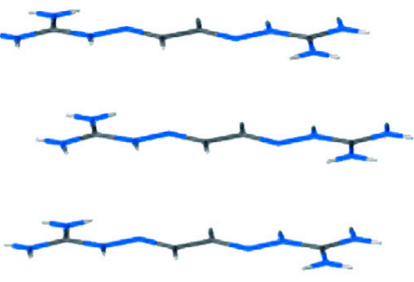

B
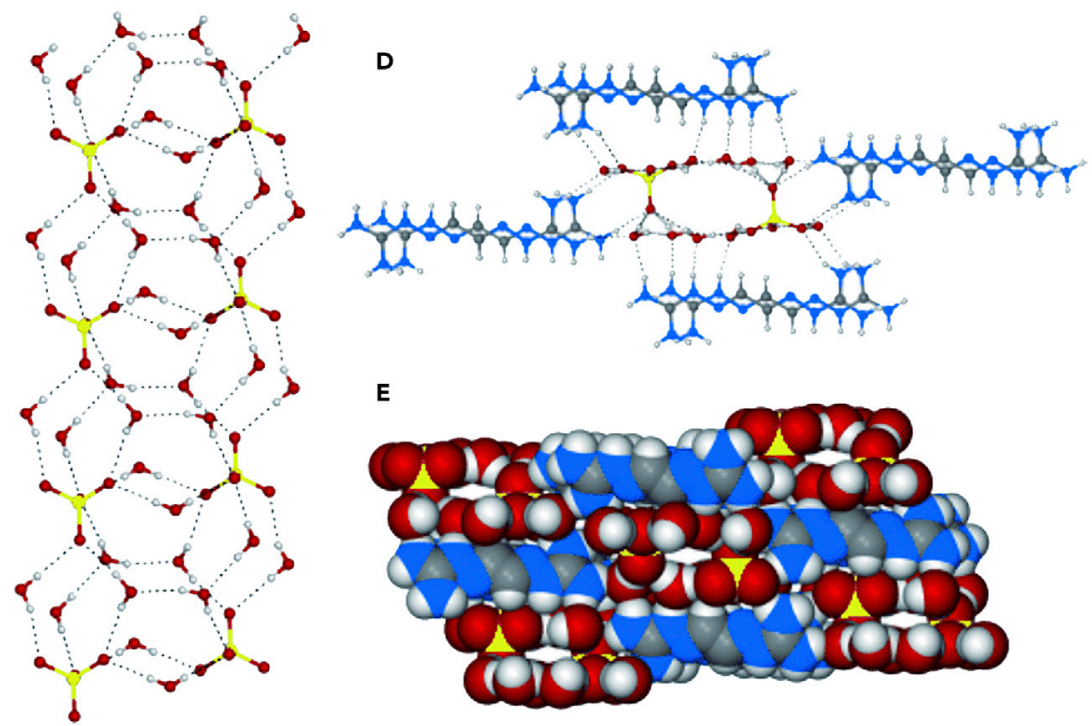

E

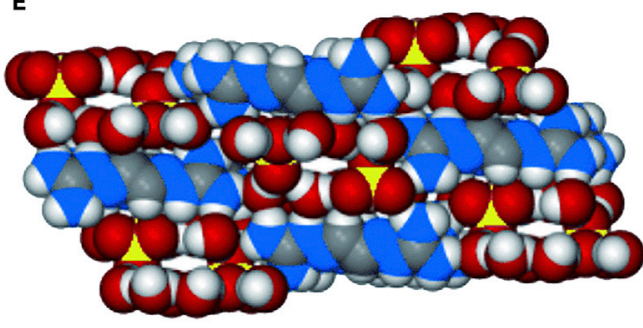

Figure 40. X-Ray Single-Crystal Structure of 120

(A) ORTEP representation showing the $\mathrm{GBAH}$ cation and the anionic $\mathrm{SO}_{4}\left(\mathrm{H}_{2} \mathrm{O}\right)_{5}{ }^{2-}$ cluster.

(B) Hydrogen-bonded $\left[\mathrm{SO}_{4}\left(\mathrm{H}_{2} \mathrm{O}\right)_{5}{ }^{2-}\right]_{n}$ clusters.

(C) Stacking of the GBAH cations.

(D) Hydrogen bonding of the sulfate-water clusters by the cationic GBAH stacks is viewed down the crystallographic $b$ axis.

(E) Space-filling representation of the crystal packing is viewed down the crystallographic $b$ axis. Reprinted with permission from Custelcean et al. ${ }^{61}$ (c) 2015 Wiley-VCH Verlag GmbH \& Co. KGaA.

Tasker has continued his research into the selective extraction of chloridometalates. In a recent report, ${ }^{62}$ a series of amidoamine and amidoethers (124-129) (Figure 41) were synthesized to explore whether these systems could extract $\mathrm{PtCl}_{6}{ }^{2-}$<smiles>[X]CCC(=O)N([R])[R]</smiles>

$$
\begin{array}{lll}
124 \mathrm{R}_{1}=\mathrm{Ph} & \mathrm{R}_{2}=\mathrm{CH}_{2} \mathrm{Ph} & \mathrm{X}=\mathrm{N}-\mathrm{CH}_{2} \mathrm{Ph} \\
125 \mathrm{R}_{1}=\mathrm{Me} & \mathrm{R}_{2}=\mathrm{n}-\mathrm{Bu} & \mathrm{X}=\mathrm{N}-\mathrm{CH}_{3} \\
126 \mathrm{R}_{1}=\mathrm{H} & \mathrm{R}_{2}=2 \text {-ethylhexyl } & \mathrm{X}=\mathrm{N}-\mathrm{CH}_{3} \\
127 \mathrm{R}_{1}=\mathrm{H} & \mathrm{R}_{2}=\mathrm{n}-\mathrm{Bu} & \mathrm{X}=\mathrm{N}-\mathrm{CH}_{3} \\
128 \mathrm{R}_{1}=\mathrm{H} & \mathrm{R}_{2}=2 \text {-ethylhexyl } & \mathrm{X}=\mathrm{O} \\
129 \mathrm{R}_{1}=\mathrm{H} & \mathrm{R}_{2}=\mathrm{n}-\mathrm{Bu} & \mathrm{X}=\mathrm{O}
\end{array}
$$

Figure 41. The Structures of Tasker and Morrison's Putative Chloridometalate Extractants 

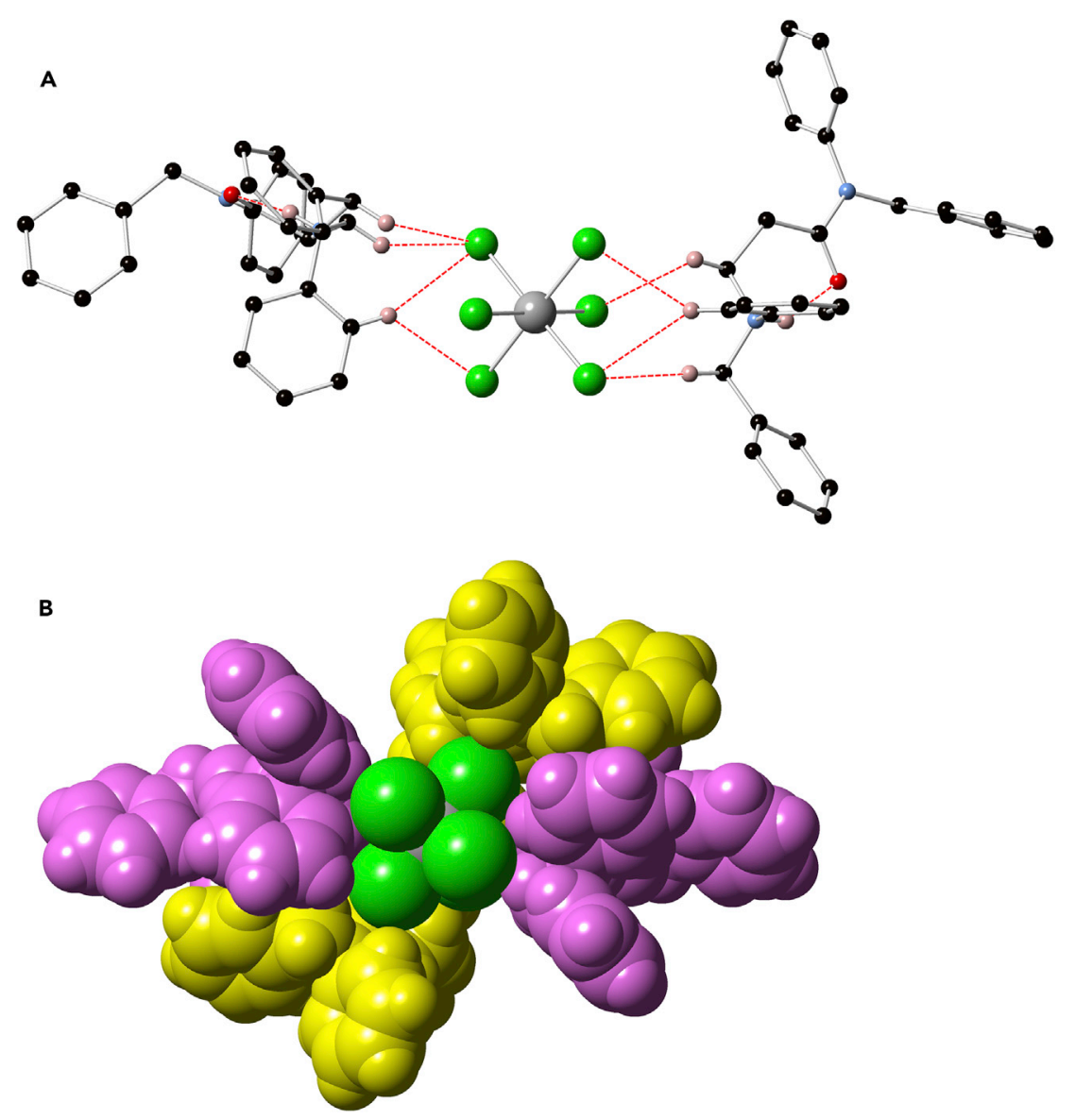

Figure 42. Selective Extraction of Chloridometalates over Chloride

(A) X-Ray crystal structure of $\left[\left(124 \cdot \mathrm{H}_{2} \mathrm{PtCl}_{6}\right]\right.$ shows contacts between ligand $\mathrm{C}-\mathrm{H}$ groups and $\mathrm{PtCl}_{6}{ }^{2-}$. Colors: $\mathrm{Cl}$, green; $\mathrm{O}$, red; and $\mathrm{N}$, blue. Most hydrogen atoms have been omitted for clarity. (B) A space-filling view shows contacts from two further $124 \cdot \mathrm{H}^{+}$units (purple) from the adjacent $\left[\left(124 \cdot \mathrm{H}_{2} \mathrm{PtCl}_{6}\right]\right.$ assemblies.

preferentially over chloride from $6 \mathrm{M} \mathrm{HCl}$ solution. Compounds 124, 126, and 128 were found to selectively extract the metalate over chloride. Compounds 124 and 126 were found to be more efficient extractants, which was attributed to their basicity making the formation of the protonated form of the extractant more favorable for 124 and 126. DFT calculations suggested that, during extraction, the metalate is bound by an array of polarized $\mathrm{CH}$ hydrogen-bond donors in addition to cationic $\mathrm{NH}$ or $\mathrm{OH}$ groups. This array of interactions is illustrated in the solid-state structure of $\left[\left(124 \mathrm{H}_{2} \mathrm{PtCl}_{6}\right]\right.$ (Figure 42).

\section{SELF-ASSEMBLING SYSTEMS INVOLVING ANIONS}

Self-assembly is a rapidly emerging theme in anion supramolecular chemistry. Recent progress has unveiled that anions can play a variety of different roles in assembly processes. These include directing the assembly of a particular structure, binding to a self-assembled metal-organic complex, and forming or disrupting a hydrogen-bonding network in a soft material. Many of these systems can be expected or have been shown to possess dynamic structural, mechanical, or optical properties responsive to the addition or removal of environmentally and biologically 
A<smiles></smiles>

130a $\mathrm{R}=\mathrm{CH}_{3}$

$130 \mathrm{~b} R=\mathrm{H}$

c

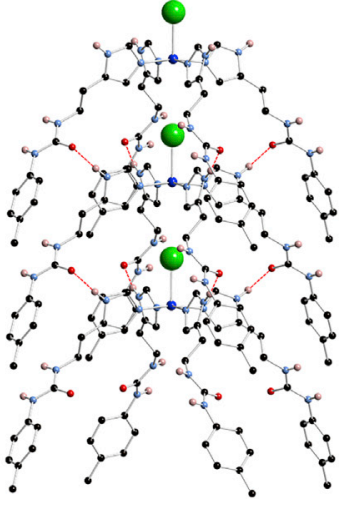

B

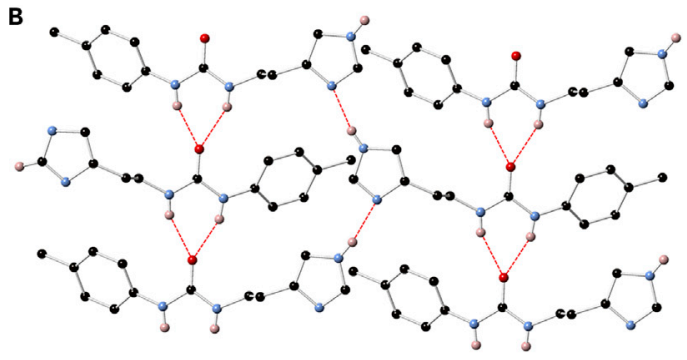

D

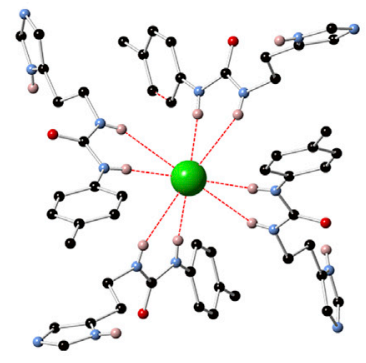

Figure 43. Anion-Bridged Supramolecular Imidazole-Urea Gels

(A) General structure of compounds $130 \mathrm{a}$ and $130 \mathrm{~b}$

(B) The single-crystal and crystal structures of 130 a.

(C) $\mathrm{CuCl}_{2}$ stacking via imidazole $\mathrm{NH} \cdots \mathrm{O}$ hydrogen bonding

(D) Hydrogen bonding of four urea groups to a non-coordinated chloride anion.

Most hydrogen atoms are omitted for clarity. Colors: $\mathrm{H}$, pale pink; C, black; N, pale blue; $\mathrm{O}, \mathrm{red} ; \mathrm{Cl}$, green; and $\mathrm{Cu}$, blue.

relevant anions. Anion-participating self-assemblies thus may represent promising candidates for manufacturing biomedical functional materials.

James et al. ${ }^{63}$ have been pioneers in the area of the interaction between anions and hydrogen-bonded gels. Recently, this group reported an imidazole functionalized urea with switchable hydrogelation properties that are turned off by metal coordination, giving coordination arrays containing bound anions. Compound 130a was found to be an effective hydrogelator and could gelate mixtures of water with other solvents such as methanol, whereas compound $130 \mathrm{~b}$ was found to not act as a hydrogelator. The crystal structure of 130a shows the compound forming a tape via urea hydrogen bonding with the additional formation of a hydrogen-bonding array between imidazoles forming a zigzag hydrogen-bonded tape (Figure 43B). The gelation properties of 130a were probed in the presence of zinc(II) and copper(II) metal ions, which were expected to bind strongly to the imidazole nitrogen atom. Rheological experiments were conducted with 130a in the presence of $\mathrm{Cu}\left(\mathrm{NO}_{3}\right)_{2}$ and $\mathrm{ZnCl}_{2}$. It was found that both metal salts substantially weakened the gel. The crystal structure of the $\mathrm{CuCl}_{2}$ complex of 130a was elucidated, revealing copper coordination to the imidazole nitrogen atoms (Figure 43C) and chloride complexation to the urea groups (Figure 43D). Therefore, in this case, gelation is perturbed by both metal and anion coordination.

White and MacLachlan ${ }^{64}$ used anions to template the formation of hexagonal nanotubes. Tetrahydrotriptycene ligand 131 was synthesized via literature methods, and its anion complexation properties were studied in $\mathrm{CD}_{3} \mathrm{CN}$ solution. Interestingly, with the anions studied (Table 2), only the formation of a 1:1 complex was observed despite the presence of two putative binding sites. The authors attributed this to 
Table 2. Association Constants and Approximate Free Energies of Binding of Tetrabutylammonium Salts to 131

\begin{tabular}{|l|l|l|l|l|}
\hline \multicolumn{2}{|l|}{ WinEQNMR2 } & \multicolumn{2}{l|}{$\begin{array}{l}\text { Supramolecular.org Fitting } \\
\text { Program }\end{array}$} \\
\hline Anion & $K_{\mathrm{a}}\left(\mathrm{M}^{-1}\right)$ & $\boldsymbol{\Delta G}\left(\mathrm{kJ} \mathrm{mol}^{-1}\right)$ & $K_{\mathrm{a}}\left(\mathrm{M}^{-1}\right)$ & $\Delta \mathrm{G}\left(\mathrm{kJ} \mathrm{mol}^{-1}\right)$ \\
\hline $\mathrm{Cl}^{-}$ & $558(18)$ & -15.7 & $554(14)$ & -15.7 \\
\hline $\mathrm{Br}^{-}$ & $85(5)$ & -11.0 & $92(3)$ & -11.2 \\
\hline $\mathrm{I}^{-}$ & $40(2)$ & -9.1 & $43(3)$ & -9.3 \\
\hline $\mathrm{NO}_{3}^{-}$ & $37(1)$ & -9.0 & $38(1)$ & -9.0 \\
\hline
\end{tabular}

Association constants and approximate free energies were calculated by two different fitting programs. The estimated SEs of fitting are given in parentheses. These are the errors in the fitting of the curve and are an approximate measure of the random error in the data, not accounting for systematic error.

the formation of the 1:1 complex deactivating the second binding site to anion complexation.

Crystals of the tetrabutylammonium bromide complex of compound 131 could be obtained by vapor diffusion of pentane or diethyl ether into solutions of the receptor in a wide range of solvents in the presence of either 1 or 2 equiv of tetrabutylammonium bromide. The structure (Figures 44B-44D) showed that compound 131

A

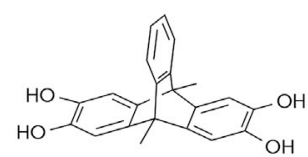

131

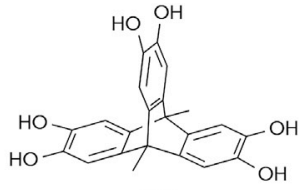

132

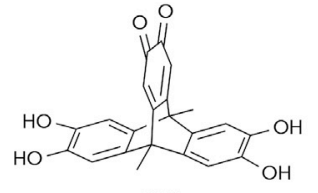

133

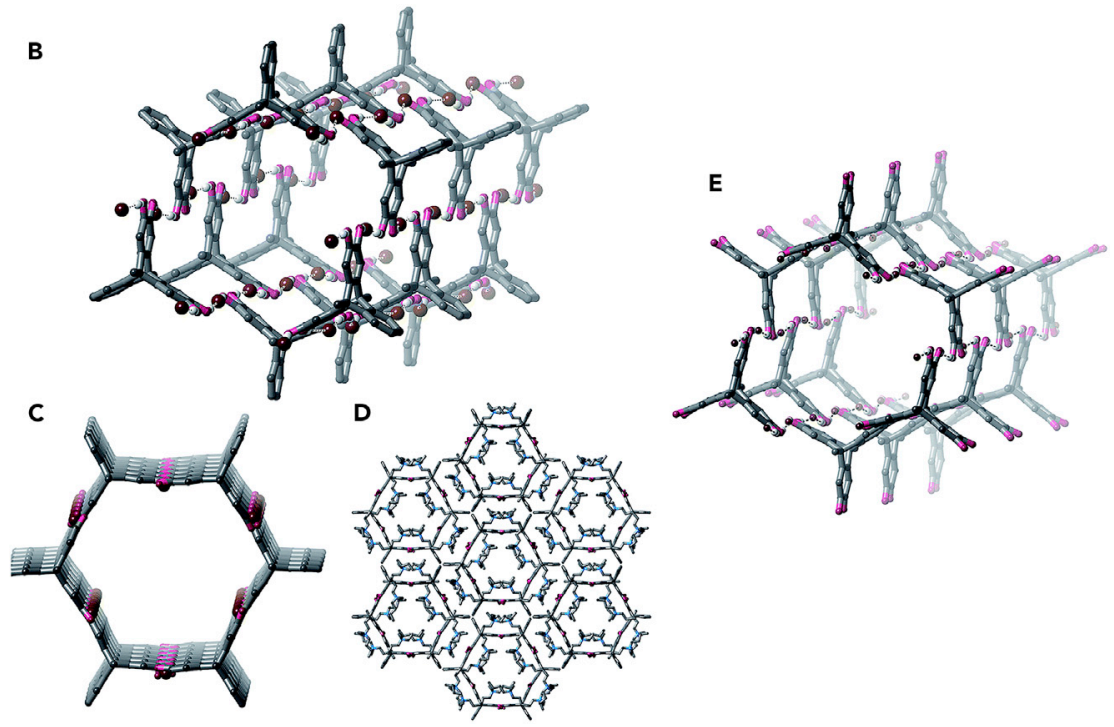

Figure 44. Anion-Templated Hexagonal Nanotubes

(A) Structures of tetrahydrotriptycene ligands 131-133.

(B-D) X-ray crystal structure of $\left[131 \cdot\left(\mathrm{TBA}^{+} \mathrm{Br}^{-}\right)_{2}\right]_{n}$ in an offset view $(\mathrm{B})$, overlay view $(\mathrm{C})$, and overall packing view (D).

(E) The crystal structure of nanotubes formed by compound 133, $\left[133 \cdot\left(\mathrm{TBA}^{+} \mathrm{Br}^{-}\right)_{2}\right]_{\mathrm{n}}$. TBA cations and most hydrogen atoms are omitted for clarity.

Reproduced with permission from White and MacLachlan. ${ }^{64}$ Published by The Royal Society of Chemistry. 
A<smiles>c1ccc(-c2csc(Nc3cccc(Nc4nc(-c5ccccn5)cs4)c3)n2)nc1</smiles>

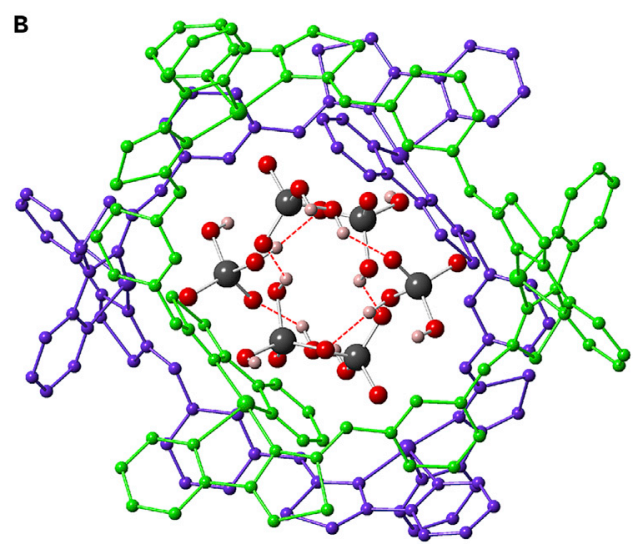

Figure 45. Formation of Dinulear Double Helicates Directed by Dihydrogenphosphate Anions (A) Structure of compound 134.

(B) The X-ray crystal structure of $\left[\left\{\mathrm{Cu}_{3} \cdot 134_{3} \cdot\left(\mathrm{H}_{2} \mathrm{PO}_{4}\right)_{3}\right\}^{3+}\right]_{2}$. The remaining anions and most hydrogen atoms are omitted for clarity. Colors: $\mathrm{P}$, gray; $\mathrm{O}$, red; $\mathrm{H}$, pale pink; helicates, green or purple.

crystallizes as the bromide complex via $\mathrm{OH} \cdots \mathrm{Br}^{-}$hydrogen-bond-forming hexagonal nanotubes. Each bromide was bound by two $\mathrm{OH}$ groups with the tetrabutylammonium cations occupying the nanotubes. When experiments were repeated with compound 132, the resulting crystals instead were composed of the partially oxidized compound 133 forming similar nanotubes via complexation of bromide (Figure 44E).

Faulkner et al. ${ }^{65}$ have continued their work on metal- and anion-directed self-assembly and have reported the effect of dihydrogenphosphate anions on assemblies formed between ligand 134 and $\mathrm{Cu}(\mathrm{II})$ metal ions. Reaction of 134 with $\mathrm{Cu}\left(\mathrm{BF}_{4}\right)_{2}$ in $\mathrm{CH}_{3} \mathrm{NO}_{2}$ afforded a dark blue solution. Diffusion of diisopropyl ether into this solution resulted in the formation of blue crystals containing the dinuclear double helicate $\left(\left[\mathrm{Cu}_{2} \cdot 134_{2}\right]^{4+}\right)$; X-ray crystallography revealed self-assembles to create a cavity in which the $\mathrm{BF}_{4}{ }^{-}$counter anion was hydrogen bonded to two of the amine $\mathrm{NH}$ groups and two phenyl hydrogen atoms in the helicate. The use of $\mathrm{Cu}\left(\mathrm{ClO}_{4}\right)_{2}$ instead of the tetrafluoroborate salt gave an essentially isostructural assembly. Reaction of the perchlorate complex with 0.5 equiv of tetrabutylammonium dihydrogenphosphate formed the dinuclear double helicate $\left[\mathrm{Cu}_{2} \cdot 134_{2} \cdot\left(\mathrm{H}_{2} \mathrm{PO}_{4}\right)\right]^{3+}$, which reacted with further dihydrogen phosphate to give a tricopper circular helicate $\left[\mathrm{Cu}_{3} \cdot 134_{3} \cdot\left(\mathrm{H}_{2} \mathrm{PO}_{4}\right)_{3}\right]^{3+}$. This complex self-assembled through hydrogen bonding between the dihydrogen phosphate anions into the dimer $\left[\left\{\mathrm{Cu}_{3} \cdot 134_{3} \cdot\left(\mathrm{H}_{2} \mathrm{PO}_{4}\right)_{3}\right\}^{3+}\right]_{2}$ (Figure 45B), encapsulating the six dihydrogen phosphate anions in a cylinderlike array.

Löffler et al. ${ }^{66}$ have recently reported the synthesis of the interpenetrated double palladium cage 136 (Scheme 2). The double cage contains a stack of four palladium ions each bridged by a tetrafluoroborate anion. The authors found that they could exchange the terminal tetrafluoroborates for chloride or bromide, which decreased the distance between the terminal pairs of palladium ions and 

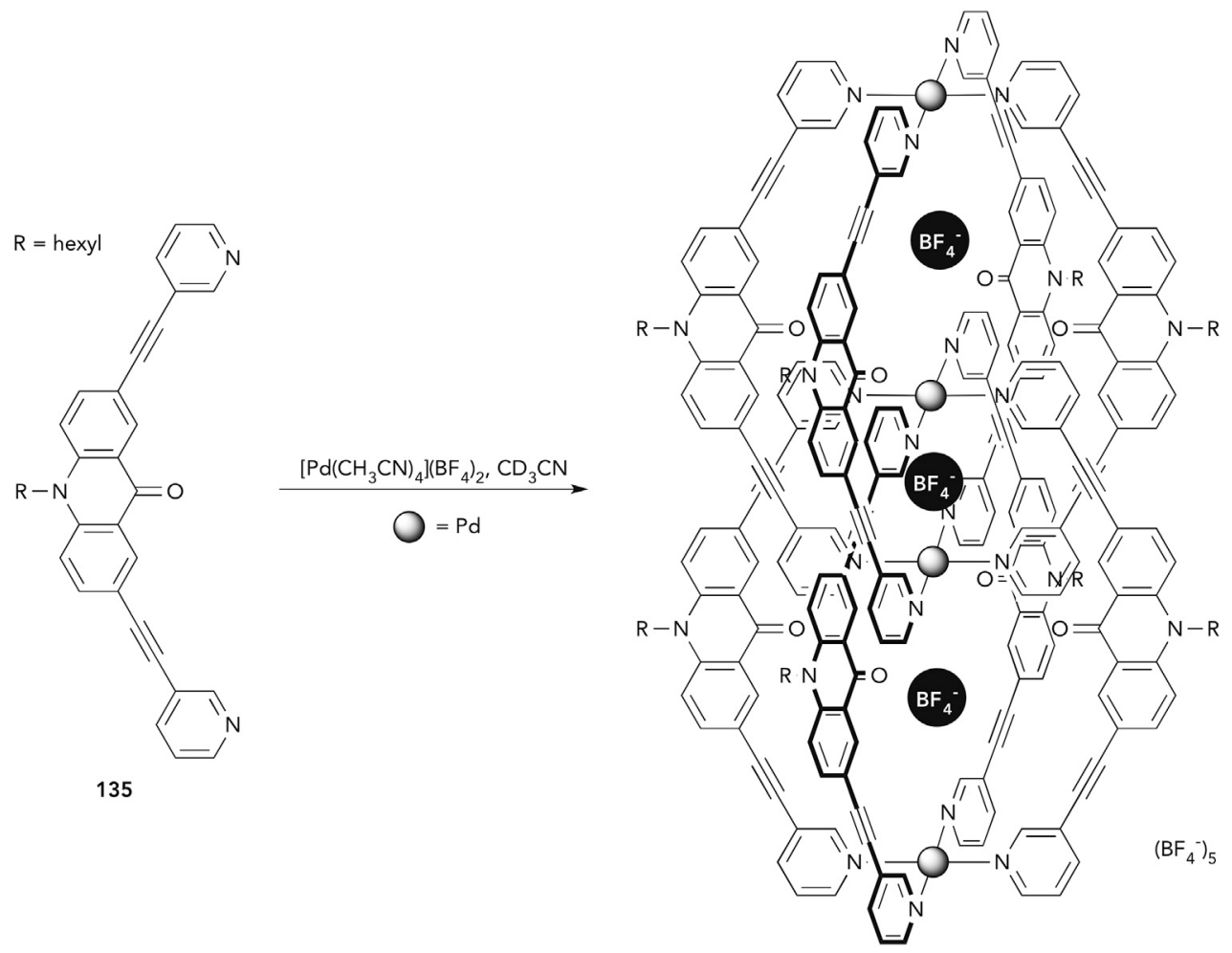

$\left[3 \mathrm{BF}_{4} @ \mathrm{Pd}_{4} 135_{8}\right]$

136

Scheme 2. Assembly of Ligand $135, \mathrm{Pd}^{2+}$, and $\mathrm{BF}_{4}{ }^{-}$to form Cage 136

concomitantly increased the size of the central cavity of the complex (Figure 46). This allowed replacement of the central tetrafluoroborate with a neutral guest such as benzene.

Zhu et al. ${ }^{67}$ also synthesized compound 137 (Scheme 3). In contrast to their previous results with ligand 135, they found that reaction of 137 with 0.5 equiv of $\left[\mathrm{Pd}\left(\mathrm{CH}_{3} \mathrm{CN}\right)_{4}\right]\left(\mathrm{BF}_{4}\right)_{2}$ in $\mathrm{CD}_{3} \mathrm{CN}$ heated at $70^{\circ} \mathrm{C}$ for $5 \mathrm{hr}$ afforded only the monomeric bispalladium cage $\left[\mathrm{Pd}_{2} 137_{4}\right]^{4+}$, presumably because the shorter ligand gave rise to a smaller cavity that did not have space for the sandwich arrangement of metals and $\mathrm{BF}_{4}{ }^{-}$anions seen in structure 136 . The addition of 1.5 equiv of chloride or bromide to the cage and heating for $5 \mathrm{hr}$ resulted in the formation of an interpenetrated double cage with halide anions between the pairs of palladium ions. NMR analysis showed that the interpenetrated cage was in equilibrium with the monomeric cage and the free ligand 137. The release of free ligand was likely caused by competition for metal complexation by the halide. A triple catenane 138 trans$\left.\left[\left(\mathrm{PdBr}_{2}\right)_{2} 137_{2}\right]\right\}_{3}$ was isolated and its structure was elucidated by single-crystal X-ray diffraction. In this structure, because the $\mathrm{PdBr}_{2}$ units are neutral, no anions occupy the voids between the metal cations, and so the intermetallic distances are smaller than in the doubly interpenetrated cages (Figure 47).

Preston et al. ${ }^{68}$ used halide complexation to switch the structure of a $\left[\mathrm{Pd}_{2} 139_{4}\right]^{4+}$ cage to a $\left[\mathrm{Pd}_{2} 139_{2} \mathrm{Cl}_{4}\right]$ macrocycle (Scheme 4). ${ }^{1} \mathrm{H}-\mathrm{NMR}$ experiments in dimethylformamide (DMF)- $d_{7}$ at $298 \mathrm{~K}$ showed the conversion of the free ligand 139 into cage 140. Subsequent addition of 4 equiv of tetrabutylammonium chloride afforded 


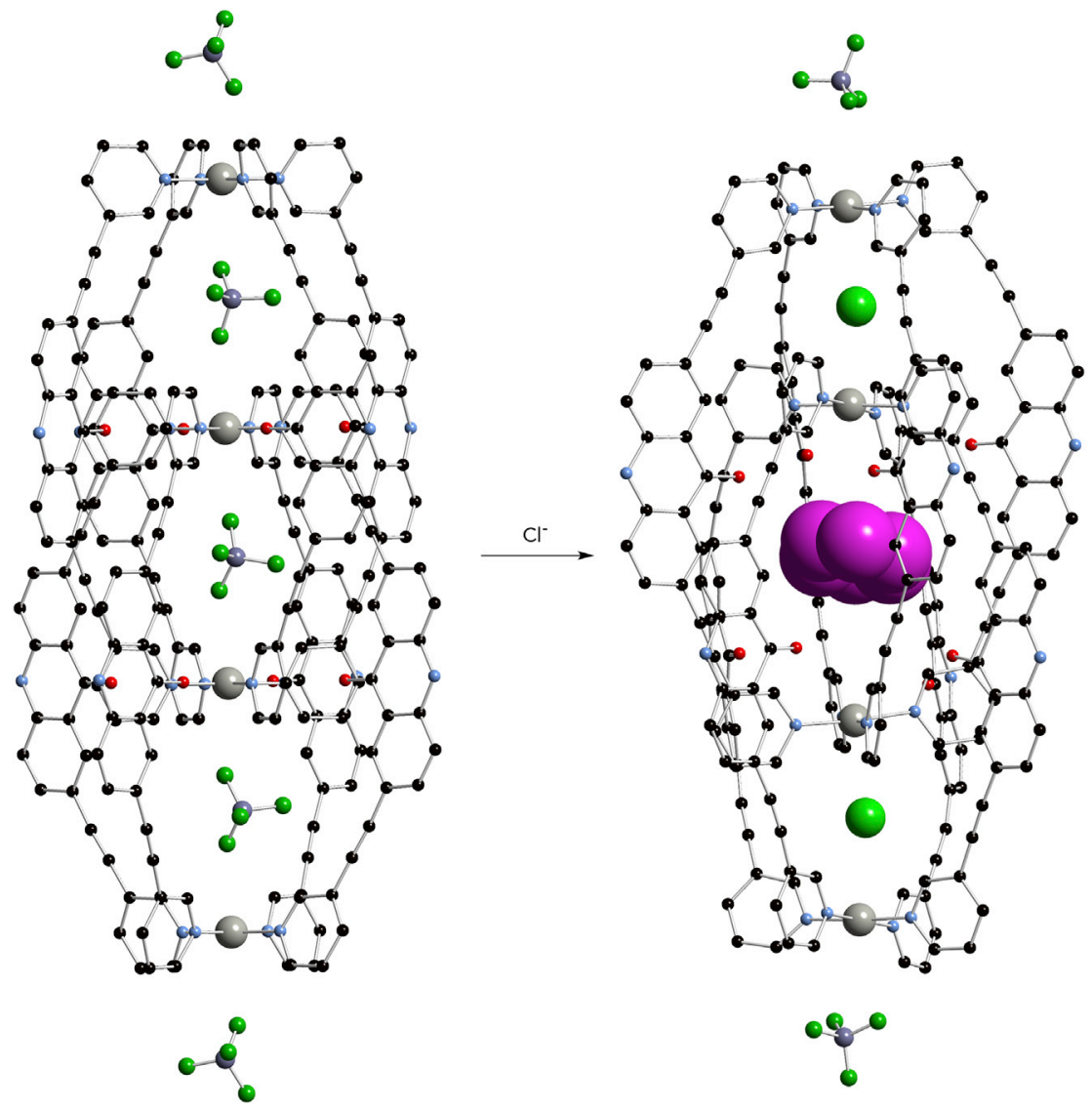

Figure 46. X-Ray Crystal Structures of Cage 136: [3BF $\left.{ }_{4} @ \mathrm{Pd}_{4} 135_{8}\right]$ on the Left and $[2 \mathrm{Cl}+$ $\mathrm{C}_{6} \mathrm{H}_{6} @ \mathrm{Pd}_{4} 135_{8}$ ] on the Right

Colors: C, black; N, pale blue; O, red; Cl, green; F, green; $\mathrm{B}$, pale purple; Pd, gray; and $\mathrm{C}_{6} \mathrm{H}_{6}$, magenta. For clarity, hydrogen atoms, hexyl substituents, and some of the solvent molecules have been removed.

macrocycle 141 and 2 equiv of free ligand. This could be converted back to cage 140 by the addition of 4 equiv of $\mathrm{AgBF}_{4}$. The addition of mesylate anions to the cage gave evidence of association and the formation of a $140 \cdot$ (mesylate $)_{2}$ complex, and analysis of the shifts of the protons in the cage provided evidence that the mesylates were associating with the exo-hedral faces of the palladium complex. Cage 140 also formed a complex with 2 equiv of cis-platin, and the platinum complexes bound within the cage. It was possible to form a complex with two cis-platin complexes inside the cavity of the cage, and two mesylate anions bound to the exterior faces of the metal complexes. The addition of chloride and the formation of the macrocycle 141 released both the cis-platin and mesylate guests.

Klein et al. ${ }^{69}$ have complexed the BINOL-based bis-pyridine ligand 142 to palladium to form a homochiral $\left[\mathrm{Pd}_{4}(142)_{8}\right]$ complex templated by two tetrafluoroborate anions (Scheme 5). Two equivalents of compound 142 and 1 equiv of $\left[\mathrm{Pd}\left(\mathrm{CH}_{3} \mathrm{CN}\right)_{4}\right]\left(\mathrm{BF}_{4}\right)_{2}$ were heated at $70^{\circ} \mathrm{C}$ for $3 \mathrm{hr}$, and subsequent ESI-MS of the reaction mixture revealed the formation of the $\mathrm{Pd}_{4}(142)_{4}$ complex. The X-ray crystal structure (Scheme 5) revealed the role of the $\mathrm{BF}_{4}{ }^{-}$anions in the formation of the complex with the tetrafluoroborates occupying cavities at either end of the assembly. A repeat of the synthesis using palladium nitrate instead of tetrafluoroborate did 


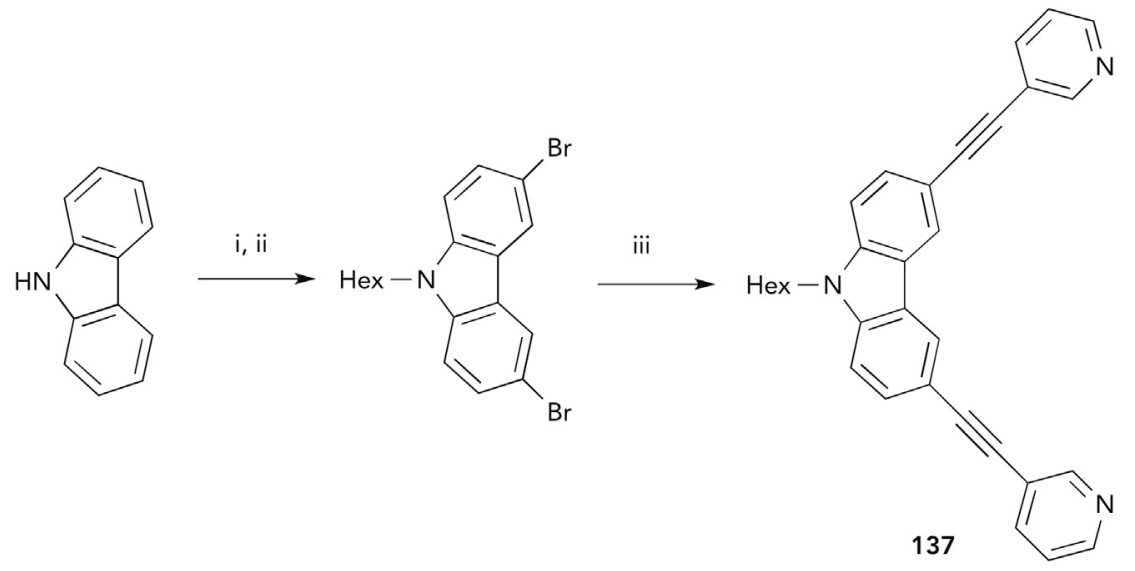

Scheme 3. Synthesis of Compound 137

(i) NBS, DMF, $0^{\circ} \mathrm{C}$.

(ii) 1-bromohexane, $50 \% \mathrm{NaOH}, \mathrm{DMSO}$.

(iii) 3-ethynylpyridine, $\mathrm{Cul}, \mathrm{Pd}\left(\mathrm{PPh}_{3}\right)_{2} \mathrm{Cl}_{2}, \mathrm{NEt}_{3}, 90^{\circ} \mathrm{C}$.

not result in the formation of defined complexes. Therefore, this synthesis represents an unusual example of a tetrafluoroborate peripherally templated structure.

Riddell et al. $^{70}$ have continued their work on metallosupramolecular assemblies and have demonstrated anion-driven structural transformations between a number of metal complexed assemblies of the bis-imine formed between 3,3'-diformyl-6, $6^{\prime}$-bypyridine and $p$-toluidine. This includes the formation of a $\mathrm{Cd}_{10} \mathrm{com}$ plex templated by bifluoride $\left(\mathrm{HF}_{2}^{-}\right)$(Figure 48). The templating anion is hydrogen bonded to bipyridyl $\mathrm{CH}$ hydrogens with distances in the range of 2.29-2.50 $\AA$. Ramsay and Nitschke ${ }^{71}$ have also recently reported the synthesis of a $\mathrm{Fe}_{8} \mathrm{Mo}_{12}$ cubic receptor with peripheral allosteric binding sites that modulate the selectivity of a central cavity for neutral or anionic guests.

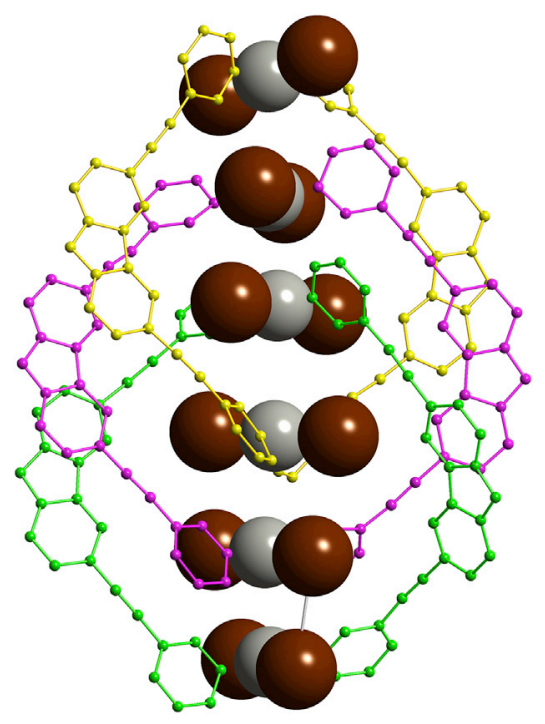

Figure 47. The Single-Crystal Structure of Triple Catenane 138: $\left\{\text { trans- }\left[\left(\mathrm{PdBr}_{2}\right)_{2} 137_{2}\right]\right\}_{3}$

The hexyl substituents and all hydrogen atoms are omitted for clarity. Colors: Pd, gray; Br, brown; and ligands 137, yellow, magenta, and green. 


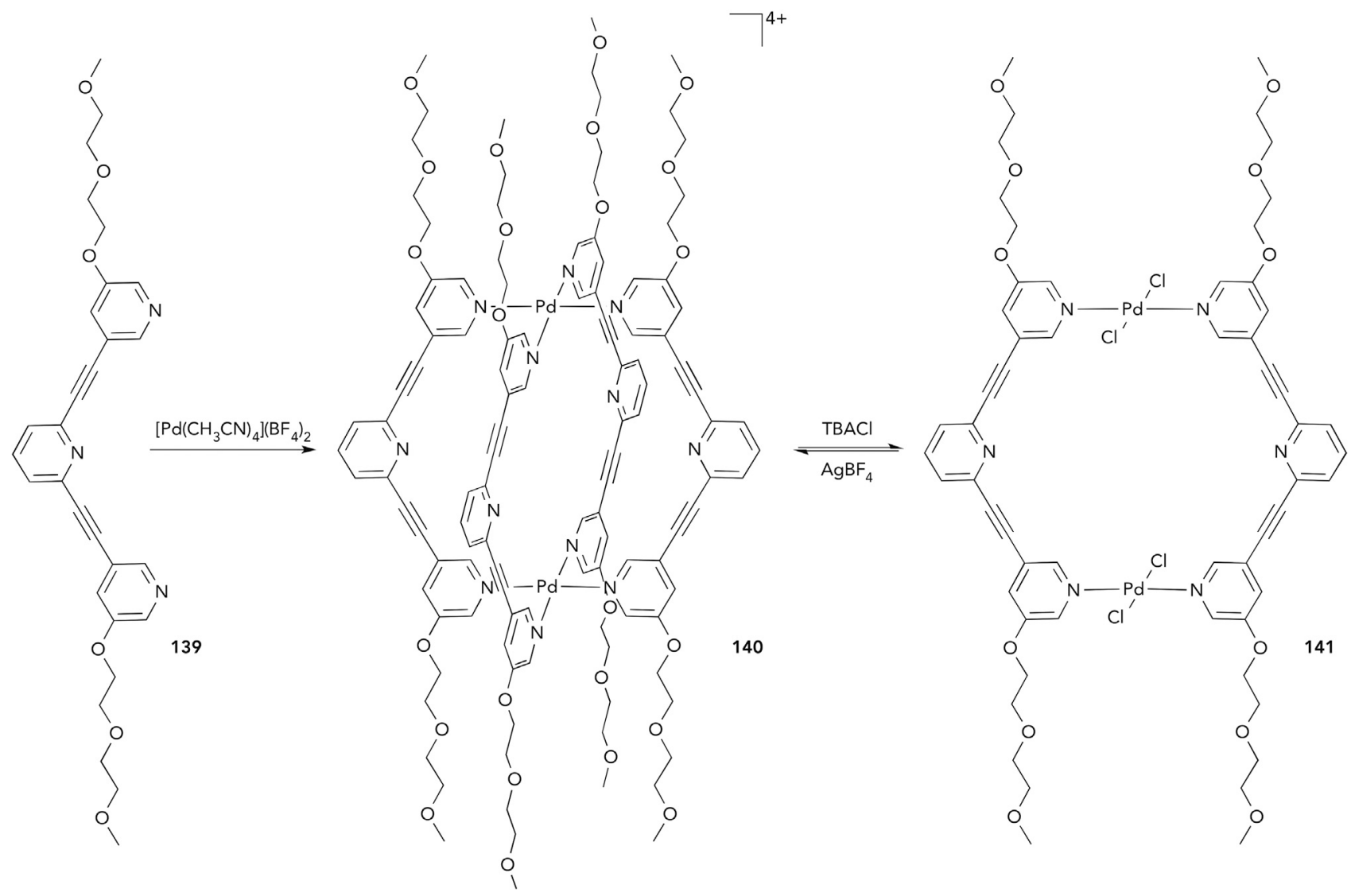

Scheme 4. Formation of Cage 140 from Ligand 139 and the Reversible Formation of Macrocycle 141 with $\left[\mathrm{Bu}_{4} \mathrm{~N}\right] \mathrm{Cl}$ and $\mathrm{AgBF}_{4}$ as Stimuli

Ayme et al. ${ }^{72}$ have reported that self-assembled molecular knots and links can function as highly effective receptors for halide anions. Solomon link [2]catenane 143, pentafoil knot 144, and Star of David [2]catenane 145 were prepared as their PF $_{6}{ }^{-}$ salts (Figure 49). The cavities at the center of these assemblies had diameters of $3.8,3.4$, and $4.8 \AA$, respectively. Except upon addition of chloride or bromide to 145 , ESI-MS showed that only one halide anion exchanged for $\mathrm{PF}_{6}{ }^{-}$, and ${ }^{1} \mathrm{H}-\mathrm{NMR}$ experiments showed that the halide bound in the central cavity of the assembly.
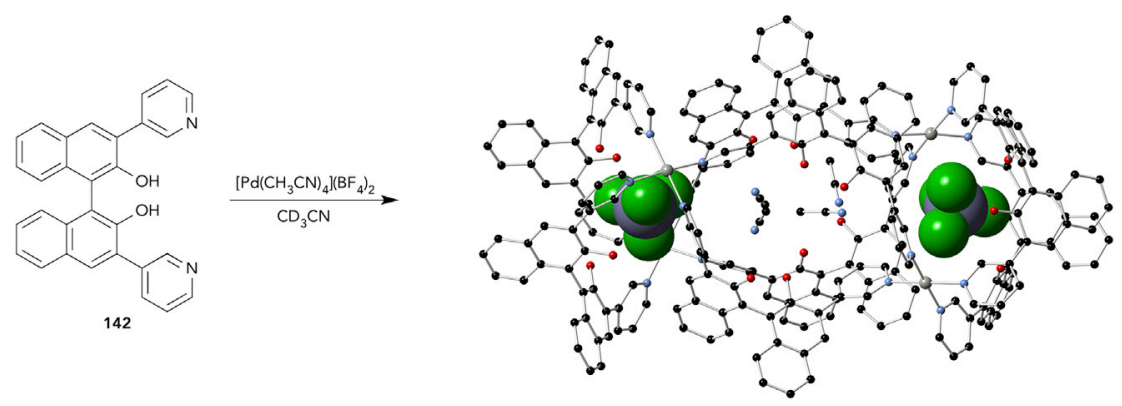

Scheme 5. Assembly of Axially Chiral Ligand 142 with $\mathrm{Pd}^{2+}$ in the Formation of $\mathrm{Pd}_{4}(142)_{4}$ Complex

X-ray crystal structure. All hydrogen atoms are omitted for clarity. Colors: C, black; N, pale blue; O, red; F, green; B, pale purple; and Pd, gray. 


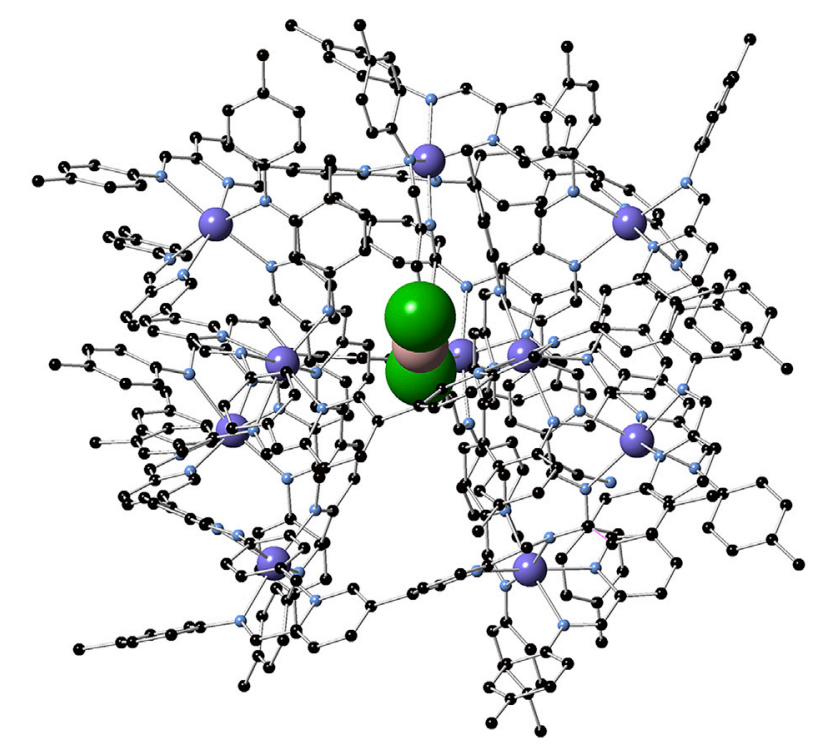

Figure 48. X-Ray Crystal Structure of Nitschke's $\mathrm{HF}_{2}{ }^{-}$Templated $\mathrm{Cd}_{10}$ Complex Most hydrogen atoms are omitted for clarity. Colors: H, beige; C, black; N, pale blue; F, green; and $\mathrm{Cd}$, purple.

The equilibrium constants for the exchange of one hexafluorophosphate anion for a single halide anion were measured in $\mathrm{CD}_{3} \mathrm{CN}$ solution (Table 3). A variety of different types of NMR titration experiments (including competitive assays) were used as detailed in Table 3. The largest cavity present in assembly 145 was found to bind only iodide anions with a stability constant of $1.2 \pm 0.1 \times 10^{4} \mathrm{M}^{-1}$. In contrast, the highest-affinity complex was that formed between the pentafoil knot 144 and chloride; it had a stability constant of $(3.6 \pm 0.2) \times 10^{10} \mathrm{M}^{-1}$, measured by competitive binding with $\mathrm{AgPF}_{6}$.

Zhou and Sun ${ }^{73}$ have reported the synthesis of cage 147 from four anthracenebridged benzimidazole ligands 146 and palladium nitrate in DMSO solution (Scheme 6). The cage contains a cavity surrounded by the four hydrophobic anthracene groups in which eight $\mathrm{CH}$ hydrogen-bond donors from the benzimidazole groups can interact with a bound nitrate anion. The crystal structure of the complex shows that the nitrate is disordered over four orientations, and each orientation interacts with at least six $\mathrm{CH}$ hydrogen-bond donors. A tetrafluoroborate complex of the cage could also be prepared with the anion encapsulated within the structure. Preparation of the cage from $\mathrm{Pd}\left(\mathrm{PF}_{6}\right)_{2}$ was expected to result in the formation of an empty cage because the anion was too large to fit in the cavity. However, it was found that this cage encapsulated an adventitious chloride anion. The chloride complex was used in stability-constant-determination studies with a range of anionic guests (Table 4), which demonstrated the high affinity of this cage for nitrate. Larger oxo-anions were found not to interact with the cage, which the authors reasoned was because these guests were too large to be encapsulated within the cavity. Interestingly, fluoride was also not observed to bind to the cage structure.

Chifotides et al. ${ }^{74}$ have shown that anion- $\pi$ interactions are the major driving force in the formation of self-assembled metallamacrocycles formed from 3,6-bis(2-pyridyl)1,2,4,5-tetrazine 148 in excellent yields. It was shown by a variety of techniques, including single-crystal $\mathrm{X}$-ray structure determination, that tetrafluoroborate and 

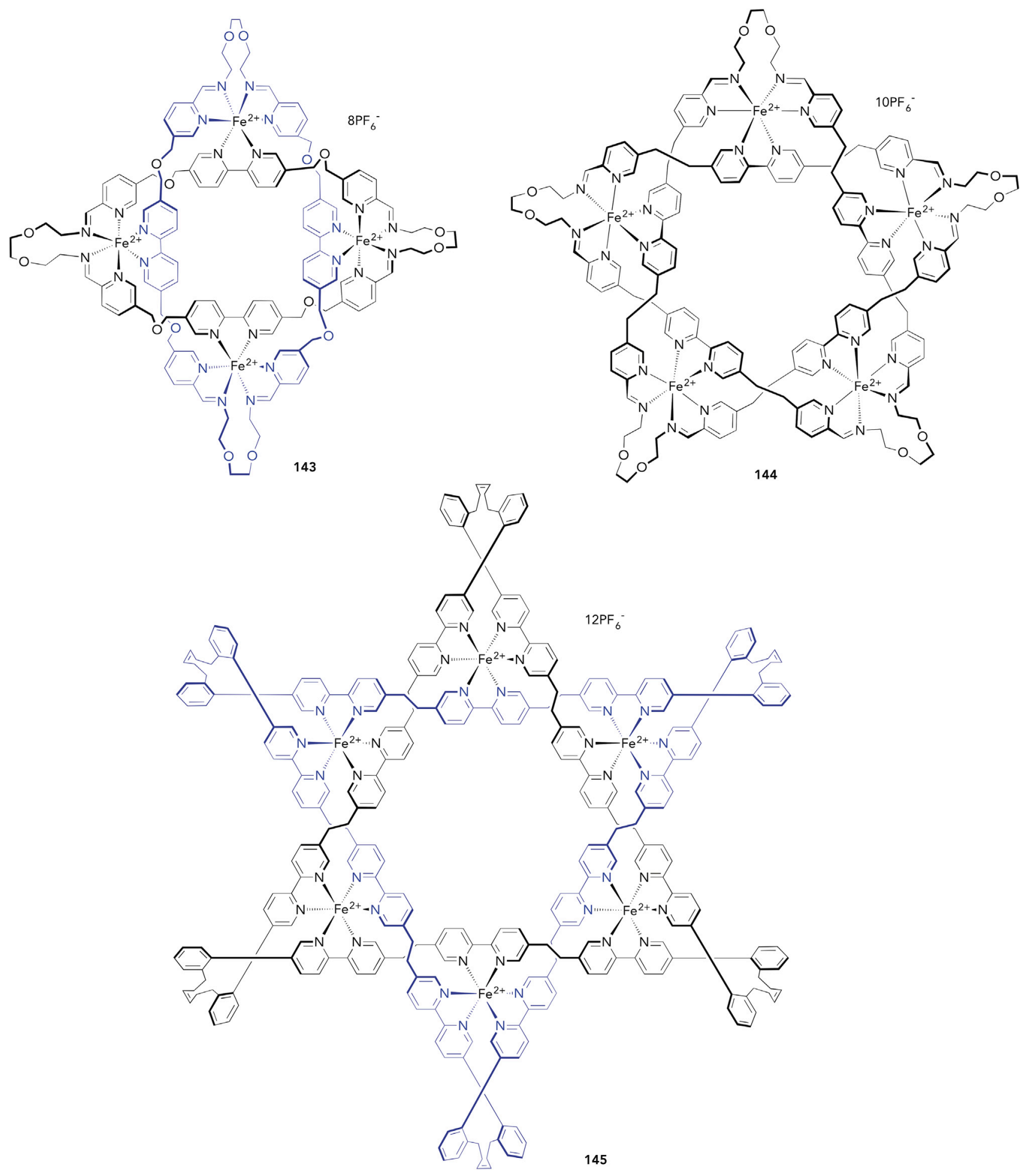

Figure 49. Structures of Solomon Link [2]catenane 143, Pentafoil Knot 144, and Star of David [2] catenane 145 Shown as Their $\mathrm{PF}_{6}{ }^{-}$Salts

perchlorate template the formation of molecular squares $\left[\mathrm{Fe}_{4}(148)_{4}\left(\mathrm{CH}_{3} \mathrm{CN}\right)_{8}\right] \supset$ [anion] $]_{8}$ (Figure 50A), whereas hexafluoroantimonate, hexafluorophosphate, and hexafluoroarsenate template the formation of molecular pentagons $\left[\mathrm{Fe}_{5}(148)_{5}\right.$ 
Table 3. Equilibrium Constants, $K_{1}$ in $\mathbf{M}^{-1}$, for the Exchange of One $\mathrm{PF}_{6}{ }^{-}$Anion for One Halide Anion for Complexes of Molecular Knots and Links 143, 144, and 145 in $C_{3}$ CN at 295 K

\begin{tabular}{|l|l|l|l|}
\hline Receptor & $\mathrm{Cl}^{-}(\mathrm{d}=3.6 \AA)$ & $\mathrm{Br}^{-}(\mathrm{d}=3.9 \AA)$ & $\mathrm{I}^{-}(\mathrm{d}=4.4 \AA)$ \\
\hline$[143]\left(\mathrm{PF}_{6}\right)_{8}$ & $(3.0 \pm 2.5) \times 10^{8 \mathrm{a}, \mathrm{b}}$ & $(1.0 \pm 0.5) \times 10^{7 \mathrm{a}, \mathrm{b}}$ & $(2.1 \pm 0.2) \times 10^{5 c}$ \\
\hline$[144]\left(\mathrm{PF}_{6}\right)_{10}$ & $(3.6 \pm 0.2) \times 10^{10 d}$ & $(1.7 \pm 0.2) \times 10^{10 d}$ & $(5.8 \pm 1.3) \times 10^{5 c}$ \\
\hline$[145]\left(\mathrm{PF}_{6}\right)_{12}$ & $-{ }^{e}$ & $-^{-}$ & $(1.2 \pm 0.1) \times 10^{4 c}$ \\
\hline
\end{tabular}

Equilibrium constants are the average of several experiments (titrations or competition experiments). The errors given are intrinsic limits of the method or twice the SD of the experimental data.

a Determined by competitive binding against a calix[4]bipyrrole derivative.

${ }^{b}$ Determined by competitive binding against [144] $\left(\mathrm{PF}_{6}\right)_{10}$.

'Determined by ${ }^{1} \mathrm{H}-\mathrm{NMR}$ titration.

${ }^{\mathrm{d} D e t e r m i n e d}$ by competitive binding with $\mathrm{AgPF}_{6}$.

${ }^{\mathrm{e}} \mathrm{A}$ single halide anion is not selectively bound within the central cavity.

$\left.\left(\mathrm{CH}_{3} \mathrm{CN}\right)_{10}\right] \supset$ [anion $]_{10}$ (Figure 50B). ${ }^{19} \mathrm{~F}$ magic-angle spinning NMR studies showed that encapsulated templating anions had downfield chemical shifts of 3.5-4.0 ppm in comparison with non-encapsulated anions.

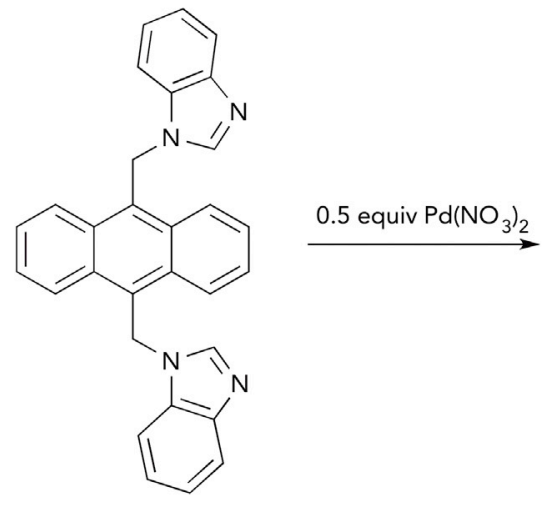

146

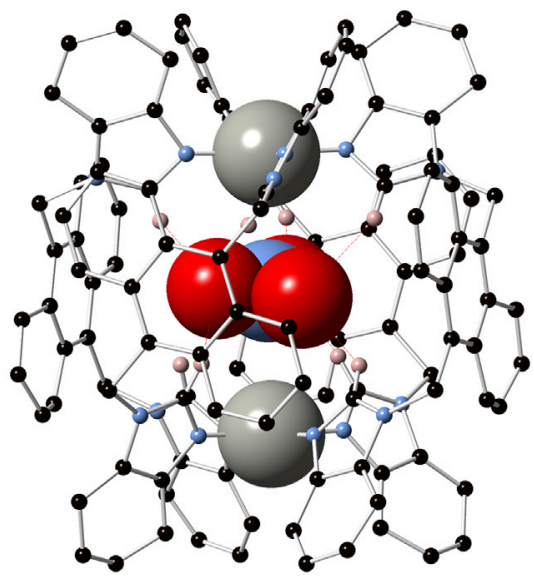

147

Scheme 6. The Self-Assembly of Anthracene-Bridged Benzimidazole Ligands 146 with $\mathrm{Pd}^{2+}$ in the Formation of Complex 147

X-ray crystal structure. Most hydrogen atoms are omitted for clarity. Colors: H, pale pink; C, black; $\mathrm{N}$, pale blue; $\mathrm{O}$, red; and $\mathrm{Pd}$, gray.

Anion- $\pi$ interactions have also been used by He et al. ${ }^{75}$ to control the assembly of vesicular structures. The interaction between macrocycle 149 and amphiphiles such as SDS was studied, and the authors found that 149 formed a complex with SDS via anion- $\pi$ interactions (Figure 51 ). SDS forms micelles in water above the critical micelle concentration of $8-10 \mathrm{mM}$. It was found that a 1:1 mixture of 149 and SDS had a much lower critical aggregation concentration of $5.0 \times 10^{-6} \mathrm{M}$. A variety of techniques, including scanning electron microscopy and transmission electron microscopy, were used to characterize the aggregates, and it was found that the complex formed vesicular structures with an average hydrodynamic diameter of $185 \mathrm{~nm}$ and a narrow size distribution. Macrocycle 150 had previously been shown to not form anion- $\pi$ complexes and did not form vesicles with SDS. The addition of competing anions (nitrate [3 equiv], chloride [5 equiv], or bromide [3 equiv]) to the vesicles formed between 149 and SDS resulted in complete disassembly, presumably as the anions displaced the SDS head group from the 
Table 4. The Equilibrium Constants of Anion Exchange for $147 \cdot \mathrm{Cl}^{-}$in $\mathrm{DMSO}-\mathrm{d}_{6}$

\begin{tabular}{|l|l|l|l|}
\hline Anion & $K\left(\mathrm{M}^{-1}\right)$ & Anion & $K\left(\mathrm{M}^{-1}\right)$ \\
\hline $\mathrm{NO}_{3}{ }^{-}$ & $2.56 \times 10^{2}$ & $\mathrm{NO}_{2}{ }^{-}$ & $4.12 \times 10^{-3}$ \\
\hline $\mathrm{Br}^{-}$ & $2.86 \times 10^{-1}$ & $\mathrm{~F}^{-}$ & $-^{\mathrm{a}}$ \\
\hline $\mathrm{I}^{-}$ & $2.33 \times 10^{-2}$ & $\mathrm{AcO}^{-}$ & $-^{\mathrm{a}}$ \\
\hline $\mathrm{BF}_{4}{ }^{-\mathrm{b}}$ & $2.5 \times 10^{-2}$ & $\mathrm{CO}_{3}{ }^{2-}$ & $-^{\mathrm{a}}$ \\
\hline
\end{tabular}

Equilibrium constants were determined by the integration of the $\mathrm{CH}$ resonances.

${ }^{a}$ No distinct exchange peaks appeared.

${ }^{b}$ Determined by exchange of $147 \cdot \mathrm{BF}_{4}{ }^{-}$with tetrabutylammonium chloride.

macrocycle. Disassembly could also be triggered by protonation of the SDS head group. Similar vesicles could be formed between 149 and sodium dodecyl phosphate and sodium laurate.

Luo et al. ${ }^{76}$ have used metal-imidazolate coordination cages and inorganic anions to synthesize a series of supramolecular frameworks containing mesoporous cavities. Solvothermal synthesis of the cages from 5-methyl-4-formylimidazole and m-xylylenediamine with $\mathrm{Co}\left(\mathrm{ClO}_{4}\right)_{2} \cdot 6 \mathrm{H}_{2} \mathrm{O}, \mathrm{Co}\left(\mathrm{BF}_{4}\right)_{2} \cdot 6 \mathrm{H}_{2} \mathrm{O}$, and $\mathrm{Co}\left(\mathrm{BF}_{4}\right)_{2} \cdot 6 \mathrm{H}_{2} \mathrm{O}-\mathrm{KPF}_{6}$ resulted in isomeric compounds 151, 152, and 153, respectively (Scheme 7). Singlecrystal X-ray diffraction showed that the compounds have the same hierarchical structures with cobalt metal ions bound to the bisimidazole ligands forming a cage containing eight metal ions. The anions link the cages together in the structure to form a higher-order supramolecular network containing large voids capable of encapsulating large guests, including vitamin $B_{12}$.

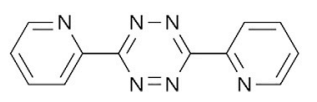

148

A

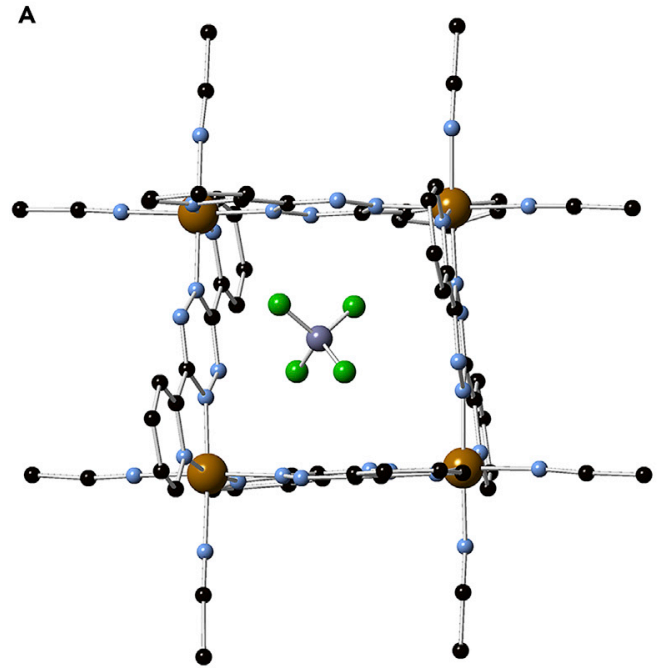

B

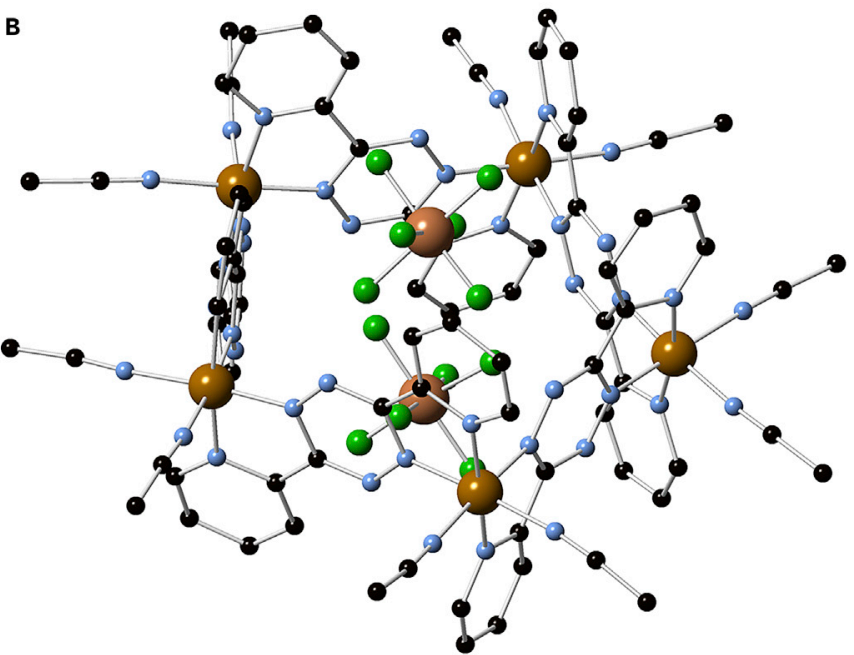

Figure 50. Structure of Compound 148

(A) The single-crystal $\mathrm{X}$-ray structure of $\left[\mathrm{Fe}_{4}(148)_{4}\left(\mathrm{CH}_{3} \mathrm{CN}\right)_{8} \supset \mathrm{BF}_{4}\right]^{7+}$ in $\left[\mathrm{Fe}_{4}(148)_{4}\left(\mathrm{CH}_{3} \mathrm{CN}\right)_{8}\right] \supset$

$\left[\mathrm{BF}_{4}\right]_{8}$.

(B) The single-crystal X-ray structure of $\left[\mathrm{Fe}_{5}(148)_{5}\left(\mathrm{CH}_{3} \mathrm{CN}\right)_{10} \supset 2 \mathrm{SbF}_{6}\right]^{8+}$ in $\left[\mathrm{Fe}_{5}(148)_{5}\left(\mathrm{CH}_{3} \mathrm{CN}\right)_{10}\right] \supset$

$\left[\mathrm{SbF}_{6}\right]_{10}$.

All hydrogen atoms are omitted for clarity. Colors: C, black; N, pale blue; F, green; B, pale purple;

$\mathrm{Fe}$, brown; and $\mathrm{Sb}$, brown. 

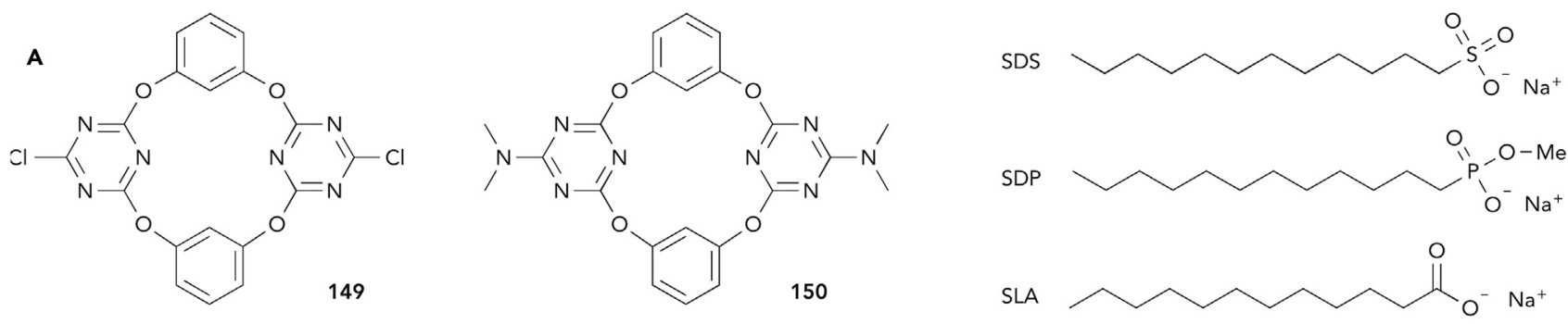

B

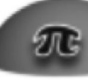

\section{$\pi$}

Supramolecular amphiphile
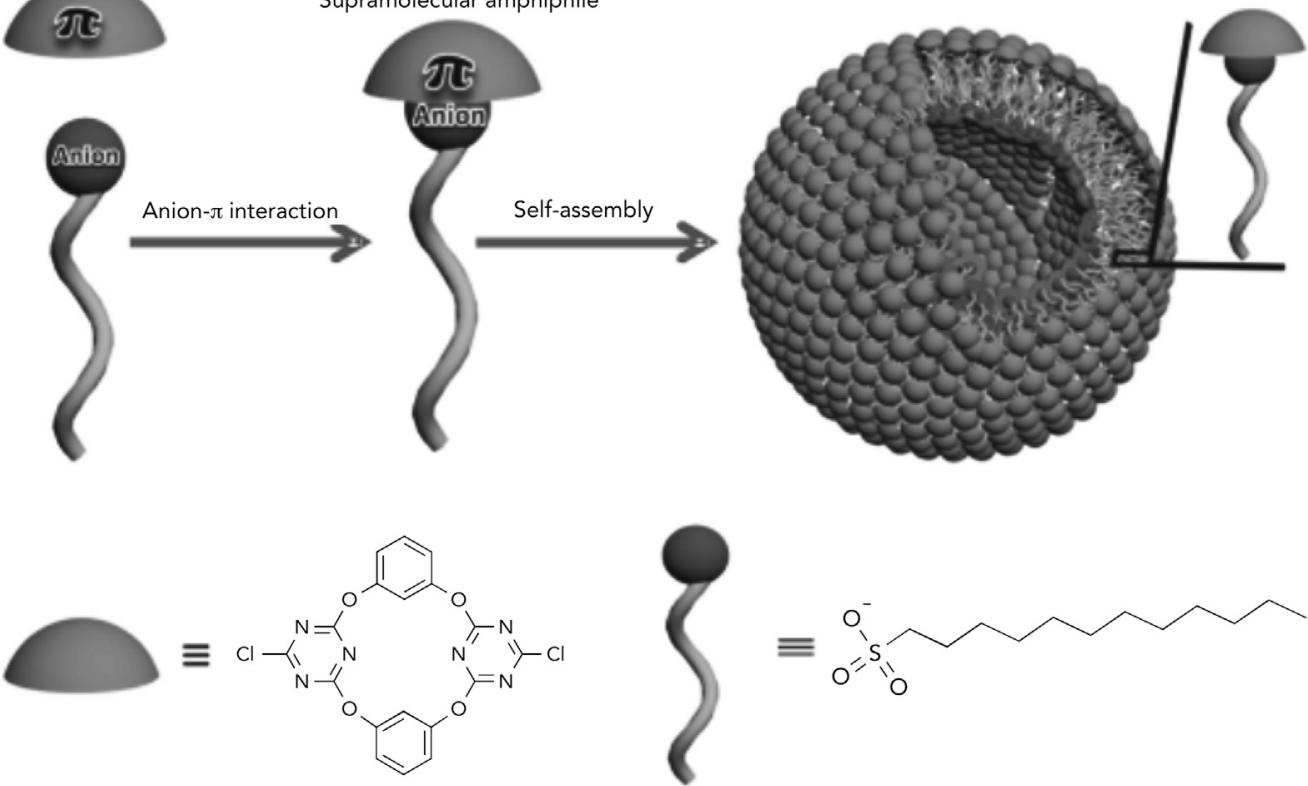

Figure 51. Vesicle Formation Controlled by Anion- $\pi$ Interactions

(A) Structures of macrocycles 149 and 150 and anionic amphiphiles: SDS, sodium dodecyl

phosphate, and sodium laurate.

(B) The formation of vesicles induced by anion- $\pi$ interactions.

Adapted with permission from He et al. ${ }^{75}$ (c) 2015 Wiley-VCH Verlag GmbH \&Co. KGaA.

Wu et al. ${ }^{77}$ have reported the formation of a phosphate-templated tetrahedral cage between ligand 154 and phosphate anions. Three bis-urea hydrogen-bond donor groups coordinate to each phosphate in the structure via 12 hydrogen-bonding interactions (Figure 52). This structure is particularly interesting because the phosphate bis-urea units may be regarded as replacing metal ion nitrogen-donor ligand units found in metal-containing tetrahedral supramolecular cages. Therefore, this can be regarded as an "umpolung" version of this type of self-assembled cage.

Pandurangan et al. ${ }^{78}$ have recently reported an interesting example of self-sorting self-assembly of a 4:4 sulfate ligand cage. Proton NMR titrations were performed with $\mathrm{SO}_{4}{ }^{2-}$ and revealed that 155-157 form both a 2:1 receptor-sulfate complex and, at higher anion concentrations, a 1:1 complex. The crystal structure of the 2:1 complex of receptor 156 with sulfate was elucidated and showed that the anion was bound by 12 urea NH groups (Figure 53B). During the synthesis of 156, a side product containing only two urea groups (158) was isolated. A mixture of 156 and 158 was treated with sulfate in acetonitrile solution. The resulting crystalline material 


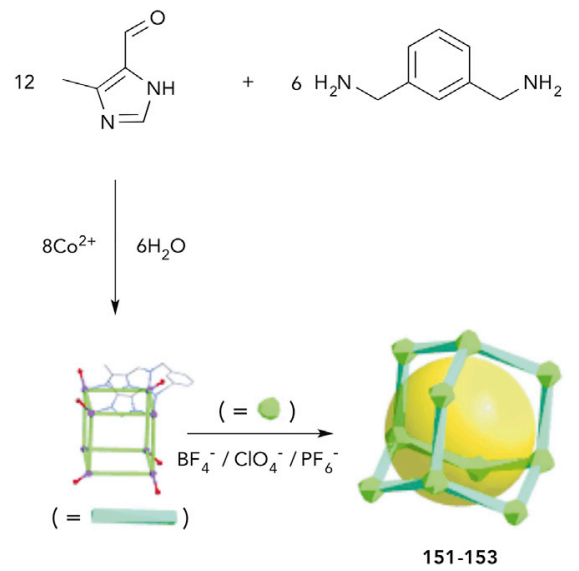

Scheme 7. The Hierarchical Self-Assembly of Frameworks $\mathrm{BF}_{4}{ }^{-} 151, \mathrm{ClO}_{4}{ }^{-} 152$, and $\mathrm{PF}_{6}{ }^{-} 153$ The yellow sphere represents the cavity in the framework. Reprinted with permission from Luo et al. ${ }^{76}$ (c) 2015 Wiley-VCH Verlag GmbH \&Co. KGaA.

consisted of a self-sorted mixture of the sulfate complex of 158 in addition to the sulfate complex of 156 . The sulfate complex of 158 was unexpectedly complex and consisted of four protonated 158 ligands binding a cluster of four sulfate anions (Figure 53C). The four closely packed sulfate anions were bound through 36 hydrogen-bonding interactions in addition to electrostatic interactions with the ligands.

\section{TRANSMEMBRANE ANION TRANSPORT}

The biological relevance of transmembrane anion-transport processes has encouraged a strong interest in the development of synthetic anion receptors capable of facilitating translocation of anionic species across lipid bilayer membranes, such as the monoatomic chloride anion to the significantly larger DNA biomolecule. This focused area of anion receptor research is still in its early stages. Therapeutic applications have been suggested for diseases including cystic fibrosis and cancer. So far, many synthetic anion receptors have been reported to effectively facilitate anion transport in synthetic membrane models, and some have shown promising biological activity in cells, including the induction of anion flux and anti-cancer activity (cytotoxicity). Future research that sheds light on their mechanisms of action in living organisms, as well as the development of anion transporters with well-defined function and low toxicity, will be required for medical application.

Prodigiosin 159 is a natural product produced by bacteria of the Serratia and Streptomyces genus and is best known as one of the most active chloride anion transporters. This tripyrrolic compound binds to chloride anion upon protonation of the C-ring (159. $\mathrm{H}^{+} \supset \mathrm{Cl}^{-}$; Figure 54); this binding process facilitates transmembrane cotransport of $\mathrm{H}^{+} / \mathrm{Cl}^{-}$in cells and was shown to alter intracellular $\mathrm{pH}$ and trigger apoptosis in cancer cells. Rastogi et al. ${ }^{79}$ and Marchal et al. ${ }^{80}$ systematically studied the transmembrane chloride-transport activities of prodigiosin and the synthetic analogs 160-162 by using egg-yolk L- $\alpha$-phosphatidylcholine (EYPC) liposomal-based $\mathrm{Cl}^{-} / \mathrm{NO}_{3}{ }^{-}$exchange assay with lucigenin (a chloride-selective fluorescent probe) at $\mathrm{pH}$ 7.4. This study revealed that the addition of a methyl group on the C-ring 160 did not affect the transport activity in relation to the natural prodigiosin 159 . However, replacing the methoxy motif with phenoxy (OAr) groups on the B-ring 161 or modification of the pentyl chain to an electron-withdrawing ester group on 


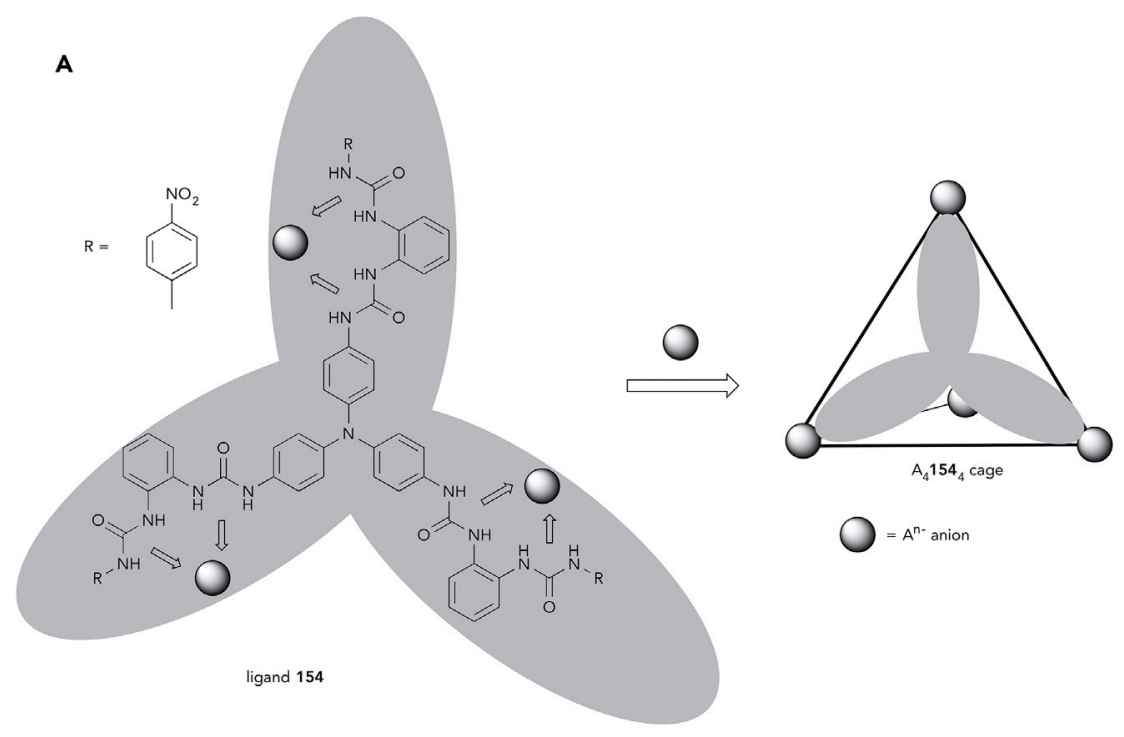

B

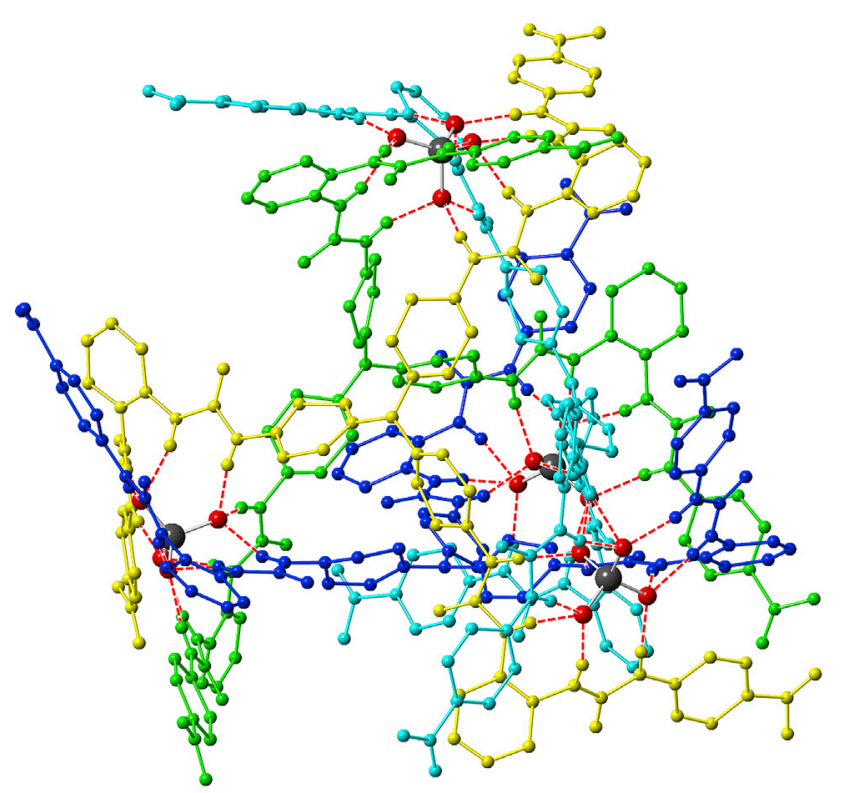

Figure 52. Self-Assembly of Tetrahedral Anion Cage Directed by Phosphate Anions (A) Self-assembly of the $\mathrm{A}_{4} 154_{4}$ tetrahedral anion cage from phosphate anions and ligand 154.

(B) The X-ray crystal structure of $\left[\left(\mathrm{PO}_{4}\right)_{4} 154_{4}\right]^{12-}$. Most hydrogen atoms are omitted for clarity.

the C-ring 162 decreased the chloride-transport activities of these prodigiosenes. UV-Vis studies in 1:1 $\mathrm{CH}_{3} \mathrm{CN}$ :water $(0.1 \mathrm{M} \mathrm{NaCl})$ at $25^{\circ} \mathrm{C}$ correlated the change in transport activities to the $p K_{a}$ values of protonated prodigiosenes $\left(p K_{a} \sim 6.5-7.4\right)$ rather than with $159\left(\mathrm{p} K_{\mathrm{a}} \sim 8.2\right.$ ). Nonetheless, most of the synthetic prodigiosenes are still excellent transporters, and the in vitro studies against a wide range of 59-60 malignant cell lines have shown that these analogs retain good anti-cancer properties in comparison with the natural product 159.

Tambjamines (e.g., 163f) are naturally occurring marine alkaloids structurally similar to prodigiosenes with an enamine moiety in place of the pyrrole $\mathrm{C}$-ring and can also facilitate transmembrane $\mathrm{H}^{+} / \mathrm{Cl}^{-}$cotransport. Hernando et al. ${ }^{81}$ continued with the 


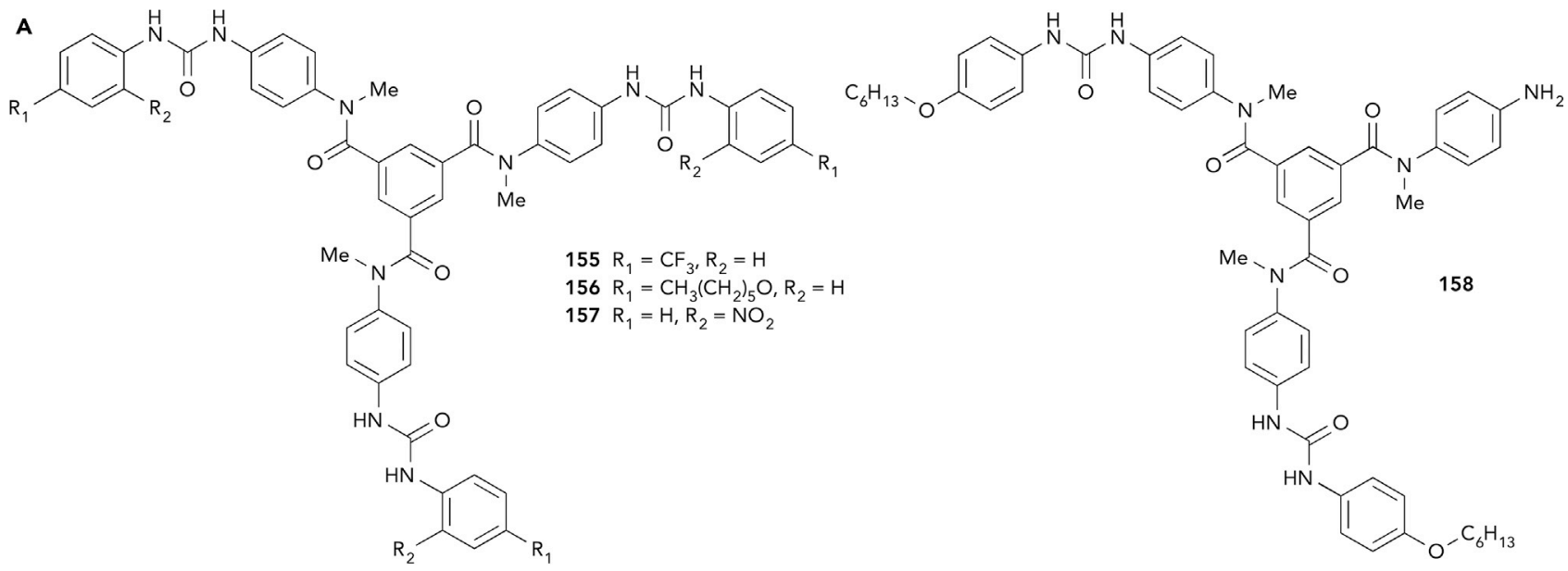

B

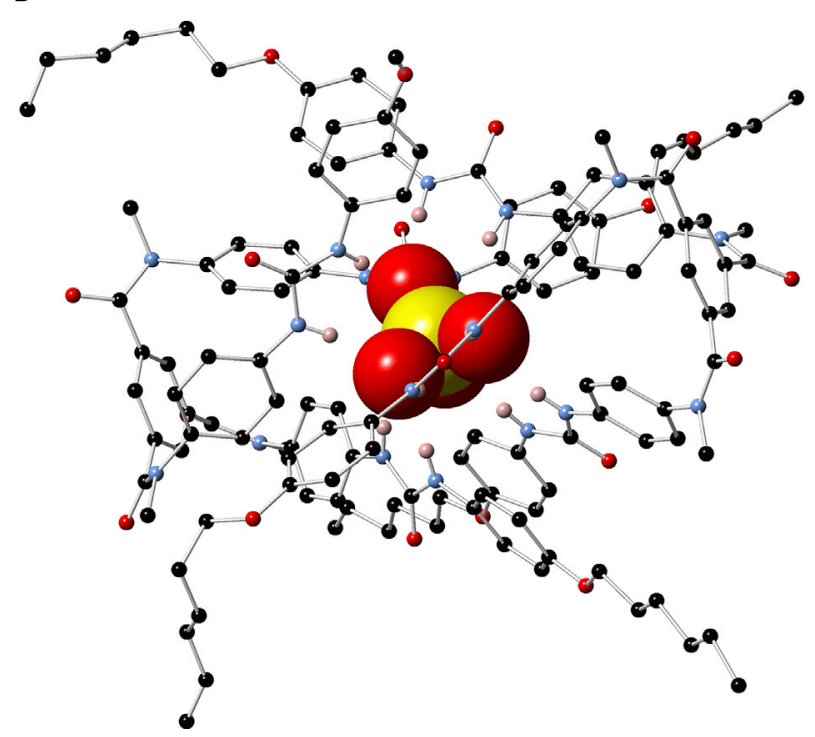

C

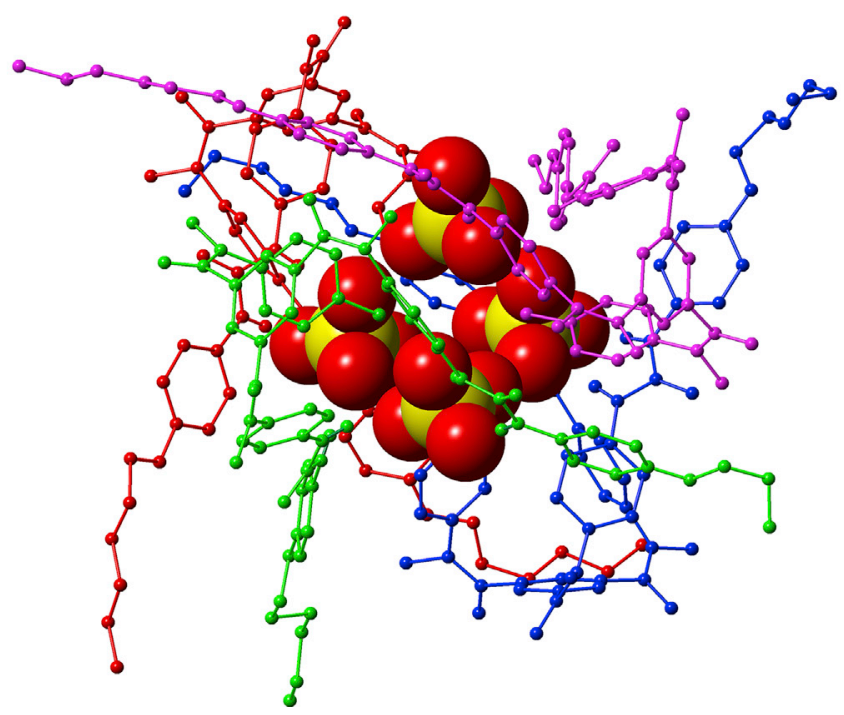

Figure 53. Self-Sorting and Self-Assembly of a 4:4 Tripodal Urea:Sulfate Cage

(A) Tripodal receptors 155-157 and bis-urea 158.

(B) The X-ray crystal structure of the 2:1 complex formed between receptor 156 and $\mathrm{SO}_{4}{ }^{2-}$.

(C) The X-ray crystal structure of $\left[\left(\mathrm{SO}_{4}{ }^{2-}\right)_{4} \cdot(158 \cdot \mathrm{H})_{4}\right]$ shows encapsulation of the four sulfate anions. Most hydrogen atoms are omitted for clarity.

study of synthetic tambjamine analogs (163 and 164; Figure 55), afforded in the form of hydrochloride salts, and have reported that these compounds with aromatic substituents are highly efficient transmembrane transporters for $\mathrm{Cl}^{-} / \mathrm{NO}_{3}{ }^{-}$and $\mathrm{Cl}^{-}$/ $\mathrm{HCO}_{3}{ }^{-}$exchange in POPC liposome, monitored by a chloride ion selective electrode (ISE) in phosphate buffer at $\mathrm{pH} \mathrm{7.2,} \mathrm{in} \mathrm{comparison} \mathrm{with} \mathrm{the} \mathrm{natural} \mathrm{product}$ 163f. In vitro studies of an MTT assay indicated that anti-cancer activities of OBn analogs 164 are more cytotoxic than the respective OMe compounds 163 . Further biological studies using acridine orange (a $\mathrm{pH}$-sensitive fluorescent stain) and Hoechst 33342 (a nucleic acid fluorescent stain) staining techniques revealed that the $\mathrm{pH}$ dissipation of the acidic intracellular organelles correlated with the antiproliferative activity of these compounds, and they underwent an apoptotic cell-death mechanism. 


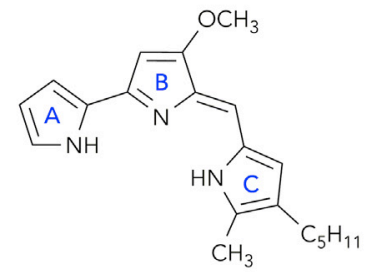

159

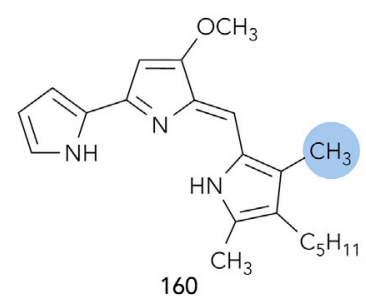

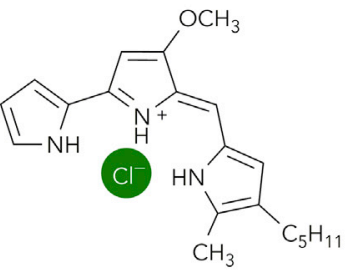

159. $\mathrm{H}^{+} \supset \mathrm{Cl}^{-}$

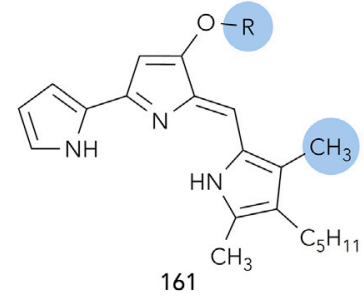

161a $R=B n$

161b $\mathrm{R}=\mathrm{Ph}$

161c $\mathrm{R}=\mathrm{p}-\mathrm{Me}-\mathrm{Ph}$

161d $\mathrm{R}=\mathrm{p}-\mathrm{MeO}-\mathrm{Ph}$

161e $\mathrm{R}=\mathrm{p}-\mathrm{NMe}_{2}-\mathrm{Ph}$

$161 f \mathrm{R}=\mathrm{p}-\mathrm{CF}_{3}-\mathrm{Ph}$

$161 \mathrm{~g} \mathrm{R}=p-\mathrm{Me}(\mathrm{CO}) \mathrm{Ph}$

$161 \mathrm{~h} \quad \mathrm{R}=\mathrm{p}-\mathrm{Cl}-\mathrm{Ph}$

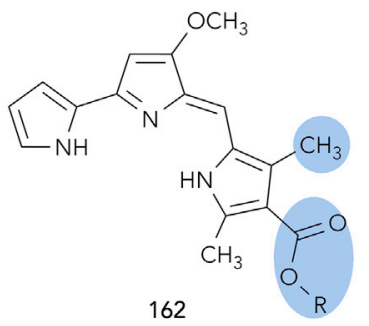

162a $R=M e$

$162 \mathrm{~b} \quad \mathrm{R}=\mathrm{i}-\mathrm{Pr}$

$162 \mathrm{c} R=\mathrm{Bu}$

162d $\mathrm{R}=\mathrm{C}_{5} \mathrm{H}_{11}$

162e $\mathrm{R}=\mathrm{C}_{6} \mathrm{H}_{13}$

$162 f \mathrm{R}=\mathrm{C}_{8} \mathrm{H}_{17}$

$162 \mathrm{~g} \mathrm{R}=\mathrm{C}_{13} \mathrm{H}_{27}$

$162 \mathrm{~h} \quad \mathrm{R}=\mathrm{C}_{14} \mathrm{H}_{29}$

162i $\mathrm{R}=\mathrm{C}_{15} \mathrm{H}_{31}$

162j $\mathrm{R}=\mathrm{C}_{16} \mathrm{H}_{33}$

$162 \mathrm{k} R=\mathrm{Bn}$

162l $\mathrm{R}=\mathrm{Ph}$

Figure 54. Structures of Prodigiosin 159 and the Protonated Form of 159 Complexing to a Chloride Anion, and Synthetic Analogs, Prodigiosenes 160-162

More recently, Soto-Cerrato et al. ${ }^{82}$ developed the tambjamine-inspired indolebased alkaloids $165 \mathrm{a}$ and $165 \mathrm{~b}$ (Figure 55) as biologically active anion transporters. Compounds $165 \mathrm{a}$ and $165 \mathrm{~b}$ are highly active transporters, as shown from POPC liposomal $\mathrm{Cl}^{-} / \mathrm{NO}_{3}{ }^{-}$and $\mathrm{Cl}^{-} / \mathrm{HCO}_{3}{ }^{-}$exchange assays monitored by chloride-ISE in phosphate buffer at $\mathrm{pH}$ 7.2. From the acridine orange and SNARF-1 (a pH-sensitive fluorescent dye) studies on human lung adenocarcinoma (A549) cells, 165a and 165b were both able to dissipate the $\mathrm{pH}$ gradient of acidic organelles and induce significant acidification of the cytoplasmic $\mathrm{pH}(\mathrm{pHi})$ with $0.33 \pm 0.10$ and $0.70 \pm$ $0.22 \mathrm{pH}$ units, respectively. Studies from POPC liposome with safranin $\mathrm{O}$ (a membrane-potential-sensitive dye) and patch-clamped studies of A549 cells transfected with voltage-sensitive fluorescent proteins (VSFP2.32) inferred that 165a and 165b were able to induce membrane potential in POPC liposomes and hyperpolarization of cellular plasma membrane. Furthermore, $165 \mathrm{a}$ and $165 \mathrm{~b}$ have both demonstrated cytotoxicity on different cancer cells and loss of stemness characteristics on cancer<smiles>[R]NC=C1[N-]C(c2ccc[nH]2)=CC1OC</smiles>

163a $R=P h$

163b $R=p-{ }^{t} \mathrm{Bu}-\mathrm{Ph}$

$163 c \mathrm{R}=\mathrm{p}-\mathrm{CF}_{3}-\mathrm{Ph}$

163d R $=$ p-MeO-Ph

163e $R=\cdots\langle\langle\rangle$

$163 R={ }^{i} \operatorname{Pr}($ tambjamine $C)$

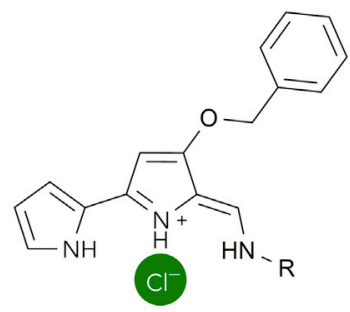

164a $\mathrm{R}=\mathrm{Ph}$

164b $R=p-{ }^{t} \mathrm{Bu}-\mathrm{Ph}$

$164 c \mathrm{R}=\mathrm{p}-\mathrm{CF}_{3}-\mathrm{Ph}$

164d $\mathrm{R}=p-\mathrm{MeO}-\mathrm{Ph}$

164e $R=\cdots\langle$<smiles>[R]NC=C1[N-]C(c2cc3ccccc3[nH]2)=CC1OC</smiles>

165a $\mathrm{R}=\left(\mathrm{CH}_{2}\right)_{2} \mathrm{Ph}$

$165 \mathrm{~b} R=$ hexyl

$165 \mathrm{c} \mathrm{R}=\left(\mathrm{CH}_{2}\right)_{2} \mathrm{OH}$

Figure 55. Structures of Tambjamine Transporters 163-164 as Hydrochloride Salts and Synthetic Indole-Based Tambjamine Transporters 165 as Hydrochloride Salts 

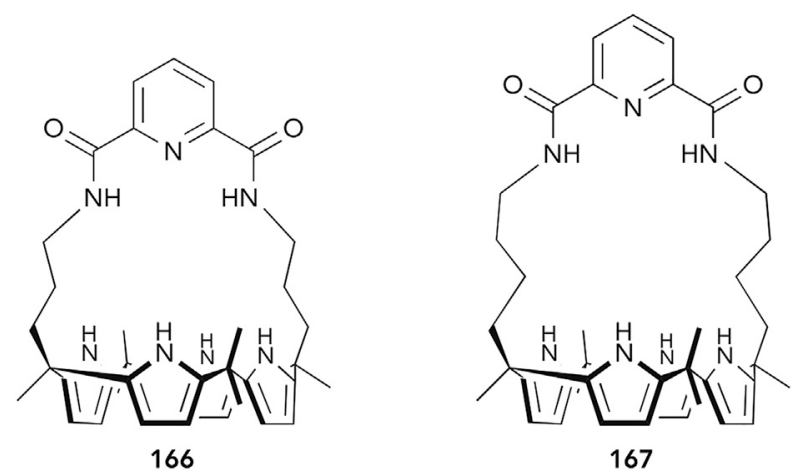

Figure 56. Structures of Diamide-Strapped Calixpyrroles 166 and 167

stem cells leading to selective elimination of the affected population. The less lipophilic 165c displayed modest transport activity and has been used as a control compound showing negligible activity in all in vitro studies, hence supporting that the biological activities of $165 \mathrm{a}$ and $165 \mathrm{~b}$ are a result of the anion-transport activity.

Ko et al. ${ }^{83}$ have shown that diamide-strapped calixpyrroles 166 and 167 (Figure 56) can mediate chloride anion transport coupled to sodium cation flux in both POPC liposomal models (in the presence of monensin cationophore) and cells, measured from several different assays. The combination of ion-transport studies in yellow fluorescent protein (YFP)-expressing Fischer rat thyroid (FRT) epithelial cells, plus A549 and HeLa cells with SBFI-AM (a sodium fluorescent probe), confirmed that transporters 166 and 167 can mediate $\mathrm{Cl}^{-}$transport in cells, coupled to the sodium influx predominantly via cellular $\mathrm{Na}^{+}$channels. Flow cytometry measurements with annexin V, propidium iodide, and JC-1 inferred that transporters 166 and 167 induced apoptotic cell death with the loss of membrane potential. The resulting cell death mediated by the transporters was strongly dependent on the presence of both $\mathrm{Cl}^{-}$and $\mathrm{Na}^{+}$in the extracellular media, indicating that transporters 166 and 167 dysregulate the steady-state cellular equilibrium by facilitating $\mathrm{NaCl}$ influx. Further cell studies have shown that transporters 166 and 167 can promote the generation of reactive oxygen species, induce the release of cytochrome $c$ from the mitochondria, and trigger apoptosis via a caspase-dependent pathway.

The urea and thiourea motifs have proven to be an effective anion-binding site in the design of transmembrane anionophores. Olivari et al. ${ }^{84}$ reported a series of bismethylurea compounds 168-169 with aromatic substituents (Figure 57). Although both trifluoromethyl $\left(\mathrm{CF}_{3}\right)$ and nitro $\left(\mathrm{NO}_{2}\right)$ are electron-withdrawing groups, the fluorination from $\mathrm{CF}_{3}$ substituents improves the lipophilicity of the compounds. Interestingly, the bis-methylurea 169 c bearing a pyridine core was shown to be the most effective transporter in this series of compounds for both $\mathrm{Cl}^{-} / \mathrm{NO}_{3}{ }^{-}$and
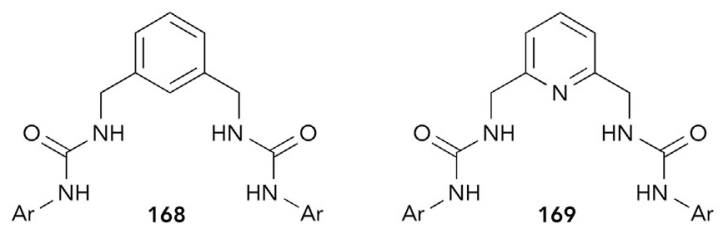

(a)<smiles>FC(F)(F)c1ccc(CBr)cc1</smiles>

(c)

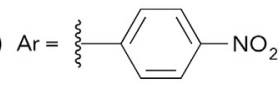

(b)<smiles>FC(F)(F)c1cc(C=[Te])cc(C(F)(F)F)c1</smiles>

Figure 57. Structures of Bis-methylureas 168 and 169

Aromatic analogs a-c for receptors 168 and 169 . 


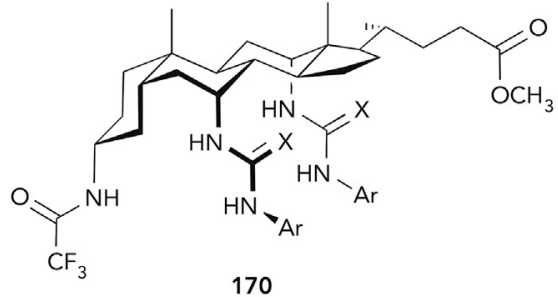

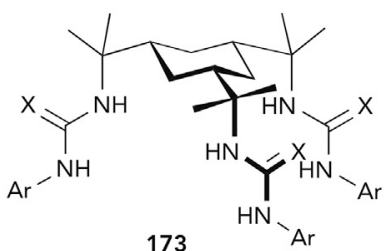
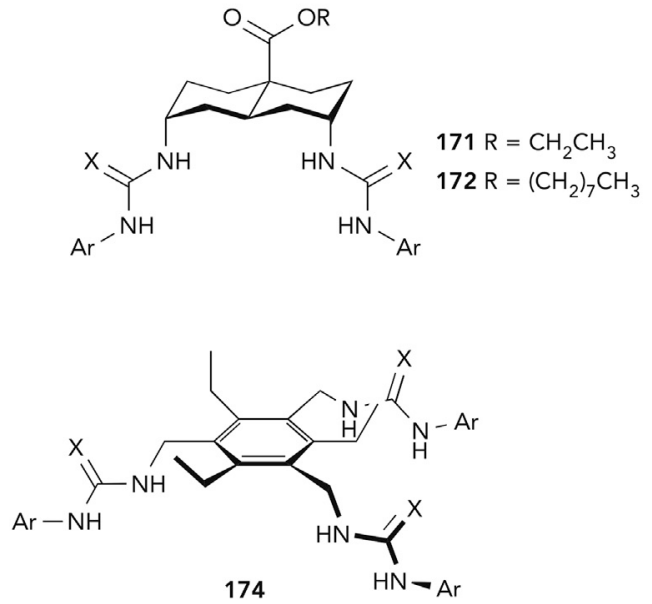

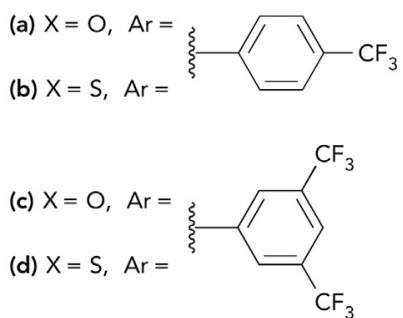

(e) $\mathrm{X}=\mathrm{O}, \mathrm{Ar}=$

(f) $\mathrm{X}=\mathrm{S}, \mathrm{Ar}=$

Figure 58. Structures of Bis/Tris(urea/thiourea) Appended to Different Scaffolds Cholapod 170, trans-decalin 171 and 172, cyclohexane 173, and triethylbenzene 174.

Substituents a-f are shown on the right.

$\mathrm{Cl}^{-} / \mathrm{HCO}_{3}{ }^{-}$exchange in POPC large unilamellar vesicles (LUVs), determined by chloride-ISE in phosphate buffer at $\mathrm{pH}$ 7.2. In addition, the study of $\mathrm{Cl}^{-} / \mathrm{NO}_{3}{ }^{-}$exchange in POPC:cholesterol (7:3) liposomes suggests that this class of anionophore functions as a mobile carrier in facilitating the transport of anions.

Valkenier et al. ${ }^{85,86}$ continued with the development of anionophores based on several different scaffolds with preorganized urea or thiourea anion-binding motifs with electron-withdrawing aromatic substituents, namely the cholapods 170, trans-decalin 171 and 172, cyclohexane 173, and triethylbenzene 174 (Figure 58). The transmembrane anion-transport activities of these anionophores were studied with a $\mathrm{Cl}^{-} / \mathrm{NO}_{3}{ }^{-}$exchange assay in POPC:cholesterol (7:3) LUVs (mean diameter $200 \mathrm{~nm}$ ) with lucigenin and pre-incorporated compounds in the vesicles. Transporters bearing the thiourea anion-binding motifs were expectedly more effective than urea in all the different scaffolds, presumably because the thiourea sulfurs have lower surface charge densities and are poorer hydrogen-bond acceptors than urea oxygens. Decalin 172d emerged as the most powerful transporter ever to be reported from Davis's group, and the transport efficiency among the more effective anionophores is in the order of $172 d>171 d>170 b>170 f>170 d>173 d>174 d$. The common trend among the decalin 171 and 172, cyclohexane 173, and triethylbenzene 174 scaffolds is the thioureido analogs, and the 3,5-bis(trifluoromethyl) phenyl substituent is the most effective transporter within each scaffold series. This is a result of the stronger chloride binding affinity rendered by the most electron-withdrawing aromatic group. Interestingly, the cholapod scaffold deviates from this trend; $170 \mathrm{~d}$, which had the highest chloride-binding affinity $\left(10^{10} \mathrm{M}^{-1}\right.$, measured in $\mathrm{CHCl}_{3}$ by a modified Cram's extraction method) among all the transporters, did not translate to better transport activity. This is possibly because the binding of chloride was too strong, causing the decomplexation step to be rate-limiting in the overall transport process. See later discussions on bis(squaramide)cholapods 188-193 for more examples in which binding affinity exceeds an upper limit and suppresses transmembrane transport activity.

Valkenier et al. ${ }^{87}$ further utilized their most effective anionophore trans-decalin $172 \mathrm{~d}$ in the study of anion-transport activity with lucigenin in POPC:cholesterol (7:3) giant 
no transporter

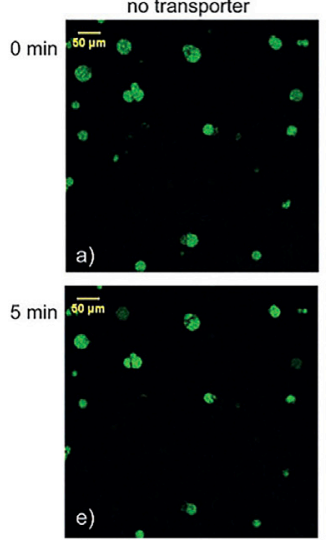

$0.01 \%$ transporter
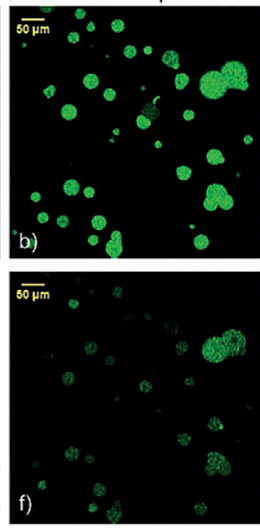

$0.04 \%$ transporter

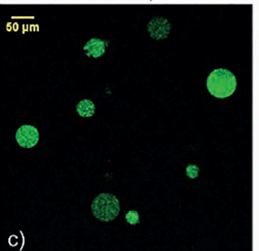

$\overline{60 \mathrm{um}}$

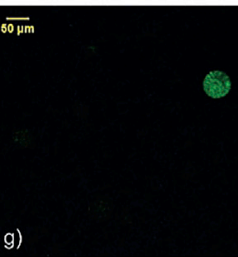

$0.1 \%$ transporter

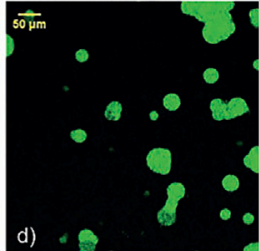

$\overline{50 \mu m}$

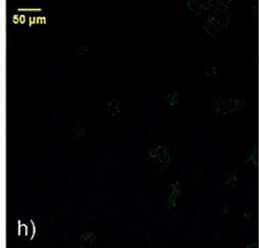

Figure 59. Confocal Fluorescence Microscopy Images of GUVs Pre-incorporated with Lucigenin and Anionophore 172d

Concentrations of $172 \mathrm{~d}$ are relative to the total lipid concentration in $\mathrm{NaNO}_{3}(225 \mathrm{mM})$ and sucrose (200 mM, internal) or glucose (200 mM, external) aqueous solutions (A-D) before and (E-H) $5 \mathrm{~min}$ after the addition of $\mathrm{NaCl}(25 \mu \mathrm{L}, 1.0 \mathrm{mM})$ to initiate the $\mathrm{Cl}^{-} / \mathrm{NO}_{3}{ }^{-}$exchange transport process. Scale bars represent $50 \mu \mathrm{m}$. Reprinted with permission from Valkenier et al. ${ }^{87}$ (c) 2015 The Authors. Published by Wiley-VCH Verlag GmbH \&Co. KGaA.

unilamellar vesicles (GUVs, 20-60 $\mu \mathrm{m}$ ), similar to cell-sized vesicles. The fluorescence quenching of lucigenin caused by the influx of chloride is evident from confocal fluorescence microscopy studies (Figure 59), with the distinctive dose-response relationship of 172d, similar to the fluorescence spectrometry studies in LUVs. In addition, GUV studies using lissamine-rhodamine-B-labeled lipid gave further insights into multilamellar giant vesicles (rather than unilamellar vesicles) affecting (slowing down) anion transport, hence enabling more reliable measurements on the rate of transport from individual vesicles.

Busschaert et al. ${ }^{88}$ reported the transmembrane transport of highly hydrophilic sulfate anions facilitated by tris(thiourea) receptors 175 and 176 (Figure 60) with high binding affinity toward sulfate $\left(>10^{4} \mathrm{M}^{-1}\right)$ determined by ${ }^{1} \mathrm{H}-\mathrm{NMR}$ titration studies in $\mathrm{DMSO}-d_{6} / 0.5 \%$ water. The rate of transmembrane sulfate transport was monitored by a $\mathrm{Cl}^{-} / \mathrm{SO}_{4}{ }^{2-}$ exchange assay in POPC LUVs (mean diameter $200 \mathrm{~nm}$ ) using two different indirect methods with chloride-ISE and lucigenin in phosphate buffer at $\mathrm{pH}$ 7.2. The tren-based tris(thiourea) 175 is a better $\mathrm{SO}_{4}{ }^{2-}$ transporter because of the

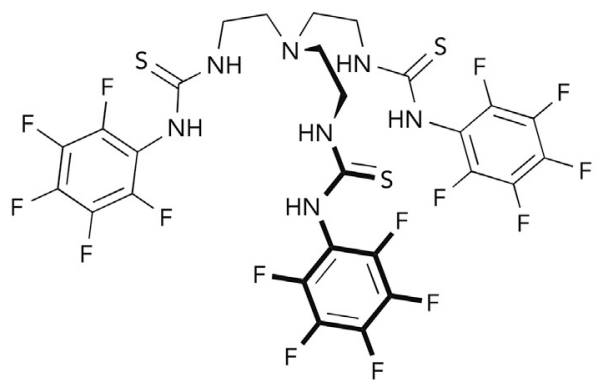

175

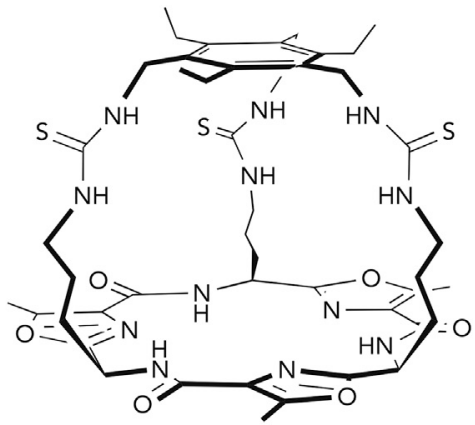

176

Figure 60. Structures of Tris(thiourea)pentafluorophenyl Tren-Based Receptor 175 and Triethylbenzene-Capped Cryptand 176 
A

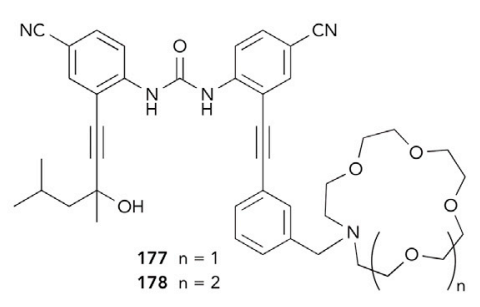

B

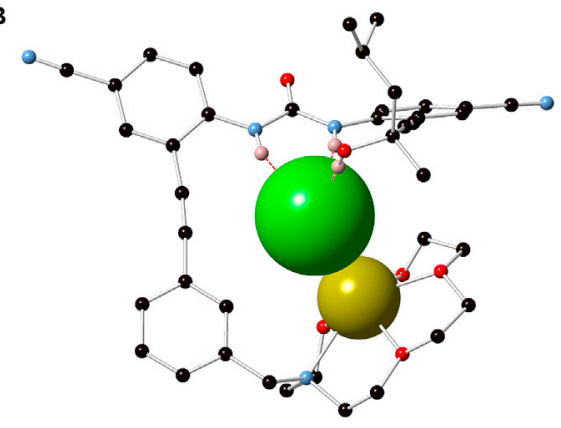

Figure 61. Urea-Azacrown lon-Pair Symporters

(A) General structure of urea-azacrown selective $\mathrm{M}^{+} / \mathrm{Cl}^{-}$symporters 177 and 178 .

(B) The single-crystal structure of $177 \cdot \mathrm{NaCl}$. Most hydrogen atoms and dichloromethane molecule are omitted for clarity.

more ideal lipophilicity (c $\log P=7.87$ ) than 176 (c $\log P=0.71)$; furthermore, the urea analog of 175 can also transport $\mathrm{SO}_{4}{ }^{2-}$ with slightly lower activity. Direct evidence of sulfate transport was shown by ${ }^{33} \mathrm{~S}-\mathrm{NMR}$ experiments using $\mathrm{Mn}^{2+}$ and $\mathrm{Fe}^{3+}$ paramagnetic agents with ${ }^{33} \mathrm{~S}$-labeled $\mathrm{SO}_{4}{ }^{2-}$ in giant POPC vesicles.

Lee et al. ${ }^{89}$ reported two urea-azacrown ion-pair receptors 177 and 178 as symporters for metal cations and chloride anions. The single-crystal structure of $177 \cdot \mathrm{NaCl}$ (Figure 61B) showed the bound $\mathrm{NaCl}$ as a contact ion pair. In the ${ }^{1} \mathrm{H}$ NMR titration studies with tetrabutylammonium chloride, the presence of sodium perchlorate or potassium hexafluorophosphate enhanced the binding of chloride anions by one order of magnitude in a $\mathrm{CD}_{3} \mathrm{CN} / \mathrm{CD}_{3} \mathrm{OH}(9: 1, \mathrm{v} / \mathrm{v})$ mixture. The $\mathrm{M}^{+} / \mathrm{Cl}^{-}$symport mechanism of 177 and 178 was established with POPC liposomal-based studies in phosphate buffer at $\mathrm{pH}$ 7.2. Compound 177 showed higher activity for $\mathrm{NaCl}$ symport over $\mathrm{LiCl}, \mathrm{KCl}, \mathrm{RbCl}$, and $\mathrm{CsCl}$, whereas 178 induced the cotransport of $\mathrm{KCl}$ at a significantly faster rate, and the individual transport rates of $\mathrm{K}^{+}$and $\mathrm{Cl}^{-}$were shown to be similar when monitored with potassium-ISE and chloride-ISE, respectively.

Choi et al. ${ }^{90}$ continued their work on anion transport using two urea and thiourea binding motifs appended to the photoresponsive diazobenzene scaffold (Figure 62). Proton NMR titration studies with tetrabutylammonium chloride in DMSO- $d_{6} / \mathrm{CDCl}_{3}$ $(1: 9, v / v)$ with $0.1 \%$ water showed a clear trend of stronger binding toward the cis-isomers than the corresponding trans-isomers by one order of magnitude. The binding affinity was enhanced with the electron-withdrawing phenyl substituents, such as $179 \mathrm{f}\left(1300 \mathrm{M}^{-1}\right), 179 \mathrm{~g}\left(2,800 \mathrm{M}^{-1}\right)$, and $180\left(5,900 \mathrm{M}^{-1}\right)$; furthermore, meta-positioned receptors resulted in stronger binding to $\mathrm{Cl}^{-}, 181\left(8,400 \mathrm{M}^{-1}\right)$, and $182\left(>10^{4} \mathrm{M}^{-1}\right)$ compared with $179 \mathrm{~g}$ and 180 . Although the transport activities for trans-isomers are negligible, the more encapsulated binding effect by the cis-isomers resulted in moderate to high $\mathrm{Cl}^{-} / \mathrm{NO}_{3}{ }^{-}$antiport activities in POPC LUVs with strong correlation to the $\mathrm{Cl}^{-}$binding affinities. In situ isomerization of 180 from trans to cis, resulting in the transport process "switching on" was demonstrated after irradiation with UV (365 nm) light for $20 \mathrm{~s}$. In cells, cis-181 and cis-182 were active in facilitating chloride influx of YFP-transfected FRT cells monitored from the halide fluorescence quenching of YFP.

Monosquaramides (e.g., 183) have shown to be excellent anion-binding receptors and transmembrane $\mathrm{Cl}^{-}$transporters. Wu et al. ${ }^{91}$ have developed a dynamic 

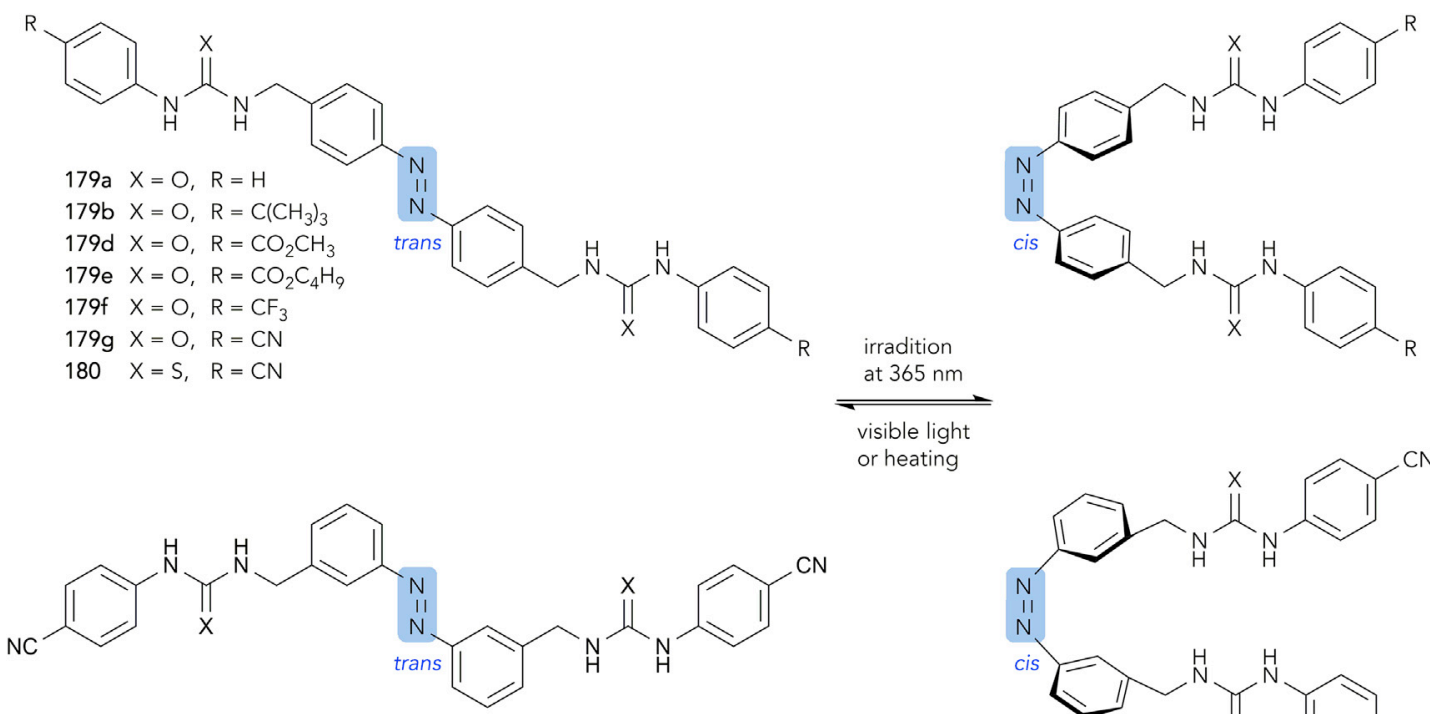

$181 X=0$

$182 \times=S$

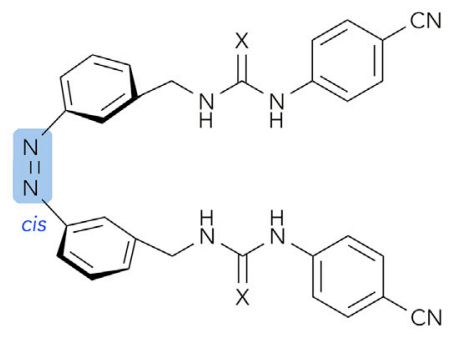

Figure 62. Structures of Bis(urea/thiourea) Diazobenzene-Based Chloride Anion Transporters 179-182

covalent chemistry approach to facilitate transmembrane transport of amino acids (Figure 63). The transport of amino acids was monitored by several techniques, such as ${ }^{13} \mathrm{C}$-NMR in POPC giant multilamellar vesicles with ${ }^{13} \mathrm{C}$-labeled glycine and fluorescence spectrometry using calcein $\left(\mathrm{C} \mathrm{Cu}^{2+}\right.$-sensitive fluorescent probe), 8-hydroxypyrene-1,3,6-trisulfonic acid (HPTS, a pH-sensitive dye), and osmotic response at $90^{\circ}$ light scattering, in POPC LUVs. The transport of amino acids was facilitated by the formation of hemiaminal or imine with a lipophilic benzaldehyde and the binding of squaramide 183 toward the carboxylate motif, followed by an exchange antiport process with $\mathrm{OH}^{-}$. The more lipophilic benzaldehydes 184 and 185 were more effective at facilitating the transport of glycine in the presence of 183 than in the presence of 186 and 187.

Recognizing the strong binding and transmembrane anion-transport capabilities of squaramides, Edwards et al. ${ }^{92}$ developed the bis-squaramide receptors 188 193 (Figure 64) with a rigid preorganized steroidal scaffold. The binding affinities toward chloride anion were measured in $\mathrm{CHCl}_{3}$ using a modified $\mathrm{Cram}$ 's extraction method using tetrabutylammonium chloride, and shown to be remarkably strong, with a correlation in binding affinities to the acidities of the $\mathrm{NH}$ hydrogen-bond donors, $188\left(4.8 \times 10^{10} \mathrm{M}^{-1}\right)<189\left(1.6 \times 10^{11} \mathrm{M}^{-1}\right)<190$ $\left(2.9 \times 10^{13} \mathrm{M}^{-1}\right)<191\left(4.5 \times 10^{13} \mathrm{M}^{-1}\right)<192\left(1.2 \times 10^{14} \mathrm{M}^{-1}\right)<193(1.2 \times$ $\left.10^{14} \mathrm{M}^{-1}\right)$. Notably, the chloride binding stability constants of these steroidal squaramide receptors are the highest reported from neutral anion receptors. The transmembrane anion-transport activities of these compounds were studied with a $\mathrm{Cl}^{-} / \mathrm{NO}_{3}{ }^{-}$exchange assay in POPC:cholesterol (7:3) LUVs (mean diameter $200 \mathrm{~nm})$, with lucigenin $(0.8 \mathrm{mM})$ and compounds pre-incorporated in the vesicles at a receptor:lipid ratio of 1:2,500. Contrary to previous studies of cholapod-thiourea receptors, stronger binding with chloride did not result in better transport activity. The $\mathrm{Cl}^{-} / \mathrm{NO}_{3}{ }^{-}$exchange efficacies mediated by compounds 189-193 were attenuated with similar half-lives of 110-150 s. This suggests that the remarkably strong binding affinities have exceeded an upper limit where any 
<smiles>O=c1c(Nc2cc(C(F)(F)F)cc(C(F)(F)F)c2)c(Nc2cc(C(F)(F)F)cc(C(F)(F)F)c2)c1=O</smiles>

183<smiles>O=Cc1cc(C(F)(F)F)cc(C(F)(F)F)c1</smiles><smiles>O=Cc1ccc(C(F)(F)F)cc1C(F)(F)F</smiles>

185<smiles>C[C@H](N)C(=O)O</smiles><smiles>CNCC(=O)O</smiles>

alanine

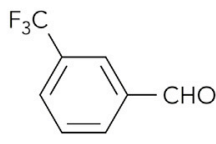

186<smiles>O=Cc1ccc(C(F)(F)F)cc1</smiles>

187

sarcosine

B

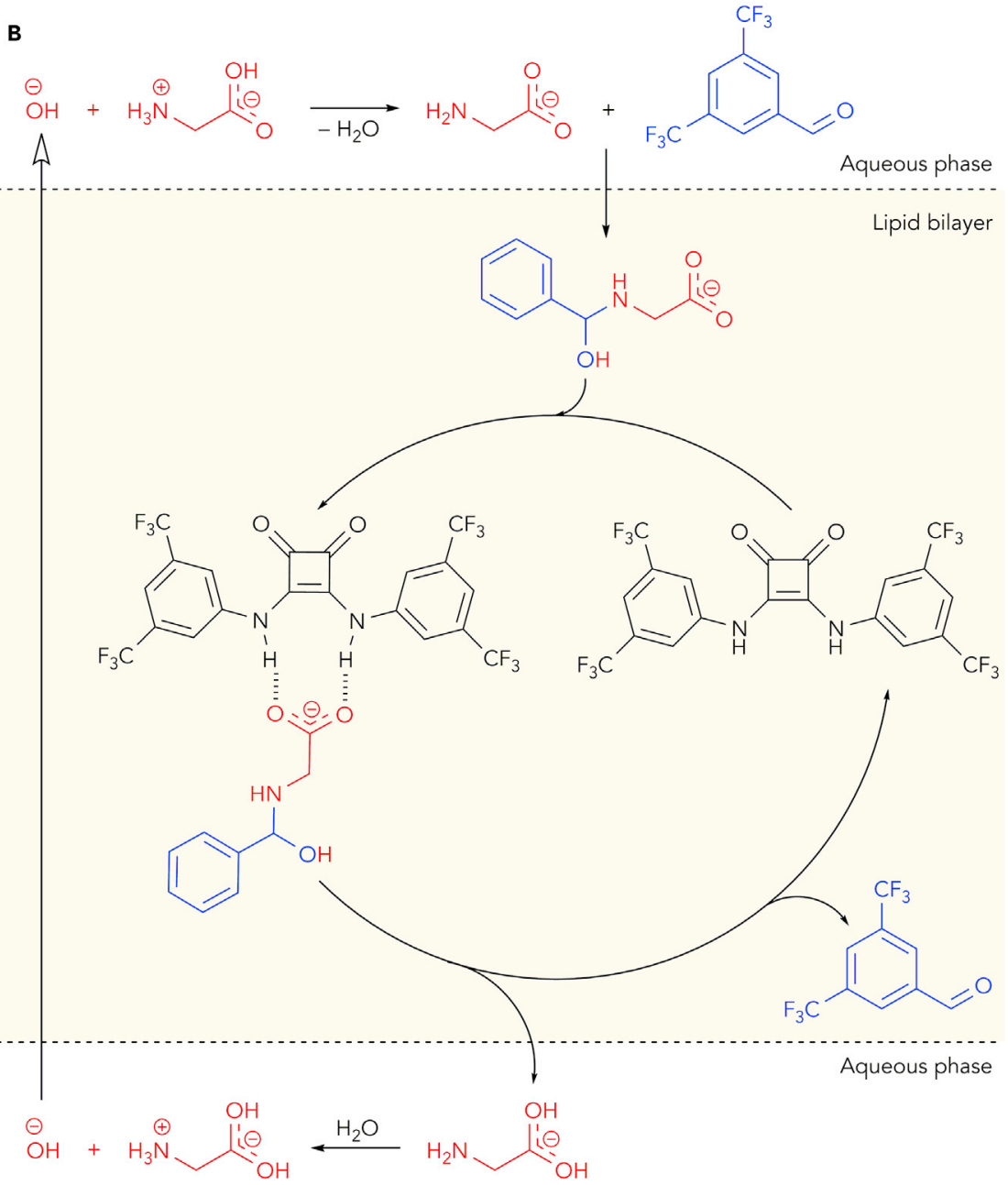

Figure 63. Dynamic Covalent Transport of Amino Acids

(A) Structures of squaramide anionophore 183, lipophilic benzaldehydes 184-187, and amino acids.

(B) Mechanism of transmembrane glycine transport utilizing hemiaminal or imine dynamic covalent chemistry (imine formation and $\mathrm{OH}^{-}$transport facilitated by 183 are not shown). 

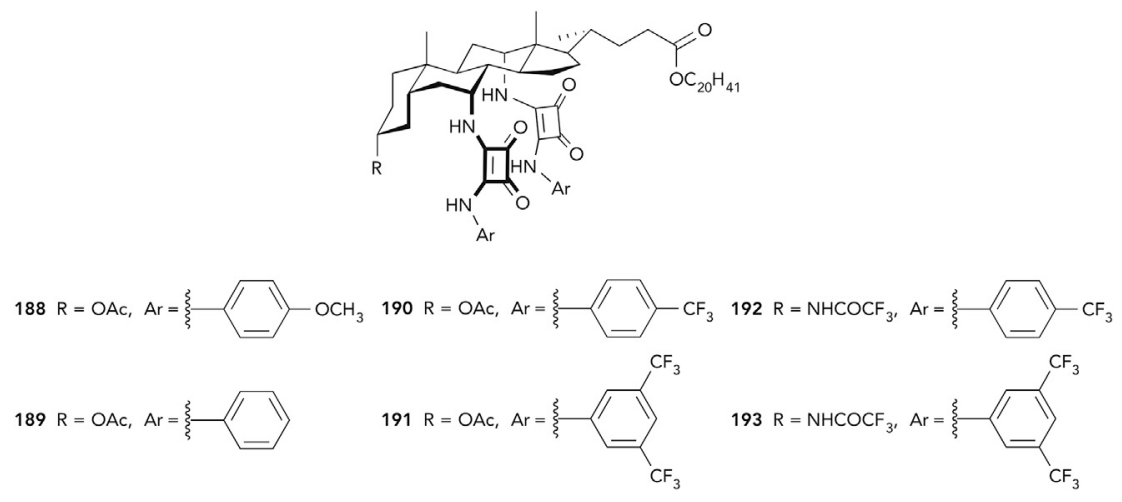

Figure 64. Structures of Steroidal Squaramide Receptors 188-193

further increase in binding strength is unproductive for transmembrane transport activity.

The syntheses of a series of thiosquaramides ${ }^{93} 194-197$ and an oxothiosquaramide ${ }^{94} 198$ that function as $\mathrm{pH}$-dependent anion transporters have been reported (Figure 65). Titration binding studies with tetrabutylammonium chloride by ${ }^{1} \mathrm{H}-\mathrm{NMR}$ in DMSO- $d_{6} / 0.5 \%$ water, fitted to a $1: 1$ binding model, derived the $K_{\mathrm{a}}$ of thiosquaramides 194-197 $\left(60-400 \mathrm{M}^{-1}\right)$ and oxothiosquaramide $198\left(470 \mathrm{M}^{-1}\right)$. The $\mathrm{pH}$-dependent chloride anion-transport activities were determined using the POPC liposomal $\mathrm{Cl}^{-} / \mathrm{NO}_{3}{ }^{-}$exchange assay, monitored by chloride-ISE in phosphate buffer at $\mathrm{pH} 7.2$ and citrate buffer at pH 4.0. Whereas thiosquaramides 196 and 197 were inactive in both neutral and acidic media because lipophilicities were too high, compounds 194, 195, and 198 were significantly more active at $\mathrm{pH} 4.0$ than at $\mathrm{pH}$ 7.2. $\mathrm{pH}$-spectrophotometric titration studies in $\mathrm{CH}_{3} \mathrm{CN} / \mathrm{H}_{2} \mathrm{O}$ $(9: 1, \mathrm{v} / \mathrm{v})$ demonstrated that the $\mathrm{NH}$ hydrogen-bond donors of these receptors were much more acidic than the respective analogous oxosquaramides. The derived $\mathrm{p} K_{\mathrm{a}}$ values of 194 (7.3), $195(5.3)$, and 198 (6.6) provide evidence that these receptors were mainly deprotonated as negatively charged species at neutral $\mathrm{pH}$, hence transport activities were enhanced at $\mathrm{pH} 4.0$ with the receptors in the neutral state. In addition, $\mathrm{H}^{+} / \mathrm{Cl}^{-}$symport (or the equivalent $\mathrm{OH}^{-} / \mathrm{Cl}^{-}$antiport) induced by these receptors was demonstrated by a POPC liposomal assay using LUVs loaded with HPTS (ratiometric $\mathrm{pH}$ probe).

Kuchelmeister et al. ${ }^{95}$ have continued with the development of cationic peptidic tweezers conjugated to guanidinocarbonyl pyrrole moiety (GCP) 199 (Figure 66) for DNA binding and delivery into cells, subsequently leading to transfection. By screening a combinatorial library of 259 solid-phase-bound molecular tweezers
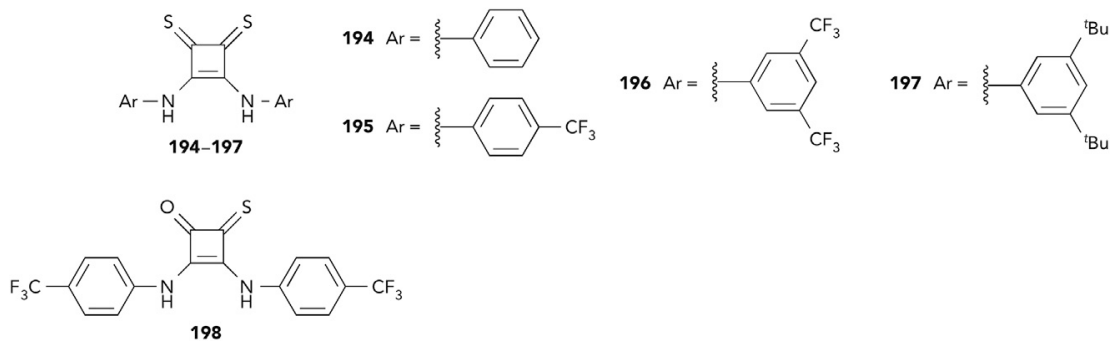

Figure 65. Structures of Thiosquaramides 194-197 and an Oxothiosquaramide 198 


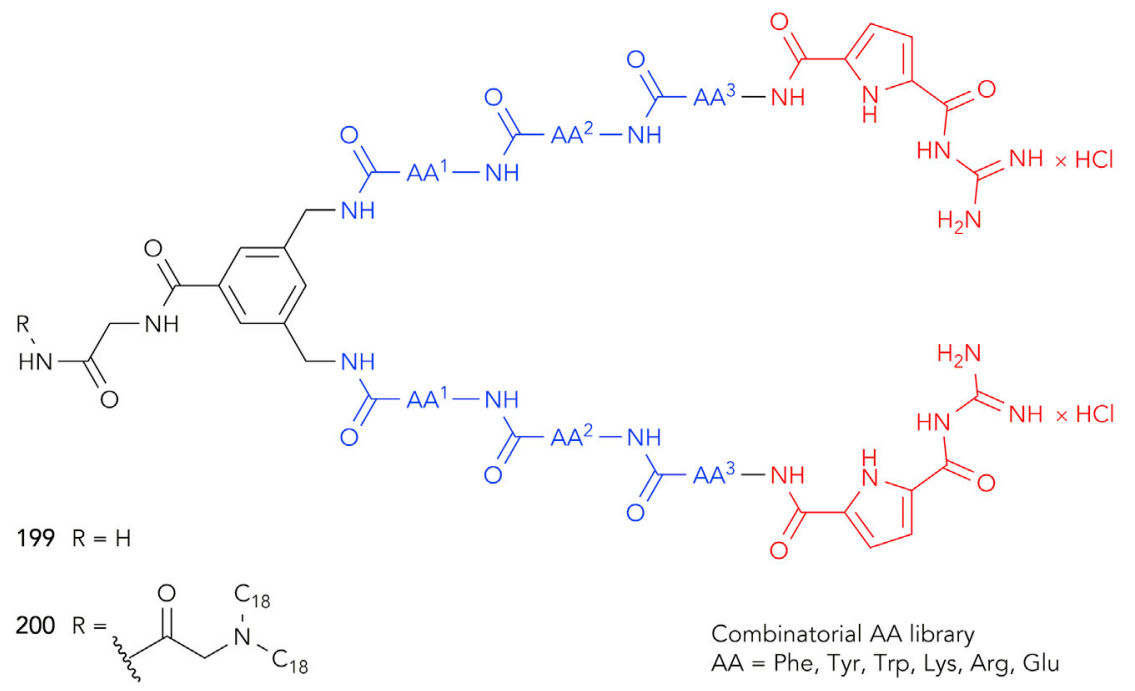

Figure 66. Peptidic Tweezers as Efficient Vectors for Gene Delivery

The general structure of a combinatorial library of 259 molecular tweezers 199 and 200 bears two identical peptide sequence (blue; amino acids, $A A^{1}-A A^{3}$ ) tethered to guanidinocarbonyl pyrrole anion-binding motifs (red).

binding toward the plasmid pF143-GFP (6,238 base pairs) using an ethidium bromide displacement assay, it was identified that sequences containing Trp or Tyr gave higher affinity. This is possibly because both amino acids are able to intercalate into DNA, and the aromaticity may also contribute to van der Waals interactions. The molecular tweezers of Trp-Arg-Lys-GCP (199a) and Trp-Lys-Arg-GCP (199b) emerged with the highest affinities, and the DNA binding of the free receptors was further measured by ITC experiments in sodium cacodylate buffer $(0.01 \mathrm{M})$ at pH 7 with pF143-GFP, which produced two binding events. The first binding step was endothermic and entropically driven, attributed to the unspecific backbone charge interactions, with moderate binding constants $\left(K_{\mathrm{a} 1}\right)$ of $\sim 10^{5} \mathrm{M}^{-1}$; the second step was exothermic, resulting from specific complexation with DNA, with strong binding constants $\left(K_{\mathrm{a} 2}\right)$ of $5.5 \times 10^{8} \mathrm{M}^{-1}$ for $199 \mathrm{a}$. Interestingly, despite the high DNA binding affinity, the transfection experiments conducted with HEK293T cells with a mixture of pF143-GFP plasmid DNA and GCP tweezers gave poor results (6-7\%). This was a result of endosomal trapping of the DNA upon delivery into cells by the tweezers, however this was successfully circumvented by attaching two lipophilic C18 alkyl chains to transform these cationic tweezers into lipid amphiphiles 200. The resulting transfection efficiencies were greatly improved, most notably for Trp-Arg-Lys-GCP 200a with transfection activity of $88 \%$.

The anion transporters that have been discussed so far possess conventional $\mathrm{NH}$ or $\mathrm{OH}$ hydrogen-bond donors for the binding of anion to facilitate transmembrane transport. A recent development by Shang et al. ${ }^{96}$ utilize the $\mathrm{CH}$ hydrogen bond of aryl-triazole foldmers 201 and 202 to facilitate anion translocation across lipid bilayer membranes. The single-crystal structure of 201 demonstrated conformational preorganization of the foldamer via intramolecular hydrogen bonds between amide $\mathrm{NHs}$ and the triazole $\mathrm{N}^{2}$ and $\mathrm{N}^{3}$ atoms, and aryl-CHs and amide carbonyl oxygen atoms (Figure 67B). Compound 202 has a lesser degree of preorganization and was confirmed from the free rotation of the triazoles, observed from 2D nuclear Overhauser effect spectroscopy NMR studies in $\mathrm{CDCl}_{3}$. Proton NMR titration studies of 201 in $\mathrm{CD}_{2} \mathrm{Cl}_{2}$ and 202 in $\mathrm{CDCl}_{3}$ with tetrabutylammonium chloride demonstrated 
A

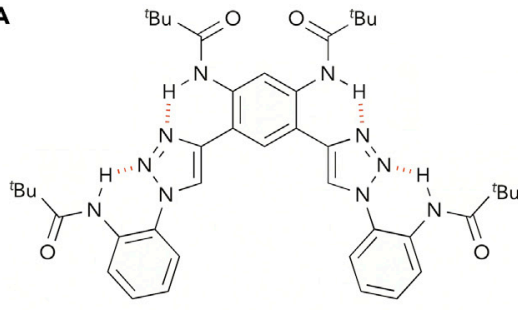

201

B

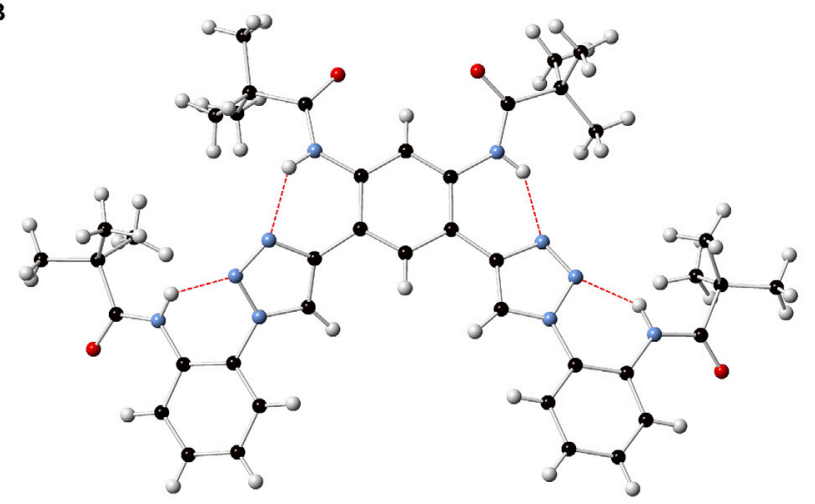

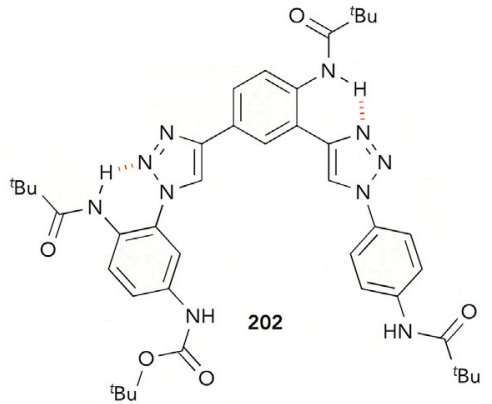

Figure 67. Preorganized Aryltriazole Foldamers as Transmembrane Chloride Transporters

(A) Structures of preorganized aryl-triazole foldmers 201 and 202

(B) The single-crystal structure of 201.

downfield shifts of the triazole-CHs and the inner facing aryl-CHs of the preorganized cleft, with binding constants of $757 \mathrm{M}^{-1}$ and $91 \mathrm{M}^{-1}$, respectively. Transmembrane chloride transport studies using EYPC LUVs loaded with $\mathrm{KCl}(100 \mathrm{mM})$ and lucigenin, suspended in HEPES buffer at $\mathrm{pH} 7.0$ and in the presence of valinomycin $(0.002 \%$, receptor-lipid concentration), demonstrated superior transport activity (with loading of $0.75 \%$, receptor-lipid concentration) facilitated by compound 201 with 97\% chloride efflux; transport activity induced by compound 202 was only $39 \%$.

Wang et al. ${ }^{97}$ developed a series of oxacalix[2]arene[2]triazone-based ion-pair transporters 203-207. The single-crystal structure of the complex of 207 and tetraethylammonium bromide revealed the anion bound to the receptor via two hydrogen bonds and anion- $\pi$ interaction from a triazine ring (Figure 68B). Studies from the $\mathrm{Cl}^{-} / \mathrm{NO}_{3}{ }^{-}$exchange assay in EYPC LUVs with lucigenin $(1.0 \mathrm{mM})$ demonstrated an activity trend of $203>204>205>206$, with no observable transport activity for 207, correlated to a combination of lipophilicities of the receptors and the electron-withdrawing effect of the substituents. Furthermore, the association constants from the fluorescence titration binding studies with tetrabutylammonium chloride in acetonitrile followed the order of the surface potential ( $\pi$-deficiency) of the triazine rings, $203\left(3.6 \times 10^{4} \mathrm{M}^{-1}\right), 204\left(3.6 \times 10^{3} \mathrm{M}^{-1}\right), 205\left(2.4 \times 10^{4} \mathrm{M}^{-1}\right)$, and $206(1.2 \times$ $\left.10^{4} \mathrm{M}^{-1}\right)$. Interestingly, mechanistic studies of the transport process revealed an $\mathrm{Na}^{+} / \mathrm{Cl}^{-}$symport process facilitated by the receptors, with a strong influence of the countercations. Chloride transport activities were enhanced with the increase in cation radii $\left(\mathrm{Li}^{+}<\mathrm{Na}^{+}<\mathrm{K}^{+}<\mathrm{Rb}^{+} \approx \mathrm{Cs}^{+}\right.$) for compounds 203, 205, and 206, whereas a reversed trend was observed for receptor 204. 
A

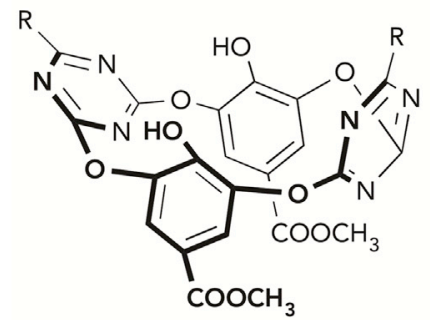

203<smiles>CC(C)(C)c1ccc(C(F)(F)F)cc1</smiles>

205

$204 \mathrm{R}=\xi \mathrm{N}$

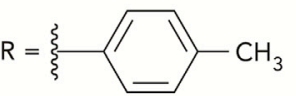

B

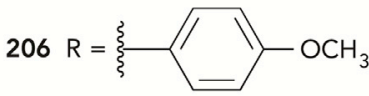

$207 \mathrm{R}=\xi-\mathrm{OCH}_{3}$

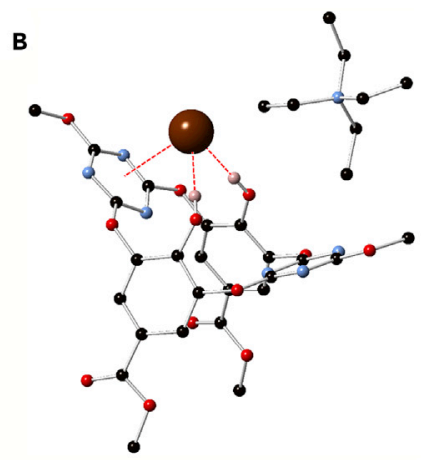

Figure 68. Oxacalix[2]arene[2]triazine Ion-Pair Symporters

(A) General structure of oxacalix[2]arene[2]triazone-based ion-pair transporters 203-207.

(B) The single-crystal structure of the complex of 207 and tetraethylammonium bromide. Most hydrogen atoms are omitted for clarity.

Vargas Jentzsch and Matile ${ }^{98}$ continued exploring halogen bond interactions in transmembrane anion transport by tethering tetrafluoroiodobenzenes on the rigid p-oligophenyl scaffold to form linear arrays of halogen bond donors. Transmembrane anion-transport activity was determined from a liposomal-based assay using EYPC LUVs loaded with HPTS ( $\mathrm{pH}$-sensitive dye). A base pulse was applied to generate a $\mathrm{pH}$ gradient; the rate of $\mathrm{pH}$ gradient dissipation mediated by the transporter from the $\mathrm{Cl}^{-} / \mathrm{OH}^{-}$exchange was measured. The linear halogen-bonding arrays 208-211 were 3.5-26 times more active than the analogous arrays of anion- $\pi$ interactions 212-215. Furthermore, the derived cooperativity coefficient ( $m$, typical range $=1<m<2$ ) from the intrinsic multivalency contributions of the linear arrays of halogen bond donors was remarkably good, resulting in an unprecedented $m=3.37$, whereas the anion- $\pi$ interaction arrays gave a respectable cooperativity coefficient of 2.13. This quantitative evidence supports the anion-hopping transport mechanism facilitated by the transmembrane halogen-bonding cascades, as illustrated in Figure 69B. Despite the considerable synthetic efforts expended in making these compounds, which might limit their practical application, the halogen-bondhopping mechanism demonstrated here represents a conceptual advance in anion transport. Moreover, different anion selectivity profiles from those of hydrogenbond-based transporters may be expected.

Gravel et al. ${ }^{99}$ have developed a reversibly controllable chloride transporter, based on adamantyl-functionalized imidazolium bis(fluoromethylsulfonyl)amide $\left(\mathrm{NTf}_{2}\right)$ salt (Figure 70A), with inhibition controlled by the inclusion of $\beta$-cyclodextrins ( $\beta$-CyD). The single-crystal structure of the $216 \cdot(\beta-C y D)_{2}$ complex (Figure $70 \mathrm{~B}$ ) and ${ }^{1} \mathrm{H}-\mathrm{NMR}$ Job plot analysis in $\mathrm{D}_{2} \mathrm{O} / \mathrm{CD}_{3} \mathrm{CN}(1: 1, \mathrm{v} / \mathrm{v})$ confirmed the $1: 2$ inclusion of $\beta-C y D$, and strong positive cooperativity binding constants of $K_{11}\left(400 \mathrm{M}^{-1}\right)$ and $K_{12}$ $\left(1800 \mathrm{M}^{-1}\right)$ were derived from the NMR titration studies. Transmembrane-transport studies from a $\mathrm{Cl}^{-} / \mathrm{NO}_{3}{ }^{-}$exchange assay in EYPC LUVs with lucigenin (2.0 mM) in phosphate buffer at $\mathrm{pH} 6.2$ demonstrated the decrease in transport activity mediated by 216 (20\%, receptor:lipid concentration) with the addition of $\beta$-CyD; at 4 equiv of $\beta-C y D$, the transport process was completely inhibited. Although the inhibition mechanism is due to the fast formation of an inclusion complex of $\beta-C y D$ with adamantyl-functionalized imidazolium during transport, a reverse process to restore transport activity can be modulated by the addition of competitive adamantane guests. The addition of 1 -adamantaneethanol (5 equiv) emerged as the best adamantane analog to form the inclusion complex with $\beta-C y D$ to 
A

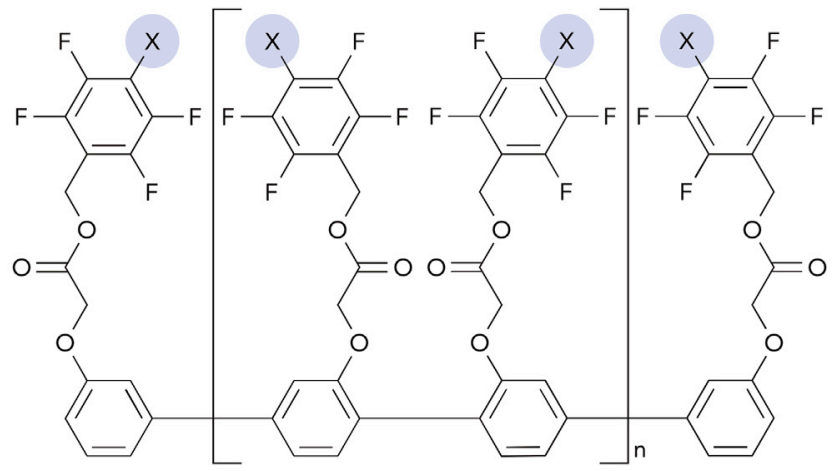
$208 x=1, n=0$
$212 X=F, n=0$
$209 x=1, n=1$
$213 X=F, n=1$
$210 X=1, n=2$
$214 X=F, n=2$
$211 X=1, n=3$
$215 X=F, n=3$

B

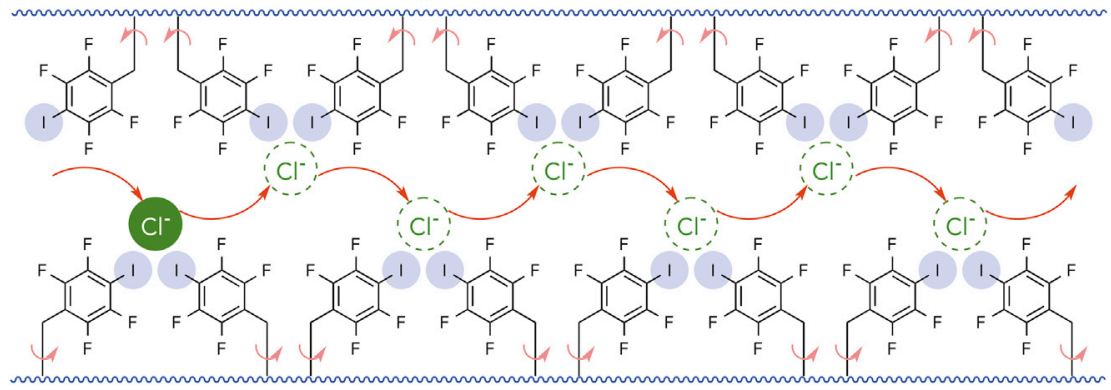

Figure 69. Transmembrane Chloride Transport Mediated by Halogen-Bonding Cascades (A) General structures of halogen-bond donors in linear arrays 208-211 and the controls for anion- $\pi$ interactions 212-215.

(B) Schematic illustration of anion hopping mediated by transmembrane halogen-bonding cascades.

immediately release 216 and restore transport activity. The reversible chloride transport process was also demonstrated in a black lipid membrane bilayer experiment composed of 1,2-diphytanoyl-sn-glycero-3-phosphocholine (DPhPC). These transporters require very high concentrations to induce observable anion transport; therefore, they are not suitable for biological applications. Nevertheless, the work demonstrated the potential of reversibly switching transport activity by using hostguest chemistry.
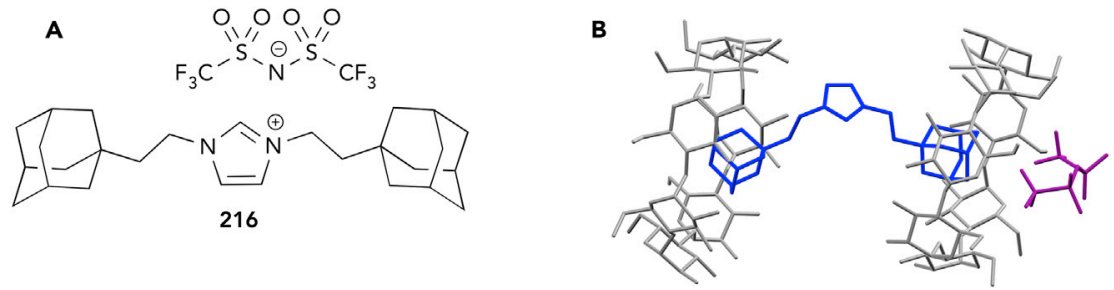

Figure 70. Adamantyl-Functionalized Imidazolium as a Reversible Chloride Transporter (A) Structure of adamantyl-functionalized imidazolium NTf 2 salt 216.

(B) The single-crystal structure of $216 \cdot(\beta-C y D)_{2}$ complex. Colors: imidazolium ${ }^{+}$, blue; $\mathrm{NTf}_{2}{ }^{-}$, purple; and $\beta$-CyD, gray. All hydrogen atoms and the solvent molecules are omitted for clarity. 


\section{CATALYSIS}

Anion-receptor-directed catalysis is a relatively new concept in non-covalent organocatalysis; however, this approach has received a tremendous amount of attention and interest over the last few years. Wasa et al. ${ }^{100}$ continue to develop the application of chiral thiourea catalyst 217 in the asymmetric Mannich synthesis of amino esters 220 (Scheme 8). In this work, the tertiary aminothiourea catalyst (10 mol \%), in the presence of $4 \AA$ molecular sieves at $-30^{\circ} \mathrm{C}_{\text {in }} \mathrm{CH}_{2} \mathrm{Cl}_{2}$, afforded the Mannich product 220 in $90 \%$ yield and $93 \%$ ee, from an $\alpha$-chloroglycine ethyl ester 218 of a carboxybenzyl (CBz)-protecting group and dibenzoylmethane 219. Thiourea catalysts without a tertiary amino group gave no desired product, and substrates of other protecting groups (compared with $\mathrm{CBz}$ ) resulted in poorer overall yield and enantioselectivity. The stoichiometric $\mathrm{HCl}$ byproduct of the reaction had a detrimental effect on the catalyst by forming a salt with its tertiary amine. This was circumvented by adding trimethylamine $(25 \mathrm{~mol} \%)$ to regenerate the active catalyst. The authors proposed two mechanistic pathways: (1) an imine formation pathway involving the non-covalent interaction of thiourea with the iminoester and (2) a more plausible pathway in which the thiourea catalyst abstracts chloride from $\alpha$-chloroglycine ethyl ester 218.

Zhao et al. ${ }^{101}$ reported the first example of using rhodium-bisphosphine catalyst assisted by thiourea 221 in the asymmetric hydrogenation of unprotected $\mathrm{NH}$ imines (Scheme 9), affording 99\% conversion and 94\% ee with 1 mol \% catalyst (Rh-catalyst:221 ratio $=1: 1.1$ ), and a slightly lower $95 \%$ conversion and $94 \%$ ee with a much lower catalyst loading of $0.2 \mathrm{~mol} \%$. The robustness of this catalytic system was demonstrated with various imine substrates 222 of different meta and para $\left(-\mathrm{CH}_{3},-\mathrm{F},-\mathrm{Cl}\right)$ substitutions on the phenyl ring or a naphthyl aromatic group, affording high yields and enantioselectivities. Various analogs of thiourea 221 were studied; notably, replacing $-\mathrm{CF}_{3}$ with $-\mathrm{CH}_{3}$ on the phenyl ring gave $76 \%$ conversion and $90 \%$ ee; the use of an urea analog afforded $22 \%$ conversion and $66 \%$ ee; and the absence of an anion-binding motif gave only $2 \%$ conversion and $55 \%$ ee. Furthermore, when the chloride counteranion was replaced with trifluoromethanesulfonate, the optimal catalytic system gave an inferior $20 \%$ conversion and $53 \%$ ee. These<smiles>CN(C)[C@@H]1CCCC[C@H]1NC(=S)Nc1cc(C(F)(F)F)cc(C(F)(F)F)c1</smiles>

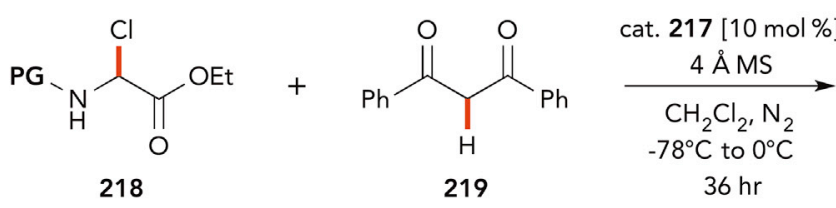<smiles>CCOC(=O)C(NC(=O)c1ccccc1)C(C(=O)c1ccccc1)C(=O)c1ccccc1</smiles> 

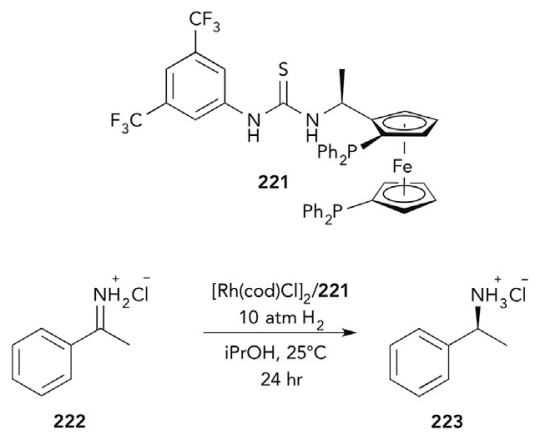

Scheme 9. Rhodium- and Bisphosphine-Catalyzed Asymmetric Hydrogenation of Unprotected NH Imine 222, Assisted by Thiourea 221

results show the significant effect of anion-binding-directed catalysis of thiourea 221 in this system.

Mittal et al. ${ }^{102}$ continued the development of a dual-catalysis anion-binding approach for asymmetric nucleophilic catalysis by generating the chiral acylating reagent in situ, composed of the acylating reagent with 4-dimethylaminopyridine (DMAP) and a chiral anion receptor (Scheme 10A). To amplify subtle differences in all the studies, 0.5 equiv of acylating reagent was used, hence $50 \%$ was the maximum

A<smiles>CN(C)c1ccncc1</smiles>

nucleophilic catalyst

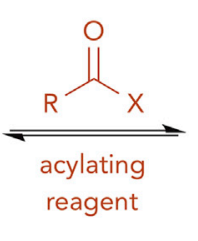

Ion pair I achiral

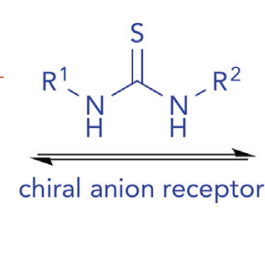<smiles>[R2]NC(=S)N[Y]([Y])([H])[H]</smiles>

Ion pair II

chiral

B<smiles>CC(N)c1ccccc1</smiles><smiles>O=C(OC(=O)c1ccccc1)c1ccccc1</smiles>

DMAP [5 mol \%] $\underset{\text { thiourea [5 mol \%] }}{\stackrel{\mathrm{PhCH}_{3}, 4 \AA \mathrm{MS}}{\longrightarrow}}$ $-78^{\circ} \mathrm{C}, 2 \mathrm{hr}$

$227( \pm)$ 0.5 equiv.<smiles>C[C@H](NC(=O)c1ccccc1)c1ccccc1</smiles>

C<smiles>CC(N)c1ccccc1</smiles>

$227( \pm)$<smiles>[R]C([X])=O</smiles>

0.5 equiv.

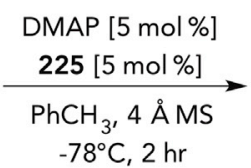

$-78^{\circ} \mathrm{C}, 2 \mathrm{hr}$<smiles>[R]C(=O)N[C@@H](C)c1ccccc1</smiles>

228

Scheme 10. Dual-Catalysis Anion-Binding Approach

(A) Generating the chiral acylating reagent composed of the acylating reagent with DMAP and a chiral anion receptor 224-226.

( $B$ and $C$ ) Kinetic resolution of benzylic amine 227 via benzoylation. 

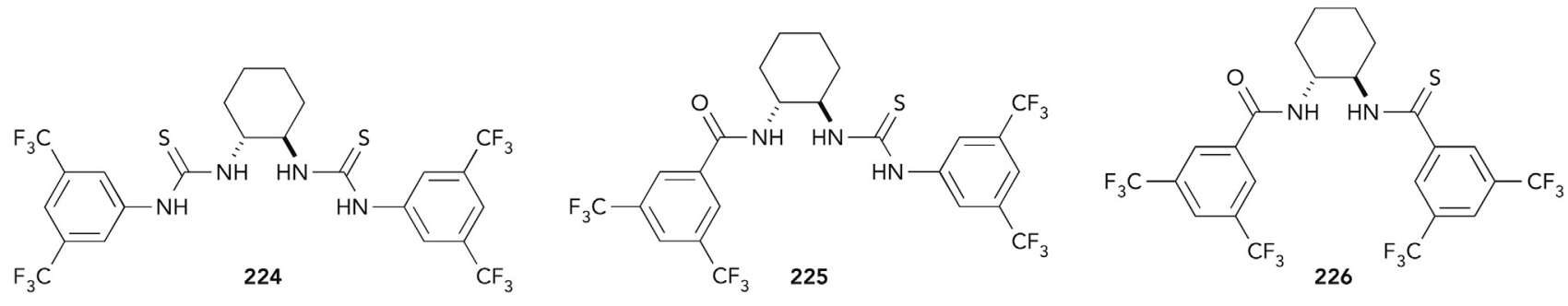

Figure 71. Structures of Chiral Anion Receptors 224-226

conversion. At $5 \mathrm{~mol} \%$ loading for both DMAP and a chiral anion receptor catalyst 224-226 (Figure 71), the benzoylation of 227 (Scheme 10B) with catalyst 224 afforded a selectivity factor (s-factor) of 8.5 (44\% conversion), whereas catalyst 225 gave an improved s-factor of 13.0 (41\% conversion). Studies from various chiral receptor catalysts found that the 3,5-bis(trifluoromethyl)phenyl thiourea moiety is crucial; for instance, receptor $226 \mathrm{did}$ not afford any selectivity (s-factor $=1.0$, $22 \%$ conversion). Interestingly, higher catalyst loading (10 mol \%) of 225 and DMAP gave better conversion (50\%) but compromised the selectivity (s-factor = 8.6), and this was caused by an aggregation effect of 225 shown by ${ }^{1} \mathrm{H}-\mathrm{NMR}$ studies in $\mathrm{CDCl}_{3}$. Benzoylation with benzoyl fluoride, chloride, or bromide (Scheme 10C) demonstrated the preference of the smallest halide for better selectivity, hence supporting the proposed mechanism of the ion-pairing effect depicted in Scheme 10A. Additional computational studies using DFT methods provided further insights into the experimental preference for the benzoylation of $R$-configured benzylic amine 227.

The oxidation of carbon monoxide to carbon dioxide or carbonate ions is normally catalyzed by metal complexes in homogeneous systems or on surfaces of metal oxide materials. Nava et al. ${ }^{103}$ demonstrated that a synthetic anion receptor, cavitand 229, can mediate the oxidation of carbon monoxide by peroxide anion without a metal catalyst (Scheme 11). The authors found that treatment of the $\left[(T B A)_{2}\right]\left[229 \cdot \mathrm{O}_{2}{ }^{2-}\right]$ complex with $\mathrm{CO}$ in THF/DMF $(10: 1, \mathrm{v} / \mathrm{v})$ mixture led to quantitative formation of the $\left[(\mathrm{TBA})_{2}\right]\left[229 \cdot \mathrm{CO}_{3}{ }^{2-}\right]$ complex, in which the carbonate ion was encapsulated by nine $\mathrm{N}-\mathrm{H}$ hydrogen bonds. The same carbonate complex could be generated by treatment of the monodeprotonated cryptand with $\mathrm{HCO}_{3}{ }^{-}$, free cryptand with $\mathrm{K}_{2} \mathrm{CO}_{3}$ slurry, or by exposure of a mixture of the free cryptand and tetrabutylammonium hydroxide with an ambient atmosphere. The authors used isotopic labeling to confirm that the carbon atom of the formed

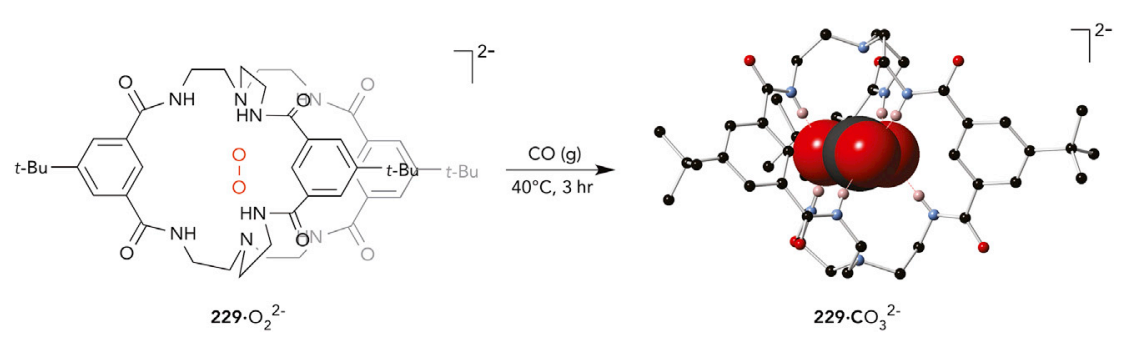

Scheme 11. Transformation of CO to the Carbonate Ion Encapsulated by Receptor 229, Mediated by the 229-Peroxide Anion Complex

The crystal structure of the 229-carbonate complex is shown. Non-interacting hydrogen atoms and counter ions are omitted for clarity. 


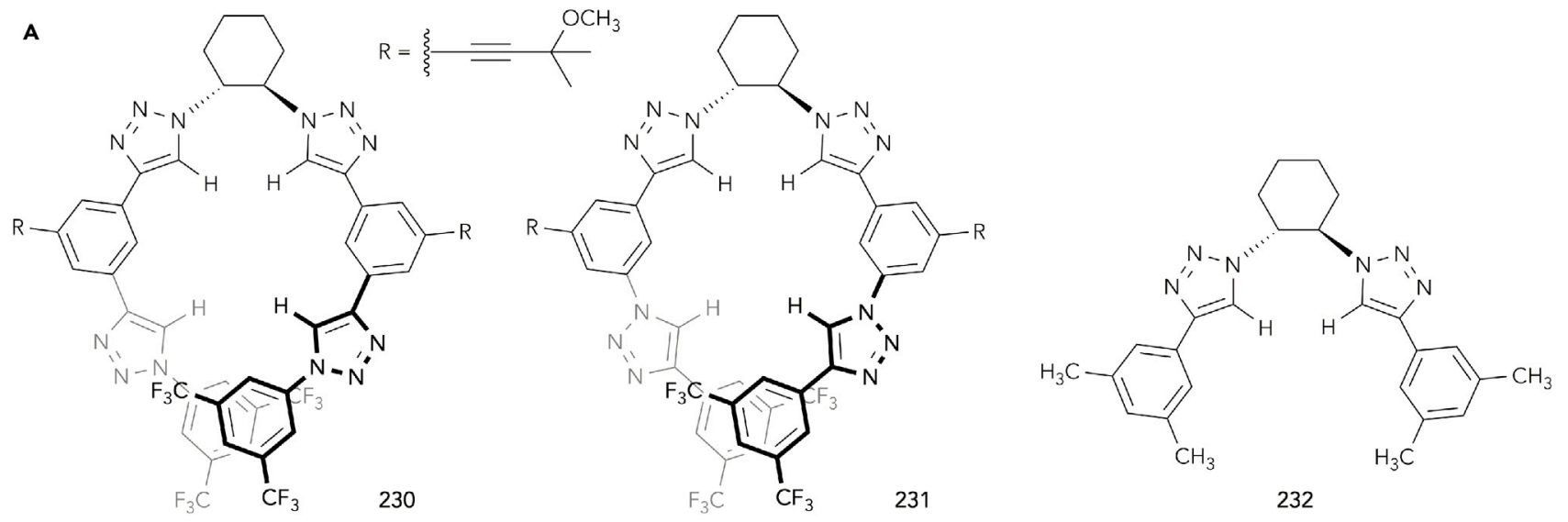

B<smiles>c1ccc2ncccc2c1</smiles>

233

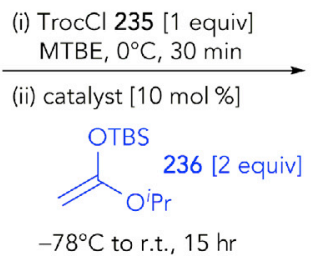<smiles>CCCC(=O)CC1C=Cc2ccccc2N1[O+]</smiles>

234

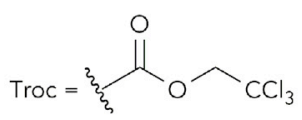

Figure 72. Catalysis with Chiral Helical Oligotriazoles

(A) Structures of chiral anion-binding catalysts: helical tetratriazoles 230-231 and bistriazole 232.

(B) Asymmetric dearomatization of quinoline 233 by $\mathrm{N}$-acyl Mannich addition with 235 and 236 .

carbonate was derived from $\mathrm{CO}$ and two of the oxygen atoms from the peroxide anion in the original complex. In this example, the cryptand served as a solubilizing agent for the reactant peroxide anion and the product carbonate ion, although its possible involvement in the reaction beyond the solubilizing effect remains unclear.

Zurro et al. ${ }^{104}$ have previously introduced chiral bistriazole 232 as a selective chloride anion-binding catalyst; and more recently, they developed chiral helical tetratriazole-based catalysts 230-231 for the asymmetric dearomatization of quinoline 233 via $\mathrm{N}$-acyl Mannich addition. The reaction was carried out in methyl tert-butyl ether, with 2,2,2-trichloroethyl chloroformate 235 as an acylating agent and isopropyl tert-butyldimethylsilyl ketene acetal 236 in the presence of anionbinding catalysts (Figure 72B), and the enantiomeric ratio (er) was determined by chiral high-performance liquid chromatography. The tetratriazole catalysts provided high enantioselectivity with a high yield: $(R, R)-230$ gave $96: 4$ er and a 76\% yield, $(R, R)-231$ gave 95:5 er and an 80\% yield, and enantiomer $(S, S)-230$ gave the opposite enantiomeric product of $\mathbf{2 3 4}$ with a similar level of enantioselectivity (4:96 er) and yield (70\%). Reaction in the presence of chiral bistriazole 232 gave an excellent yield (91\%) but very poor enantioselectivity of 41:59 er; this is presumably due to the non-existence of helical chirality in 232, thus suggesting that the central chirality of the bistriazole motif is not sufficient for asymmetric induction. In addition, the catalytic system of $(R, R)-230$ demonstrated remarkable enantioselectivity robustness in different derivatives of both electron-poor and electron-rich substituted quinolines. Titration studies of $(R, R)$ 230 with $\mathrm{N}$-Troc quinolinium chloride using ${ }^{1} \mathrm{H}-\mathrm{NMR}$ in THF- $d_{6}$ demonstrated downfield shifts of triazole- $\mathrm{CH}$ signals, indicating binding of chloride in the helical 


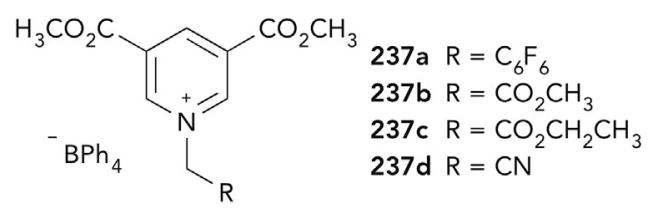

237

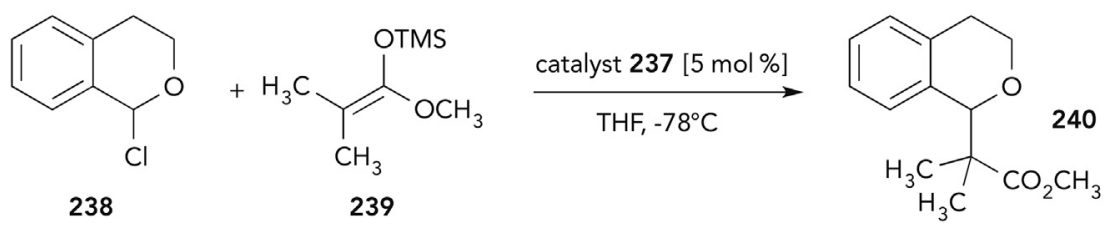

Scheme 12. Catalytic Activity of Pyridinium-BPh ${ }_{4}$ Salts $237 a-237 d$ in the Reaction of 1-Chloroisochroman 238 with Silyl Ketene Acetal 239

cavity. Furthermore, $C D$ titration studies of $(R, R)-230$ with tetrabutylammonium chloride in THF revealed amplification of helical chirality upon binding of the chloride anion.

Berkessel et al. ${ }^{105}$ developed a series of electron-poor 3,5-dicarbomethoxypyridinium tetraphenylborate salts $237 \mathrm{a}-237 \mathrm{~d}$ as an anion-binding catalyst, directed via Coulombic interactions. Proton NMR titration studies of 237 a with tetrabutylammonium chloride in THF- $d_{8} / \mathrm{CD}_{3} \mathrm{CN}(9: 1, \mathrm{v} / \mathrm{v})$ demonstrated a thermodynamic preference for chloride over $\mathrm{BPh}_{4}{ }^{-}$, with a derived association constant of $200 \mathrm{M}^{-1}$. Catalytic activity was evaluated from the alkylation of 1-chloroisochroman 238 by silyl ketene acetal 239 at $-78^{\circ} \mathrm{C}$ in THF (Scheme 12). Although no alkylated product 240 was obtained from the background reaction (without a catalyst), the pyridinium-BPh ${ }_{4}$ salts were indeed effective catalysts, with quantitative conversion of 238 and excellent yield of 240: 237a (90\%), 237b (85\%), 237c (87\%), and 237d (88\%). Unsurprisingly, catalytic inhibition by halide counteranions, such as chloride and bromide, was observed. Several observations indicated that the catalytic activities of pyridinium-BPh 4 salts proceed by ionization of chloride excision from 238 , assisted by Coulombic interaction with the catalyst, and the concomitant formation of the preferred pyridinium- $\mathrm{Cl}$ ion pair.

Zhao et al. ${ }^{106}$ developed the concept of utilizing anion- $\pi$ interactions in catalysis. The established Kemp elimination was utilized to develop this approach with carboxylate-tethered $\pi$-acidic (i.e., positive quadrupole moment) naphthalenediimides (NDIs) 241 and 242 (Figure 73A) at different concentrations and catalyst loading ratios; the reaction was initiated by partial deprotonation of the catalyst with 0.5 equiv of tetrabutylammonium hydroxide, monitored by ${ }^{1} \mathrm{H}-\mathrm{NMR}$ spectroscopy. In neat $\mathrm{CD}_{3} \mathrm{OD}$, significant catalytic activity of NDI 241 was observed, whereas the presence of control NDI 243 and $\pi$-basic (i.e., negative quadrupole moment) pyrene 244 gave negligible activities. The contrasting results between NDIs 241 and 243 demonstrated that optimal geometry of the substrate-catalyst complex and the transition-state stabilization (Figure 73B) are crucial in this catalytic system. Catalytic studies of NDls 241 and 242 in a $\mathrm{CD}_{3} \mathrm{OD} / \mathrm{CDCl}_{3}$ $(1: 1, v / v)$ mixture with Michaelis-Menten analysis revealed better catalytic proficiency from the more $\pi$-acidic NDI 242, as a result of the increased stabilization in both the ground state and transition state of $242\left(\Delta \Delta G_{\mathrm{GS}}=7.1 \mathrm{~kJ} \mathrm{~mol}^{-1}\right.$; $\left.\Delta \Delta G_{\mathrm{TS}}=30.3 \mathrm{~kJ} \mathrm{~mol}^{-1}\right)$, than from $241\left(\Delta \Delta G_{\mathrm{GS}}=6.2 \mathrm{~kJ} \mathrm{~mol}^{-1} ; \Delta \Delta G_{\mathrm{TS}}=\right.$ $28.3 \mathrm{~kJ} \mathrm{~mol}^{-1}$ ). 
A<smiles>[R1]NC(=O)[C@H](CCC(=O)O)N1C(=O)c2ccc3c4c(ccc(c24)C1=O)C(=O)N([R])C3=O</smiles><smiles>Cc1ccccc1C(=O)O</smiles><smiles>[R]n1c(=O)c2ccc3c(=O)[nH][nH]c(=O)c4ccc(c1=O)c2c34</smiles>

243<smiles>[Y10]NC(=O)C(CCC(=O)O)N1C(=O)c2cc(C#N)c3c4c(cc(C#N)c(c24)C1=O)C(=O)N([Y20])C3=O</smiles>

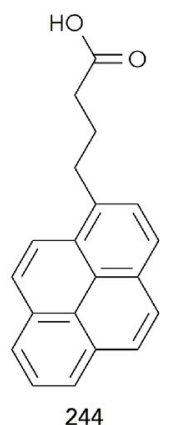

244<smiles>[R][C@H](C)CC(CC)CCCC</smiles>

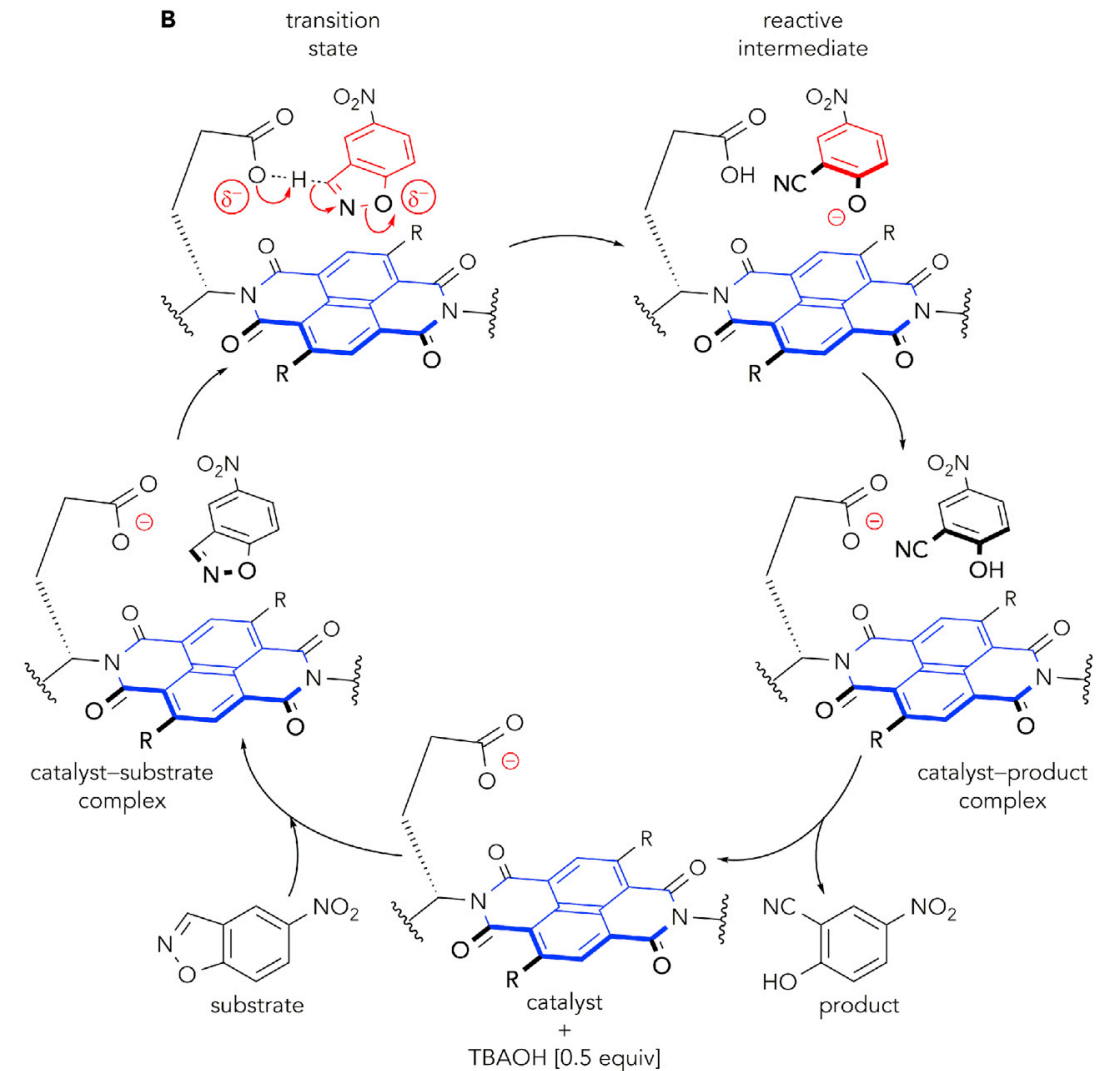

Figure 73. Catalysis with Anion- $\pi$ Interactions

(A) Structures of $\pi$-acidic NDIs 241-243 and $\pi$-basic pyrene 244 .

(B) Overview of the catalysis of Kemp elimination with anion- $\pi$ interactions mediated by NDIs.

Zhao et al. ${ }^{107}$ further explored the application of catalysis with anion- $\pi$ interactions to accelerate reactions of the versatile and important enolate chemistry. The authors performed ${ }^{1} \mathrm{H}-\mathrm{NMR}$ titration of diethyl malonate 245 and NDI-malonyl 251 with a base reagent (1,1,2,2-tetramethylguanidine) in $\mathrm{CDCl}_{3}$, and the approximate derived $\mathrm{p} K_{\mathrm{a}}$ of 251 demonstrated the stabilization of the enolate reactive intermediate (RI) 252 on the $\pi$-acidic surface in comparison with $246\left(\Delta p K_{a}=1.9\right)$, and the anion- $\pi$ interactions amounted to $\Delta \Delta G_{\mathrm{RT}}=4.7 \mathrm{~kJ} \mathrm{~mol}^{-1}$. The significance of enolate anion- $\pi$ stabilization was evaluated with the Michael addition to enone 247 (Figures 74A and 74B), monitored by ${ }^{1} \mathrm{H}-\mathrm{NMR}$ in the presence of 1,8-diazabicycloundec-7-ene, in $\mathrm{CD}_{3} \mathrm{CN} / \mathrm{CDCl}_{3}$ (1:1). NDI 251 gave a significant rate enhancement over control 245 because of stabilization of the delocalized negative charge of the transition state by $\Delta \Delta G_{\mathrm{TS}}=4.7 \mathrm{~kJ} \mathrm{~mol}^{-1}$. In a similar manner to the studies of 1,4-addition to nitroolefin 249, comparison of NDIs 251 and 245 gave a transition-state stabilization of $\Delta \Delta G_{\mathrm{TS}}=6.2 \mathrm{~kJ} \mathrm{~mol}^{-1}$. This work was extended to the one-step synthesis of coumarin 259 (Figure 74C), which involved the cascade reactions of (1) enolate formation of an acetoacetate (such as 255-257), (2) aldol condensation with resorcylaldehyde 258, (3) elimination, and (4) transesterification. The formation of 259 was monitored by UV-Vis spectrometry in $\mathrm{EtOH} / \mathrm{CHCl}_{3}(1: 1)$ in the presence of piperidine, and the acetoacetate attached to $\pi$-acidic NDI 256 gave a rate enhancement of $k_{\text {rel }}=8.0$ over 255 ; this corresponded to a transition-state stabilization of $\Delta \Delta G_{\mathrm{TS}}=5.2 \mathrm{~kJ} \mathrm{~mol}^{-1}$. The same study with an acetoacetate conjugated to $\pi$-basic pyrene 257 did not influence the reaction rate, demonstrating that $\pi-\pi$ or cation- $\pi$ interactions have no 

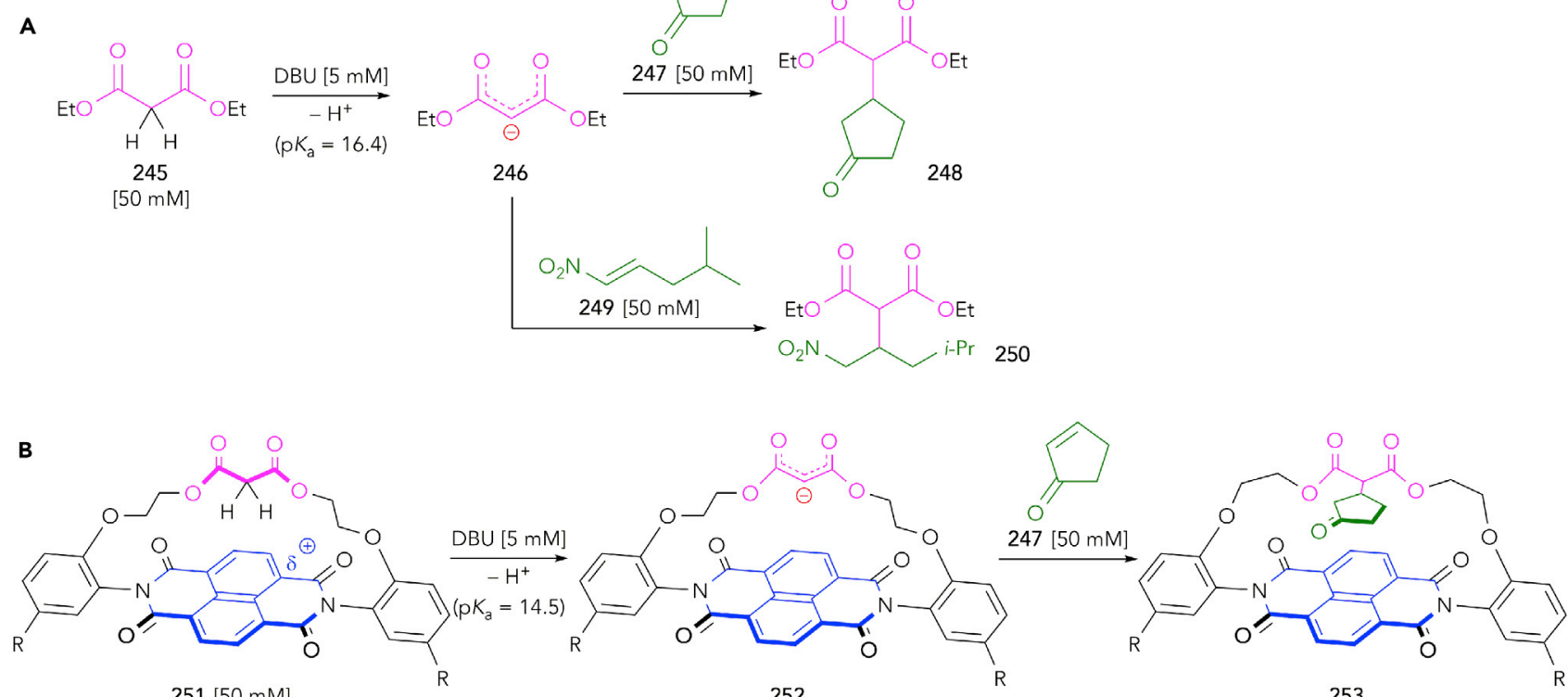

$251[50 \mathrm{mM}]$

252

253<smiles>[R]CC(C)(C)CC</smiles>

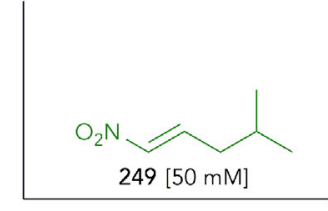

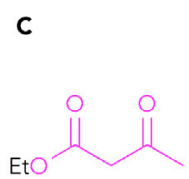

255
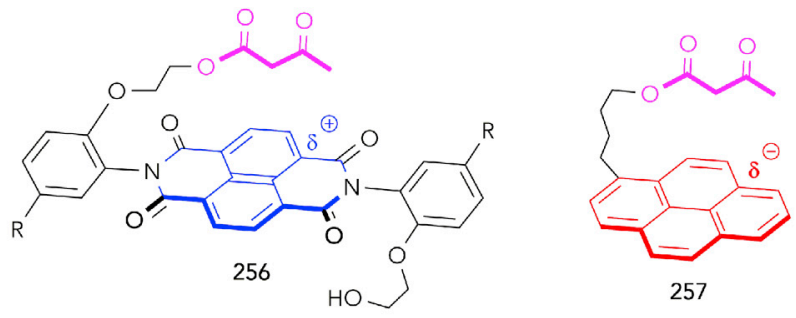

254

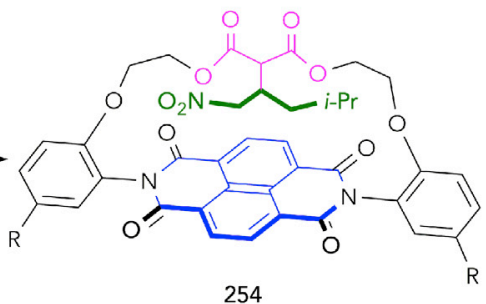<smiles>O=Cc1ccc(O)cc1O</smiles>

$258[300 \mathrm{mM}]$

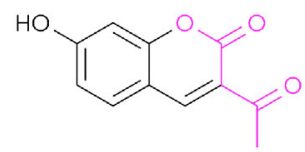

259

Figure 74. Accelerating Enolate Chemistry with Anion- $\pi$ Interactions by $\pi$-Acidic NDI Surfaces (A) Michael additions of diethyl malonate 245

(B) Michael additions of NDI-malonyl 251.

(C) Formation of coumarin 259 from resorcylaldehyde 258 and acetoacetate 255, 256, or 257

involvement in the cascade reactions. More recently, asymmetric anion- $\pi$ catalysis for enamine addition to nitroolefins mediated by the aromatic surface of $\pi$-acidic NDIs was also reported by the same group.

\section{Conclusions}

Anion coordination chemistry has continued to develop over the last 3 years with major developments in the use of non-classical interactions to bind anionic guests, in self-assembly processes involving anions, and in transmembrane anion transport. 
It is exciting to see the many applications to which anion complexation is being applied. From the development of new catalysts for more environmentally friendly chemical transformations and sensors that work in water and allow analysis via test strips to anion transporters with potential application in the treatment of diseases, this area of supramolecular chemistry is tackling real-world problems and addressing many of the areas covered by the United Nations Sustainable Development Goals. Anion receptor chemistry has also contributed to the emergence of fascinating self-assembled architectures, such as cages, knots, links, and vesicles. This new area is now attracting increasing attention. We can look forward to many more exciting developments in the coming years as the impact of anion complexation chemistry on real-world problems continues to grow.

\section{AUTHOR CONTRIBUTIONS}

Conceptualization, P.A.G.; Writing - Original Draft, P.A.G., E.N.H.W., and X.W; Writing - Review \& Editing, P.A.G., E.N.H.W., and X.W.; Funding Acquisition, P.A.G.

\section{ACKNOWLEDGMENTS}

P.A.G. thanks the EPSRC (EP/J009687/1) and the Royal Society and Wolfson Foundation for a Research Merit Award.

\section{REFERENCES AND NOTES}

1. Gale, P.A., Busschaert, N., Haynes, C.J.E., Karagiannidis, L.E., and Kirby, I.L. (2014). Anion receptor chemistry: highlights from 2011 and 2012. Chem. Soc. Rev. 43, 205-241.

2. Martínez-Aguirre, M.A., and Yatsimirsky, A.K. (2015). Brønsted versus Lewis acid type anion recognition by arylboronic acids. J. Org. Chem. 80, 4985-4993.

3. Shokri, A., Wang, X.-B., and Kass, S.R. (2013). Electron-withdrawing trifluoromethyl groups in combination with hydrogen bonds in polyols: Brønsted acids, hydrogen-bond catalysts, and anion receptors. J. Am. Chem. Soc. 135, 9525-9530.

4. Elmes, R.B.P., Turner, P., and Jolliffe, K.A. (2013). Colorimetric and luminescent sensors for chloride: hydrogen bonding vs deprotonation. Org. Lett. 15, 5638-5641.

5. De Solis, S., Elisei, F., and Gunnlaugsson, T. (2015). Lower Rim Amide (1,3) functionalised calix[4]arene amido-thiourea derivatives as dimetallic Zn(II) coordination complexes for anion recognition/sensing. Supramol. Chem. 27, 697-705.

6. Gaeta, C., Talotta, C., Della Sala, P. Margarucci, L., Casapullo, A., and Neri, P. (2014). Anion-induced dimerization in p-squaramidocalix[4]arene derivatives. J. Org. Chem. 79, 3704-3708.

7. Pinter, T., Simhadri, C., and Hof, F. (2013). Dissecting the complex recognition interfaces of potent tetrazole- and pyrrolebased anion binders. J. Org. Chem. 78, 4642-4648.

8. Long, B.M., and Pfeffer, F.M. (2014). The influence of the framework: an anionbinding study using fused [ $\mathrm{n}$ ] polynorbornanes. Chem. Asian J. 9, 10911098.
9. Boyle, E.M., Comby, S., Molloy, J.K., and Gunnlaugsson, T. (2013). Thiourea derived and colorimetric sensors for anions. J. Org Chem. 78, 8312-8319.

10. Jia, C., Wang, Q.-Q., Begum, R.A., Day, V.W., and Bowman-James, K. (2015). Chelate effects in sulfate binding by amide/ureabased ligands. Org. Biomol. Chem. 13, 6953-6957.

11. Schaly, A., Belda, R., García-España, E., and Kubik, S. (2013). Selective recognition of sulfate anions by a cyclopeptide-derived receptor in aqueous phosphate buffer. Org. Lett. 15, 6238-6241.

12. Sommer, F., and Kubik, S. (2014). Anion binding of a neutral bis(cyclopeptide) in water-methanol mixtures containing up to 95\% water. Org. Biomol. Chem. 12, 88518860.

13. Maeda, H., Shirai, T., and Uemura, S. (2013) Anion-driven structures of radially arranged anion receptor oligomers. Chem. Commun. $49,5310-5312$

14. Zubi, A., Wragg, A., Turega, S., Adams, H. Costa, P.J., Félix, V., and Thomas, J.A. (2015). Modulating the electron-transfer properties of a mixed-valence system through hostguest chemistry. Chem. Sci. 6, 1334-1340.

15. Chang, K.-C., Minami, T., Koutnik, P. Savechenkov, P.Y., Liu, Y., and Anzenbacher P. (2014). Anion binding modes in mesosubstituted hexapyrrolic calix[4]pyrrole

16. Wezenberg, S.J., Vlatković, M., Kistemaker, J.C.M., and Feringa, B.L. (2014). Multi-state regulation of the dihydrogen phosphate binding affinity to a light- and heat-responsive bis-urea receptor. J. Am. Chem. Soc. 136, 16784-16787. Tröger's bases as molecular cleft receptors isomers. J. Am. Chem. Soc. 136, 1520-1525.
17. Gavette, J.V., Mills, N.S., Zakharov, L.N. Johnson, C.A., Johnson, D.W., and Haley, M.M. (2013). An anion-modulated three-way supramolecular switch that selectively binds dihydrogen phosphate, $\mathrm{H}_{2} \mathrm{PO}_{4}^{-}$. Angew. Chem. Int. Ed. Engl. 52, 10270-10274.

18. Gavette, J.V., Evoniuk, C.J., Zakharov, L.N., Carnes, M.E., Haley, M.M., and Johnson, D.W. (2014). Exploring anion-induced conformational flexibility and molecular switching in a series of heteroaryl-urea receptors. Chem. Sci. 5, 2899-2905.

19. Shi, G., Gadhe, C.G., Park, S.-W., Kim, K.S. Kang, J., Seema, H., Singh, N.J., and Cho, S.J. (2014). Novel ionophores with $2 n$-crown-n topology: anion sensing via pure aliphatic $\mathrm{C}-\mathrm{H}$-. anion hydrogen bonding. Org. Lett. 16, 334-337.

20. Lee, S., Chen, C.-H., and Flood, A.H. (2013). A pentagonal cyanostar macrocycle with cyanostilbene $\mathrm{CH}$ donors binds anions and forms dialkylphosphate [3]rotaxanes. Nat. Chem. 5, 704-710.

21. Kang, S.O., Powell, D., Day, V.W., and Bowman-James, K. (2006). Trapped bifluoride. Angew. Chem. Int. Ed. Engl. 45, 1921-1925.

22. Ramabhadran, R.O., Liu, Y., Hua, Y., Ciardi, M., Flood, A.H., and Raghavachari, K. (2014). An overlooked yet ubiquitous fluoride congenitor: binding bifluoride in triazolophanes using computer-aided design. J. Am. Chem. Soc. 136, 5078-5089.

23. Hua, Y., Liu, Y., Chen, C.-H., and Flood, A.H. (2013). Hydrophobic collapse of foldamer capsules drives picomolar-level chloride binding in aqueous acetonitrile solutions. J. Am. Chem. Soc. 135, 14401-14412.

24. Yawer, M.A., Havel, V., and Sindelar, V. (2015). A bambusuril macrocycle that binds anions in 
water with high affinity and selectivity. Angew. Chem. Int. Ed. Engl. 54, 276-279.

25. Havel, V., Yawer, M.A., and Sindelar, V. (2015). Real-time analysis of multiple anion mixtures in aqueous media using a single receptor. Chem. Commun. 51, 4666-4669.

26. Lisbjerg, M., Jessen, B.M., Rasmussen, B., Nielsen, B.E., Madsen, A.O., and Pittelkow, M. (2014). Discovery of a cyclic $6+6$ hexamer of D-biotin and formaldehyde. Chem. Sci. 5 , 2647-2650.

27. Lisbjerg, M Valkenier, $H$, Jessen, B.M., AlKerdi, H., Davis, A.P., and Pittelkow, M. (2015). Biotin[6]uril esters: chloride-selective transmembrane anion carriers employing C-H... anion interactions. J. Am. Chem. Soc. 137, 4948-4951.

28. Carnegie, R.S., Gibb, C.L.D., and Gibb, B.C. (2014). Anion complexation and the hofmeister effect. Angew. Chem. Int. Ed. Engl. 53, 11498-11500.

29. Sokkalingam, P. Shraberg, J., Rick, S.W., and Gibb, B.C. (2015). Binding hydrated anions with hydrophobic pockets. J. Am. Chem. Soc. 138, 48-51.

30. Assaf, K.I., Ural, M.S., Pan, F., Georgiev, T., Simova, S., Rissanen, K., Gabel, D., and Nau, W.M. (2015). Water structure recovery in chaotropic anion recognition: high-affinity binding of dodecaborate clusters to $\gamma$-cyclodextrin. Angew. Chem. Int. Ed. Engl. $54,6852-6856$

31. Cavallo, G., Metrangolo, P., Milani, R., Pilati, T., Priimagi, A., Resnati, G., and Terraneo, G. (2016). The halogen bond. Chem. Rev. 116, 2478-2601.

32. Langton, M.J., Robinson, S.W., Marques, I., Félix, V., and Beer, P.D. (2014). Halogen bonding in water results in enhanced anion recognition in acyclic and rotaxane hosts. Nat. Chem. 6, 1039-1043.

33. Robinson, S.W., Mustoe, C.L., White, N.G., Brown, A., Thompson, A.L., Kennepohl, P. and Beer, P.D. (2015). Evidence for halogen bond covalency in acyclic and interlocked halogen-bonding receptor anion recognition. J. Am. Chem. Soc. 137, 499-507.

34. Semenov, N.A., Lonchakov, A.V. Pushkarevsky, N.A., Suturina, E.A., Korolev, V.V., Lork, E., Vasiliev, V.G., Konchenko, S.N., Beckmann, J., Gritsan, N.P., et al. (2014). Coordination of halide and chalcogenolate anions to heavier 1,2,5-chalcogenadiazoles: experiment and theory. Organometallics 33, 4302-4314.

35. Garrett, G.E. Gibson, G.L., Straus, R.N. Seferos, D.S., and Taylor, M.S. (2015). Chalcogen bonding in solution: interactions of benzotelluradiazoles with anionic and uncharged Lewis bases. J. Am. Chem. Soc. 137, 4126-4133.

36. Hirai, M., and Gabbaï, F.P. (2015). Squeezing fluoride out of water with a neutral bidentate antimony (V) Lewis acid. Angew. Chem. Int. Ed. Engl. 54, 1205-1209.

37. Plaunt, A.J., Harmatys, K.M., Wolter, W.R. Suckow, M.A., and Smith, B.D. (2014). Library synthesis, screening, and discovery of modified zinc(II)-bis(dipicolylamine) probe for enhanced molecular imaging of cell death. Bioconjug. Chem. 25, 724-737.

38. Turkyilmaz, S., Rice, D.R., Palumbo, R., and Smith, B.D. (2014). Selective recognition of anionic cell membranes using targeted liposomes coated with zinc(ii)bis(dipicolylamine) affinity units. Org. Biomol. Chem. 12, 5645-5655.

39. Mendez-Arroyo, J., Barroso-Flores, J., Lifschitz, A.M., Sarjeant, A.A., Stern, C.L., and Mirkin, C.A. (2014). A multi-state, allosterically-regulated molecular receptor with switchable selectivity. J. Am. Chem. Soc. 136, 10340-10348.

40. Qiao, B., Sengupta, A., Liu, Y., McDonald, K.P., Pink, M., Anderson, J.R., Raghavachari, K., and Flood, A.H. (2015). Electrostatic and allosteric cooperativity in ion-pair binding: a quantitative and coupled experiment-theory study with aryl-triazole-ether macrocycles. J. Am. Chem. Soc. 137, 9746-9757.

41. Moerkerke, S., Wouters, J., and Jabin, I. (2015). Selective recognition of phosphatidylcholine lipids by a biomimetic calix[6]tube receptor. J. Org. Chem. 80, 87208726.

42. Valderrey, V., Escudero-Adán, E.C., and Ballester, P. (2013). Highly cooperative binding of ion-pair dimers and ion quartets by a bis(calix[4]pyrrole) macrotricyclic receptor. Angew. Chem. Int. Ed. Engl. 52, 6898-6902.

43. Howe, E.N.W., Bhadbhade, M., and Thordarson, P. (2014). Cooperativity and complexity in the binding of anions and cations to a tetratopic ion-pair host. J. Am. Chem. Soc. 136, 7505-7516.

44. Fujisawa, K., Humbert-Droz, M., Letrun, R., Vauthey, E., Wesolowski, T.A., Sakai, N., and Matile, S. (2015). Ion pair $-\pi$ interactions. J. Am. Chem. Soc. 137, 11047-11056.

45. Amendola, V., Bergamaschi, G., Boiocchi, M., Fabbrizzi, L., and Mosca, L. (2013). The interaction of fluoride with fluorogenic ureas: an $\mathrm{ON}^{1}-\mathrm{OFF}-\mathrm{ON}^{2}$ response. J. Am. Chem. Soc. $135,6345-6355$.

46. Gunnlaugsson, T., Kruger, P.E., Jensen, P. Tierney, J., Ali, H.D.P and Hussey, G.M. (2005). Colorimetric "naked eye" sensing of anions in aqueous solution. J. Org. Chem. 70, 10875-10878.

47. Ashokkumar, P., Weißhoff, H., Kraus, W., and Rurack, K. (2014). Test-strip-based fluorometric detection of fluoride in aqueous media with a bodipy-linked hydrogenbonding receptor. Angew. Chem. Int. Ed. Engl. 53, 2225-2229.

48. Nie, G., Sun, Y., Zhang, F., Song, M., Tian, D., Jiang, L., and Li, H. (2015). Fluoride responsive single nanochannel: click fabrication and highly selective sensing in aqueous solution. Chem. Sci. 6, 5859-5865.

49. Liu, T., Nonat, A., Beyler, M., RegueiroFigueroa, M., Nchimi Nono, K., Jeannin, O., Camerel, F., Debaene, F., Cianférani-Sanglier, S., Tripier, R., et al. (2014). Supramolecular luminescent lanthanide dimers for fluoride sequestering and sensing. Angew. Chem. Int. Ed. Engl. 53, 7259-7263.
50. Butler, S.J., McMahon, B.K., Pal, R., Parker, D., and Walton, J.W. (2013). Bright mono-aqua europium complexes based on triazacyclononane that bind anions reversibly and permeate cells efficiently. Chem. Eur. J. $19,9511-9517$.

51. Blackburn, O.A., Chilton, N.F., Keller, K., Tait, C.E. Myers, W.K., Mclnnes, E.J.L., Kenwright, A.M., Beer, P.D., Timmel, C.R., and Faulkner, S. (2015). Spectroscopic and crystal field consequences of fluoride binding by $[\mathrm{Yb} \cdot \mathrm{DTMA}]^{3+}$ in aqueous solution. Angew. Chem. Int. Ed. Engl. 127, 10933-10936.

52. Bradberry, S.J., Byrne, J.P., McCoy, C.P., and Gunnlaugsson, T. (2015). Lanthanide luminescent logic gate mimics in soft matter: $\left[\mathrm{H}^{+}\right]$and $\left[\mathrm{F}^{-}\right]$dual-input device in a polymer gel with potential for selective component release. Chem. Commun. 51, 16565-16568.

53. Collins, C.G., Peck, E.M., Kramer, P.J., and Smith, B.D. (2013). Squaraine rotaxane shuttle as a ratiometric deep-red optical chloride sensor. Chem. Sci. 4, 2557-2563.

54. Esipenko, N.A., Koutnik, P., Minami, T. Mosca, L., Lynch, V.M., Zyryanov, G.V., and Anzenbacher, P. (2013). First supramolecular sensors for phosphonate anions. Chem. Sci. 4 3617-3623.

55. Minami, T., Liu, Y., Akdeniz, A., Koutnik, P., Esipenko, N.A., Nishiyabu, R., Kubo, Y., and Anzenbacher, P. (2014). Intramolecular indicator displacement assay for anions: supramolecular sensor for glyphosate. J. Am. Chem. Soc. 136, 11396-11401.

56. Bhowmik, S., Ghosh, B.N., Marjomäki, V., and Rissanen, K. (2014). Nanomolar pyrophosphate detection in water and in a self-assembled hydrogel of a simple terpyridine- $\mathrm{Zn}^{2+}$ complex. J. Am. Chem. Soc. $136,5543-5546$.

57. Sanchez, G., Curiel, D., Tatkiewcz, W., Ratera, I., Tarraga, A., Veciana, J., and Molina, P. (2014). Highly sensitive and selective detection of the pyrophosphate anion biomarker under physiological conditions. Chem. Sci. 5, 2328-2335.

58. Brunetti, E., Picron, J.-F., Flidrova, K Bruylants, G., Bartik, K., and Jabin, I. (2014). Fluorescent chemosensors for anions and contact ion pairs with a cavity-based selectivity. J. Org. Chem. 79, 6179-6188.

59. Zhang, Z., Kim, D.S., Lin, C.-Y., Zhang, H., Lammer, A.D., Lynch, V.M., Popov, I., Miljanić, O.Š., Anslyn, E.V., and Sessler, J.L. (2015). Expanded porphyrin-anion supramolecular assemblies: environmentally responsive sensors for organic solvents and anions. J. Am. Chem. Soc. 137, 7769-7774.

60. Chang, J., Lu, Y., He, S., Liu, C., Zhao, L., and Zeng, X. (2013). Efficient fluorescent chemosensors for $\mathrm{HSO}_{4}{ }^{-}$based on a strategy of anion-induced rotation-displaced H-aggregates. Chem. Commun. 49, 62596261.

61. Custelcean, R., Williams, N.J., and Seipp, C.A. (2015). Aqueous sulfate separation by crystallization of sulfate-water clusters. Angew. Chem. Int. Ed. Engl. 54, 10525 10529. 
62. Carson, I., MacRuary, K.J., Doidge, E.D., Ellis, R.J., Grant, R.A., Gordon, R.J., Love, J.B. Morrison, C.A., Nichol, G.S., Tasker, P.A., et al. (2015). Anion receptor design: exploiting outer-sphere coordination chemistry to obtain high selectivity for chloridometalates over chloride. Inorg. Chem. 54, 8685-8692.

63. James, S.J., Perrin, A., Jones, C.D., Yufit, D.S., and Steed, J.W. (2014). Highly interlocked anion-bridged supramolecular networks from interrupted imidazole-urea gels. Chem. Commun. 50, 12851-12854.

64. White, N.G., and MacLachlan, M.J. (2015) Anion-templated hexagonal nanotubes. Chem. Sci. 6, 6245-6249.

65. Faulkner, R.A., Harding, L.P., Higginson, J., Rice, C.R., and Slater, C. (2014). Formation of a dimer of trinuclear helicates which encapsulates an array of six hydrogenbonded anions. Angew. Chem. Int. Ed. Engl. 53, 13540-13543.

66. Löffler, S., Lübben, J., Krause, L., Stalke, D., Dittrich, B., and Clever, G.H. (2015). Triggered exchange of anionic for neutral guests inside a cationic coordination cage. J. Am. Chem. Soc. 137, 1060-1063.

67. Zhu, R., Lübben, J., Dittrich, B., and Clever, G.H. (2015). Stepwise halide-triggered double and triple catenation of selfassembled coordination cages. Angew. Chem. Int. Ed. Engl. 54, 2796-2800.

68. Preston, D., Fox-Charles, A., Lo, W.K.C., and Crowley, J.D. (2015). Chloride triggered reversible switching from a metallosupramolecular $\left[\mathrm{Pd}_{2} \mathrm{~L}_{4}\right]^{4+}$ cage to a $\left[\mathrm{Pd}_{2} \mathrm{~L}_{2} \mathrm{Cl}_{4}\right]$ metallo-macrocycle with release of endo- and exo-hedrally bound guests. Chem. Commun. 51, 9042-9045.

69. Klein, C., Gütz, C., Bogner, M., Topić, F., Rissanen, K., and Lützen, A. (2014). A New structural motif for an enantiomerically pure metallosupramolecular $\mathrm{Pd}_{4} \mathrm{~L}_{8}$ aggregate by anion templating. Angew. Chem. Int. Ed. Engl. 53, 3739-3742.

70. Riddell, I.A., Ronson, T.K., Clegg, J.K., Wood, C.S., Bilbeisi, R.A., and Nitschke, J.R. (2014). Cation- and anion-exchanges induce multiple distinct rearrangements within metallosupramolecular architectures. J. Am. Chem. Soc. 136, 9491-9498.

71. Ramsay, W.J., and Nitschke, J.R. (2014). Two distinct allosteric active sites regulate guest binding within a $\mathrm{Fe}_{8} \mathrm{Mo}_{12}{ }^{16+}$ cubic receptor. J. Am. Chem. Soc. 136, 7038-7043.

72. Ayme, J.-F., Beves, J.E., Campbell, C.J., GilRamírez, G., Leigh, D.A., and Stephens, A.J. (2015). Strong and selective anion binding within the central cavity of molecular knots and links. J. Am. Chem. Soc. 137, 98129815.

73. Zhou, L.-P., and Sun, Q.-F. (2015). A selfassembled $\mathrm{Pd}_{2} \mathrm{~L}_{4}$ cage that selectively encapsulates nitrate. Chem. Commun. 51, 16767-16770.

74. Chifotides, H.T., Giles, I.D., and Dunbar, K.R. (2013). Supramolecular architectures with $\pi$-acidic 3,6-bis(2-pyridyl)-1,2,4,5-tetrazine cavities: role of anion $-\pi$ interactions in the remarkable stability of Fe(II) metallacycles in solution. J. Am. Chem. Soc. 135, 3039-3055.

75. He, Q., Ao, Y.-F., Huang, Z.-T., and Wang, D.-X. (2015). Self-assembly and disassembly of vesicles as controlled by anion- $\pi$ interactions. Angew. Chem. Int. Ed. Engl. 54 11785-11790.

76. Luo, D., Zhou, X.-P., and Li, D. (2015). Beyond molecules: mesoporous supramolecular frameworks self-assembled from coordination cages and inorganic anions. Angew. Chem. Int. Ed. Engl. 54, 6190-6195.

77. Wu, B., Cui, F., Lei, Y., Li, S., de Sousa Amadeu, N., Janiak, C., Lin, Y.-J., Weng, L.-H., Wang, Y.-Y., and Yang, X.-J. (2013). Tetrahedral anion cage: self-assembly of a $\left(\mathrm{PO}_{4}\right)_{4} \mathrm{~L}_{4}$ complex from a tris(bisurea) ligand. Angew. Chem. Int. Ed. Engl. 52, 5096-5100.

78. Pandurangan, K., Kitchen, J.A., Blasco, S., Boyle, E.M., Fitzpatrick, B., Feeney, M. Kruger, P.E., and Gunnlaugsson, T. (2015). Unexpected self-sorting self-assembly formation of a [4:4] sulfate:ligand cage from a preorganized tripodal urea ligand. Angew. Chem. Int. Ed. Engl. 54, 4566-4570.

79. Rastogi, S., Marchal, E., Uddin, I., Groves, B. Colpitts, J., McFarland, S.A., Davis, J.T., and Thompson, A. (2013). Synthetic prodigiosenes and the influence of $\mathrm{C}$-ring substitution on DNA cleavage, transmembrane chloride transport and basicity. Org. Biomol. Chem. 11, 3834-3845.

80. Marchal, E., Rastogi, S., Thompson, A., and Davis, J.T. (2014). Influence of B-ring modifications on proton affinity, transmembrane anion transport and anticancer properties of synthetic prodigiosenes. Org. Biomol. Chem. 12, 7515-7522.

81. Hernando, E., Soto-Cerrato, V., CortésArroyo, S., Pérez-Tomás, R., and Quesada, R. (2014). Transmembrane anion transport and cytotoxicity of synthetic tambjamine analogs. Org. Biomol. Chem. 12, 1771-1778.

82. Soto-Cerrato, V., Manuel-Manresa, P. Hernando, E., Calabuig-Fariñas, S., MartínezRomero, A., Fernández-Dueñas, V., Sahlholm, K., Knöpfel, T., García-Valverde, M., Rodilla, A.M., et al. (2015). Facilitated anion transport induces hyperpolarization of the cell membrane that triggers differentiation and cell death in cancer stem cells. J. Am. Chem. Soc. 137, 15892-15898.

83. Ko, S.-K., Kim, S.K., Share, A., Lynch, V.M. Park, J., Namkung, W., Van Rossom, W., Busschaert, N., Gale, P.A., Sessler, J.L., et al. (2014). Synthetic ion transporters can induce apoptosis by facilitating chloride anion transport into cells. Nat. Chem. 6, 885-892.

84. Olivari, M., Montis, R., Karagiannidis, L.E. Horton, P.N., Mapp, L.K., Coles, S.J., Light, M.E., Gale, P.A., and Caltagirone, C. (2015). Anion complexation, transport and structural studies of a series of bis-methylurea compounds. Dalton Trans. 44, 2138-2149.

85. Valkenier, H., Judd, L.W., Li, H., Hussain, S., Sheppard, D.N., and Davis, A.P. (2014). Preorganized bis-thioureas as powerful anion carriers: chloride transport by single molecules in large unilamellar vesicles. J. Am. Chem. Soc. 136, 12507-12512.
86. Valkenier, H., Dias, C.M., Porter Goff, K.L., Jurcek, O., Puttreddy, R., Rissanen, K., and Davis, A.P. (2015). Sterically geared tristhioureas; transmembrane chloride transporters with unusual activity and accessibility. Chem. Commun. 51, 1423514238.

87. Valkenier, H. López Mora, N., Kros, A and Davis, A.P. (2015). Visualization and quantification of transmembrane ion transport into giant unilamellar vesicles. Angew. Chem. Int. Ed. Engl. 54, 2137-2141.

88. Busschaert, N., Karagiannidis, L.E., Wenzel, M., Haynes, C.J.E., Wells, N.J., Young, P.G. Makuc, D., Plavec, J., Jolliffe, K.A., and Gale, P.A. (2014). Synthetic transporters for sulfate: a new method for the direct detection of lipid bilayer sulfate transport. Chem. Sci. 5, 11181127.

89. Lee, J.H., Lee, J.H., Choi, Y.R., Kang, P., Choi, M.-G., and Jeong, K.-S. (2014). Synthetic K ${ }^{+}$/ $\mathrm{Cl}^{-}$-selective symporter across a phospholipid membrane. J. Org. Chem. 79, 6403-6409.

90. Choi, Y.R., Kim, G.C., Jeon, H.-G., Park, J. Namkung, W., and Jeong, K.-S. (2014). Azobenzene-based chloride transporters with light-controllable activities. Chem. Commun. 50, 15305-15308.

91. Wu, X., Busschaert, N., Wells, N.J., Jiang, Y.-B., and Gale, P.A. (2015). Dynamic covalent transport of amino acids across lipid bilayers. J. Am. Chem. Soc. 137, 1476-1484.

92. Edwards, S.J., Valkenier, $H$., Busschaert, N., Gale, P.A., and Davis, A.P. (2015). High-affinity anion binding by steroidal squaramide receptors. Angew. Chem. Int. Ed. Engl. 127, 4675-4679.

93. Busschaert, N., Elmes, R.B.P., Czech, D.D. Wu, X., Kirby, I.L., Peck, E.M., Hendzel, K.D. Shaw, S.K., Chan, B., Smith, B.D., et al. (2014). Thiosquaramides: $\mathrm{pH}$ switchable anion transporters. Chem. Sci. 5, 3617-3626.

94. Elmes, R.B.P., Busschaert, N., Czech, D.D. Gale, P.A., and Jolliffe, K.A. (2015). $\mathrm{pH}$ switchable anion transport by an oxothiosquaramide. Chem. Commun. 51, 10107-10110.

95. Kuchelmeister, H.Y., Karczewski, S., Gutschmidt, A., Knauer, S., and Schmuck, C. (2013). Utilizing combinatorial chemistry and rational design: peptidic tweezers with nanomolar affinity to DNA can be transformed into efficient vectors for gene delivery by addition of a lipophilic tail. Angew. Chem. Int. Ed. Engl. 52, 14016-14020.

96. Shang, J., Si, W., Zhao, W., Che, Y., Hou, J.-L., and Jiang, H. (2014). Preorganized aryltriazole foldamers as effective transmembrane transporters for chloride anion. Org. Lett. 16, 4008-4011.

97. Wang, X.-D., Li, S., Ao, Y.-F., Wang, Q.-Q. Huang, Z.-T., and Wang, D.-X. (2016). Oxacalix[2]arene[2]triazine based ion-pair transporters. Org. Biomol. Chem. 14, 330-334.

98. Vargas Jentzsch, A., and Matile, S. (2013). Transmembrane halogen-bonding cascades. J. Am. Chem. Soc. 135, 5302-5303. 
99. Gravel, J., Kempf, J., and Schmitzer, A. (2015). Host-quest strategy to reversibly control a chloride carrier process with cyclodextrins. Chem. Eur. J. 21, 18642-18648.

100. Wasa, M., Liu, R.Y., Roche, S.P., and Jacobsen, E.N. (2014). Asymmetric Mannich synthesis of $\alpha$-amino esters by anion-binding catalysis.

J. Am. Chem. Soc. 136, 12872-12875.

101. Zhao, Q., Wen, J., Tan, R., Huang, K., Metola, P., Wang, R., Anslyn, E.V., and Zhang, X. (2014). Rhodium-catalyzed asymmetric hydrogenation of unprotected $\mathrm{NH}$ imines assisted by a thiourea. Angew. Chem. Int. Ed. Engl. 53, 8467-8470.

102. Mittal, N., Lippert, K.M., De, C.K., Klauber, E.G., Emge, T.J., Schreiner, P.R., and Seidel,
D. (2015). A dual-catalysis anion-binding approach to the kinetic resolution of amines: insights into the mechanism via a combined experimental and computational study. J. Am. Chem. Soc. $137,5748-5758$.

103. Nava, M., Lopez, N., Müller, P., Wu, G. Nocera, D.G., and Cummins, C.C. (2015) Anion-receptor mediated oxidation of carbon monoxide to carbonate by peroxide dianion. J. Am. Chem. Soc. 137, 1456214565.

104. Zurro, M., Asmus, S., Beckendorf, S., MückLichtenfeld, C., and Mancheño, O.G. (2014) Chiral helical oligotriazoles: new class of anion-binding catalysts for the asymmetric dearomatization of electron-deficient
N-heteroarenes. J. Am. Chem. Soc. 136, 13999-14002.

105. Berkessel, A., Das, S., Pekel, D., and Neudörfl, J.-M. (2014). Anion-binding catalysis by electron-deficient pyridinium cations. Angew. Chem. Int. Ed. Engl. 53, $11660-11664$.

106. Zhao, Y., Domoto, Y., Orentas, E., Beuchat, C., Emery, D., Mareda, J., Sakai, N., and Matile, S. (2013). Catalysis with anion $-\pi$ interactions. Angew. Chem. Int. Ed. Engl. 52, 9940-9943.

107. Zhao, Y., Sakai, N., and Matile, S. (2014). Enolate chemistry with anion $-\pi$ interactions. Nat. Commun. 5, 3911 